

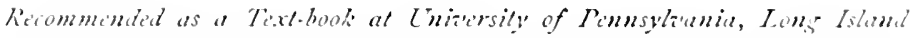

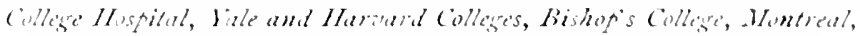

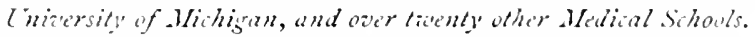

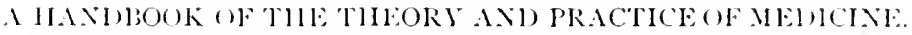
by FREDERUK T. KolierTs, M.D., M.R.c.r., l'rofessor of Materia Mel. ica aml Therapentics and of Clinical Medicine in Lniversity College IIospital; Assistant l'lysician in Brompton Consmmptive ILospital. The Fifth Edition, partially rewritten, and carefully revised throughout.

Price, in Cloth, \$5.00; Leather, \$6.00.

"I have examined it with much care, and find its arrangenent simple, lut systematic, and its treatment of subjects concise, but thorough." $-E$. D. Hud. son, $\mathscr{F} \%$, M.D., Professor of Practice, Medical Wollege of $\hat{N}_{i} w$ York.

"It is with great pleasure that I commend it to both students and practitioners, as a clear yet concise, scientific and practical work. It is a capital compendium of the classified knowledge of the subject." - Professor $\mathcal{F}$. Alims Allen, Rush Micdiral Collese, Chicaro.

- After due and careful examination and use, I have become thoroughly convinced of its great value, and have cordially recummended it to my class in Yale College."-Professor David P. Smilh.

"I have examined it with some care, and think it a good book, and shall take pleasure in mentioning it among the works which may properly be jut in the hands of students."-A. B. Palmer, M.D., Profissor of the Practicie of Medicine, Ann Arbor Unizersity, Michisan.

"I have never met with a work on Practice that seemed to me so well adapted for students. While concise, nothing is omitted that is important to be known." - Professor F. A. Thacker, Cincinnati.

"I sha' include it among the text-books of the College of Physicians and Surgeous, and strongly recommend it to my classes."-Profissor $\mathcal{F}_{0} / \mathrm{h} \mathrm{S}$. Lynch, Ballimore.

"It is unsurpassed by any work that has fallen into our hands, as a compen. dium for students preparing for examination. It is thoronghly practical, and fully up to the times." - The Clinic.

"Our opinion of it is one of almost unqualified praise. The style is clear, and the amount of useful and, indeed, indispensable information which it con. tains is marvelous. We heartily recommend it to students, teachers, and practitioners."-Boston Medial and Surgical Fournal.

"That Dr. Roberts' book is admirably fitted to supply the want of a grood handbook of medicine, so much felt by every medical student, does not arlmit of a guestion." - Studints' Fournal and Mospilal Gazitle. 



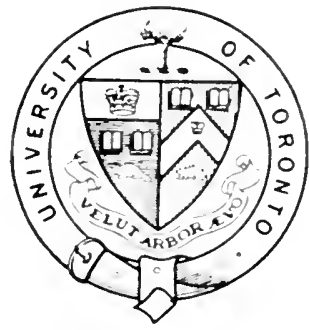

illiarn lin inton 


\section{By. Gerald F. IEu, M.D., r.R.C.s., Professor of Physiology in King's College, London. Demi-octivo, 750 pages. Uver 300 carefully printed engravings on wood. \\ Bound in Cloth, $\$ 4.00$; Leather, $\$ 5.00$.}

\footnotetext{
"By his excellent manual Prof. Yeo has supplied a want which munt have been fele by every teacher of phyciolegy. In the notse text-buok of J'ruf. Fuster, English realers hite a work which is mosurpancel, but its great size and comprehemsiveness, and it some. what mimute discunsion of mamy donbtrul points, make it at formidable object to the esen of the tirst and second years' students. Dr. leo hat written a book which is intendedtior

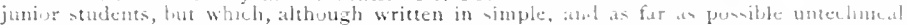
language, iv accurate and complete. ** * Noreover, being antended chetly for medical

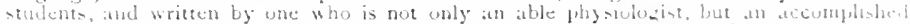
phy-ician, the needs of the physictan and surgeon are never lost sight of * * t ille text

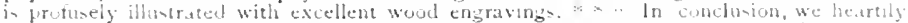

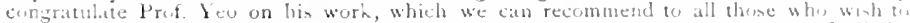
find, within a mulerate compan, a reliable and pleasantly wraten exposition of all the

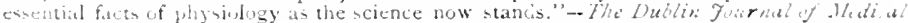

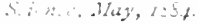

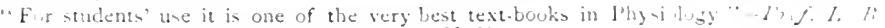

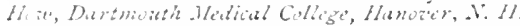

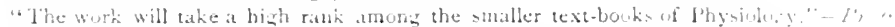

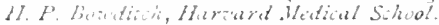

" lhe brief cxamination I have given it was so fororable that I pleced it in the ins at

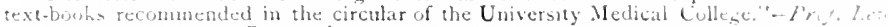

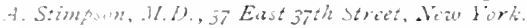

"lhere are many points in fhyvielogy that are either not comprehendeal or are mis.

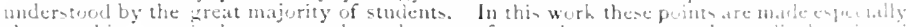
clear, and in a particuler manner these that are of most inportanee wo the medicat or dientoi practitioner. We have had long experience in teaching this branch of methe.t a :ct.e.

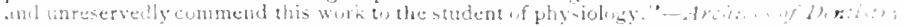

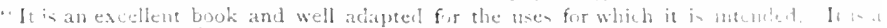

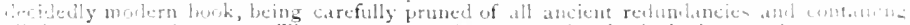

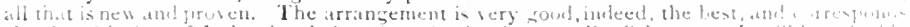

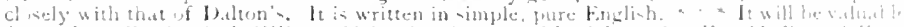

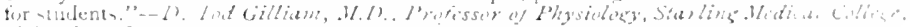
(ivintla, l).

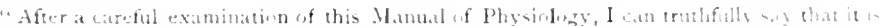

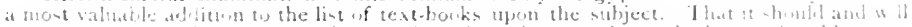

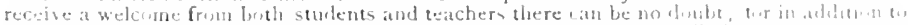

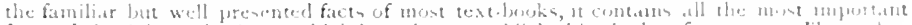

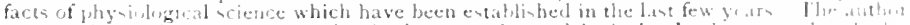

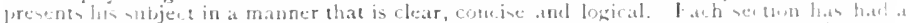

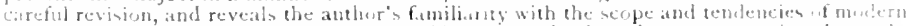

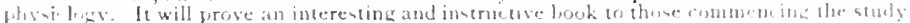

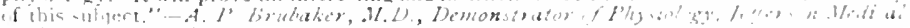

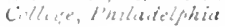


A MANUAL OF THE DISSECTION OF THE HUMAN BOD). By Luther Holdex, m.D., Late l'resident of the Royal College of Surgeons of England; Consulting Surgeon to St. Bartholomew's Hospital. Fifth Edition. Edited by John LaNGTON, M.D., F.R.C.S., Surgeon to, and Lecturer on Anatomy at, St. Bartholomew's Hospital; Nember of the Board of Examiners, Royal College of Surgeons of England; With 208 fine Wood Engravings. Octavo. About 880 pages.

Bound in Cloth, \$5.00; Leather, \$6.00.

*** This new edition has been revised with the object of making it a more thorough text-book. Over one hundred pages new matter have been added, and many new illustrations, some of which are very finely engraved and printed. Notwithstanding these new features, the price of the bouk has been lowered.

\section{GILLIAM'S}

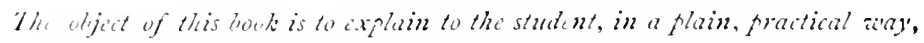
the fundamintals of I'atholesy, as an introdution to larser looks.

THE lissentias OF PATHOLOGY. By I. TOd Gillan, M.D., Professor of Physiology, Starling Medical College, formerly Professor of General Pathology, Culumbus Medical Collegre, Columbus, Ohio. 12 mo. 296 pages. 47 Illustrations.

$$
\text { Price, Cloth, } \$ 2.00 \text {. }
$$




\section{? QUIZ COMPENDS. ?}

A NEW SERIES OF LOOKS FOR STUDENTS' USE IN

\section{QUIZ-CLASS AND EXAMINATION ROOMS.}

nos These Compends are based on the most popular text-books, and the lectures of prominent prafessors.

$\Delta, y^{-}$The Authors have had large experience as Quiz Masters and attachés of colleges, and are well acquainted with the wants of students. IF 7 They are arranged in the most approved form, thorougl and concise, with illustrations whenever they can be used to advantage.

If in Can be used by students of any college.

D T lhey contain information nowhere else collected in such a condensed, practical shape.

as Size is such that they may be easily carried in the pocket, and the price is low.

Af $T$ They will be found very serviceable to physicians, as remembrancers.

\section{LIST OF VOLUMES.}

No. 1. ANATOMY. By Samuel O. L. Potter, M.D. 63 Illustra. tions. Noze ready.

No. 2. PRACTICE, Part 1. By Dan'l E. Hughes, M.d., Demonstrator of Clinical Iledicine, Jefferson College, Philadelphia. Now riatly.

No. 3. PRACTICE, Part II. Same author. Now ready.

No. 4. PHYSIOLOGY. By A. P. Brubaker, m.D., Demonstrator of Physiolozy, Jefferson College, Philadelphia. Noze riady.

No. 5. OBSTETRICS. By Henry G. LANdis, s.d., Professor of Obstetrics and Diseases of Women and Children, Starling Medical Coilege, Columbus, Ohio. Illustrated. Now rérdy.

No. 6. Materia medica. By Samuel O. L. Potter, m.d. Now Re'ady.

No. 7. INORGANIC CHEMISTRY. By G. MASONWARD, M.D., Demonstrator of Chemistry, Jeffersan College, Phlladelphía. Now recaltin.

No. 8. VISCERal anatomy. By Samuel O. L. Potter, M.d. With illustrations. Now ready.

No. 9. SURGERY. By Orville Horwitz, B.S., M.d. With numerous lllustrations. Nowerady.

No. 10. ORGANIC CHEMISTRY. Including NIedical Chemistry, Urine Analysis and the Analvsis of Water, Air and Food. By

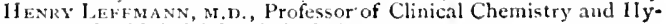
giene in the Philadelphia Polycliniç.

Others in prepatation."

Price, each, in Cloth, $\$ 1.00$.

Interleaved Edition, for taking Notes, \$1.25.

P. BLAKISTON, SON \& CO, Publishers,

1012 WALNUT ST., PHILADELPhIA.

Complete stock of Medical, Dental, Pharmaceutical and Scientific looks. Catalogues free. 


\section{A \\ COMPEND}

(1)

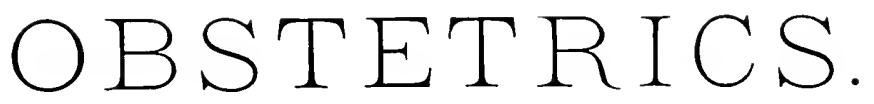

ESPECIALLY ADAPTED TO TIIE USE OF MEIMCAL STUDENTS AND PIIYSICIANS.

BY

\section{HENRY G. LANDIS, A.M., M.D.,}

Professor of Obstetrics and Diseases of Women in Starling Medical College: Fillow of the American Academy of Medicine; Nember of the American Medical Association; Author of "How to Use the Forceps," etc., etc.

SECOND EDITION. REITSED A.TD E.TLARGLI. WITH VEW ILLUSTR.ITIO.KS.

\footnotetext{
PHIIADEISHA :

P. BLAKISTON, SON \& (O).

IOI 2 WALNUT STRERT.

1885.
} 
Entered according to Act of Congress, in the year $188_{4}$, by P. BLAKISTON, SON \& CO.,

In the Office of the Librarian of Congress, at Washington, D. C. 


\section{PREFACE TO SLCOND EDITION:}

The author desires to return thanks for the uniform lindly criticism bestowed upon the first edition of this little work, and has endeavored by carefully revising its matter and manner to prepare it for contiuned usefulness. It has been male more complete by the addition of paragraphs and illustrations upon subjects before overlooked or inalequatcly treated, and by an index.

II. G. L. 


\section{PREFACE TO FIRST EDITION.}

The design of this book is to furnish a useful compend and Quiz-book for the student, and also, by the system of question and answer to bring out the more important facts in Obstetrics more clearly than can be done in the method of continuous composition. On many points it is difficult to determine what is the "received doctrine," except by the mere numerical weight of authorities. The author has, therefore, attempted to maintain a judicious eclecticism, instead of undertaking the task, impracticable within the limits of the book, of recorling all the various and more or less received teachings of all authors.

H. G. L. 


\section{TABLE OF CONTENTS.}

IXTRODUCTION PACH

THE PELIIS .

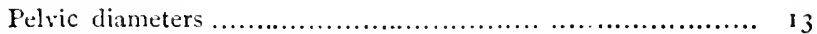

، planes ............................................ 15

، muscles .......................................... 15

REPRODUCTIVE ORGANS.

Anatomy.

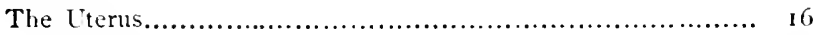

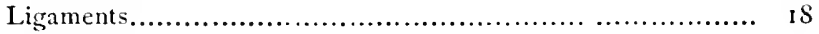

Fallopian Tubes......................................... I9

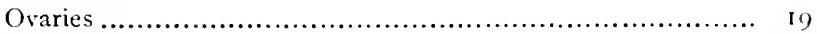

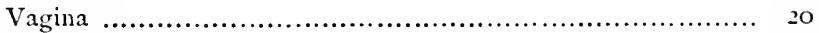

Douglas' cul-de-sac......................................... 20

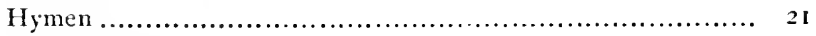

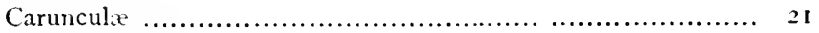

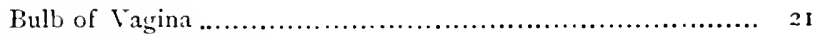

Vulvo-vaginal Glands................................... 2 I

Labia Majora........................................... 2 I

" Minora............................................. 22

Mons Veneris.............................................. 22

Commissures.............................................. 22

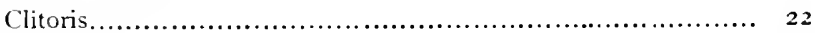

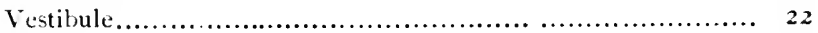

Meatus $\ldots \ldots \ldots \ldots \ldots \ldots \ldots \ldots \ldots \ldots \ldots \ldots \ldots \ldots \ldots \ldots \ldots \ldots \ldots \ldots, \quad 22$

Urethra ................................................. 23

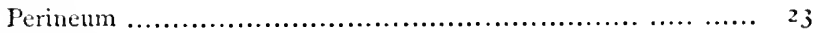

Phy'siology.

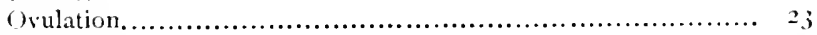

Menstruation .. ............................................. 25

The Breasts.................................................... $2 S$

PREGNANCY.

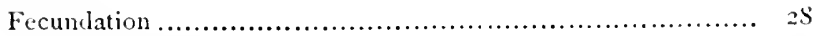

Changes in Ovum ......................................... 24) 
Changes in Womb

The Placenta .................................................... $\mathbf{3}^{2}$

Fotal Changes............................................. 33

Multiple Pregnancy.......................................... 34

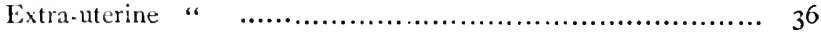

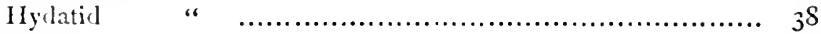

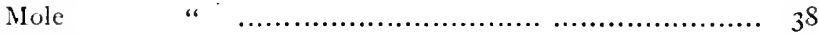

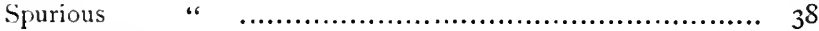

Premature Labor................................................... 39

Signs of Prignancy.............................................. 4I

LABOR.

Clinical IIstory .............................................. 49

Duties of the Physician......................................... 53

Mechanism of Labor............................................. 58

Dystocia.

Uterine Inertia ............................................... 70

Rigidity of Cervix, etc...................................... 72

Deformities of Pelvis........................................... 75

Ovular Dystocia................................................ 77

Twin Labor.................................................... So

Accidental Hemorrhage.......................................... $8 \mathbf{1}$

l'lacenta Previa .................................................. $\delta_{2}$

I'ost-partum Hemorrhage...................................... $S_{4}$

Rupture of Uterus........................................... $\$ 6$

Eclampsia......................................................... $S_{7}$

I'lacental Iyystocia................................................. $S_{9}$

Inversion of Uterus........................................... $9^{\mathbf{I}}$

Oistetrical Operations.

The Forceps................................................... 92

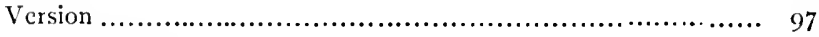

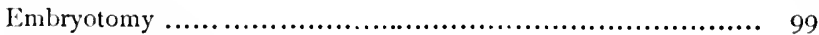

Cesarean Section.................................................... 100

Induction of Labor............................................ I02

THe PERTOD AFter Deliviry.

Involution of the Uterus..................................... I02

I'uerperal I iseases........................................... I05

Congenital Defects................................................ I

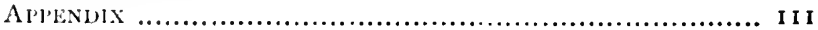




\section{QUESTIONS ON OBSTETRICS.}

\section{INTROIJUC'TION.}

\section{What is Obstetrics?}

The science and art of affording ail to women in labor.

\section{What is meant by science and art?}

The scicnce of Ubstetrics embraces the definite rules of procellure founded upon a correct knowledge of the nature of Labor and its compli. cations; the art consists in the skillful carrying out of these rules. The science may be taught in books and lectures; the art must be acyuired by practice at the bedside.

How may the subject be divided?

Ist. The Anatomy of the parts concerned in labor, viz: the reprodurtive organs and their surroundings.

2d. The Physiology of these parts.

3 d. Their Pathology, including all deviations from the natural course of labor.

4th. The treatment of natural and complicated labor.

What are the reproductive organs of woman?

Ist. Internal, viz: the ovaries, uterus, oviducts and vagina.

2d. External, viz: the hymen, mons veneris, labia majora and minora; clitoris, vestibule, perineum and meatus urinarius; also the breasts.

Where are they situated?

With the exception of the breasts, they are placed within or below the Peleis.

\section{THE PELVIS.}

What is the Pelvis?

A bony structure, placed at the end of the vertebral column.

Why is it called the pelvis?

Because, when clothed with muscles, ligaments and fascire, it resembles a basin.

Of how many bones is the pelvis composed?

lour: the sacrum, coccyx, and two ossa inmominata. 


\section{What is the sacrum?}

A wedge-shaped bone, apparently formed by the fusion of five vertebre. It is curved, being concave in front.

\section{How many articular surfaces does it present?}

Four: by one it is connected with the last lumbar vertebra, above; by one on each side, with the ossa innominata, and lyy one below, with the coccyx.

What is the coccyx?

A small and similarly werlge-shaped bone, apparently formed by the fusion of three or four vertebral bodies. It has one articular surface above, by which it is connected with the sacrum. It tapers from that bone, and is supposed to be the remains of our ancestral tail.

\section{What are the ossa innominata?}

The haunch bones, of irregular shape, articulating with the sacrum on each side, and with themselves in front. Each os innominatum is composed, originally, of three separate pieces, the ilium, ischium, and fubes. Their point of juncture is found in a cup-shaped depression on the out side of the bone, called the acetalulum.

When do the several parts of the os innominatum unite?

By the twenty-fifth year.

What uses has the pelvis?

rst. To support and transmit the weight of the body.

2d. To contain and protect certain organs.

3d. To serve as a parturient tube or canal, through which the child may he rlefmitely guided during labor.

To what parts is the weight of the body transmitted?

To the femora in the erect posture, and to the tuberosities of the ischia in the sitting posture.

How is the weight of the body transmitted to the femora?

By two heams of lone, consisting of the upper part of the sacrum and borly of the ilium on either side.

What are these beams called?

The sacro-iliac beams (see Fig. 1, page 12).

What prevents these beams from being pushed in and out at their distal ends?

Another beam is placed between them, extending from one acctabulum to the opposite one, consisting of the upper part of the pubes on either side.

What is this beam called?

The pubic bean (see Fig. I, page I2). 
Why are these beams not straight?

They are arched outwarlly to make more room in the pelvis, to enable it to fultill its second and third uses (Fig. 2).

How is the diminution in strength of the sacro-iliac beams, caused by this arching, remedied?

By buttressing the beams by that expansion of the sacrum and iliac bones, called the aings of the ilia and sacrum (Fig. 3).

How is jarring and concussion prevented?

By placing joints at the centre of each heam.

How is the diminution of strength caused by these joints remedied?

By covering them with powerful ligaments.

How is weight transmitted from the vertebral column to the tuberosities of the ischia?

By two beams of bone, placed directly under the sacro-iliac beams, consisting of the ischium and under portion of the ilium on exther side.

What are they called?

The ilio-ischiatic beams.

How are they held together in front?

By another arched beam, placed directly under the pubic beam, and called the sub-pubic beam.

What is the great sacro-sciatic notch?

The arched space under the ilio-ischiatic beam.

What bony projection is found in it?

The spine of the ischium.

What is the lesser sacro-sciatic notch?

The part of the arch below the spine of the ischium.

What is the obturator foramen?

The space between the pubic and sub-pubic beams on each side.

How is it closed?

liy a membrane which gives attachment to muscles.

How may a female pelvis be distinguished from the male?

lyy the fact that the sub-pubic beam is roundly arched in the fomale and its ertges everted. In the male there is very little arching or eversinn. (But some female pelves approach the male type.)

What joints exist in the pelvis?

Two sacro-iliac (one on each side), the pubic joint, in front, and the sacro-coccygeal joint, behind. 


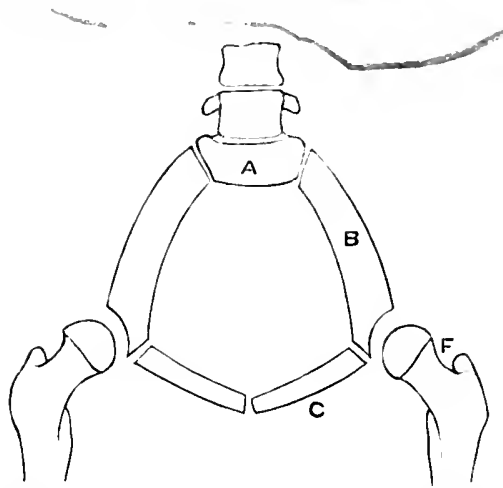

F1G. I. $-B$, with half of $A=$ the left sacro-iliac beam, transmitting weight to the femur

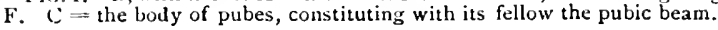

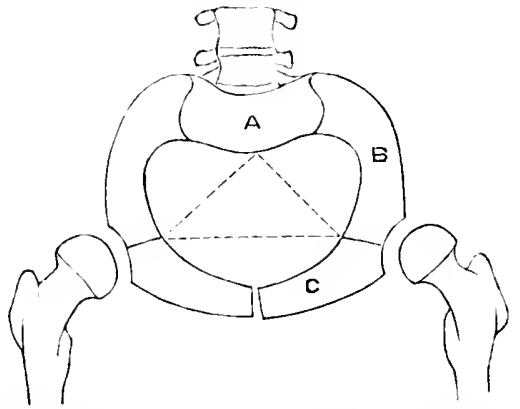

Ftr. 2.-The same as in Fig. $r$, but with the beams arched; the dotted lines show the original direction of force.

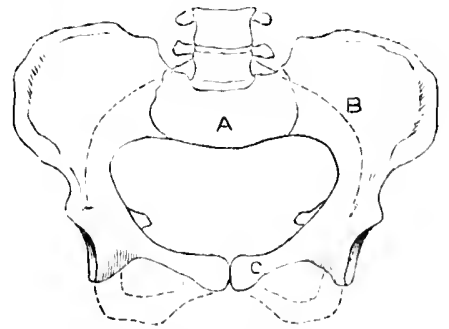

Ftg. 3.-The same as in Fig. 2, wlth the arches strengthened by the addition of the iliac wings, etc. The dotted lines below show the sub-pubic arch in frunt and the beginning of the ilio-ischiatic beams. 
What are the pelvic joints called?

Symphyses, and the pubic joint is often called, by way of dintinction, the sumphysis.

\section{What kind of joints are they?}

Amphiarthrodial. The sacro coccygeal joint is always freely movalue, and has a demonstrable synovial sac; the other joints can only be shown to have sacs during pregnancy.

\section{What is the sacral promontory?}

The projection or angle formed by the top of the sacrum in front at its junction with the vertebra above. It is often called simply the promontory.

What is the ileo-pectineal line?

A bony ridge or raised line, which, beginning at the promontory, extends around each sicle of the pelvis, within, until it meets the opposite line at the symphysis pubis.

What parts lie above it?

The wings of the sacrum and ilium, called also the false pelitis.

\section{What lies below it?}

The true or obstetric pelvis.

What is the ileo-pectineal line said to bound?

The inlet of the pelvis, because the chill must first enter the pelvis through this bony ring. It is called also the superior strait, and the pelvic brim.

Where is the pelvic outlet?

It is bounded by the tip of the coccyx behinal, by the tulverosities of the ischia on the sides, and by the sub-pubic arch in front. It is callerl also the Inferior strait.

What is the pectineal eminence?

That point in the ileo-pectineal line which is opposite the acetabulum, and is slightly raised above the ordinary level of the line.

What is the ilio-ischiatic line?

A slightly raised ridge, on the insile of the pelvis, which leggins at the pectineal eminence and ends in the ischittic sprine on either side.

What are the diameters of the pelvis?

Lines drawn from various prints of the pelvic cavity, th facilitate the description of the relations which the child's surface lecars to the fuch is during its passage through it.

What are the diameters of the inlet?

The conjugate, two oblique, and the transverse. 
What is the conjugate diameter of the inlet?

A line drawn from the promontory to the top of the symphysis pubis. It is about four inches long in the normal pelvis.

\section{What are the oblique diameters?}

lines drawn from the sacro-iliac symplyysis of either side to a point in front of the pectineal eminence of the opposite side (Meadows). The one drawn from the right sacro-iliac symphysis is called the right oblique; the one from the left symply'sis, the left oblique. They are about five inches long.

\section{What is the transverse diameter of the inlet?}

A line drawn directly across the pelvis from one pectineal eminence to the other. In the normal pelvis it is no longer than either of the obligue diameters.

\section{What are the diameters of the outlet?}

The conjugate and transierse.

\section{What is the conjugate diameter of the outlet?}

A line drawn from the tip of the coccyx to the under edge of the sym. physis pulis. It is of variable length, owing to the mobility of the coccyx, but when the latter is extended, during labor, it is the longest diameter of the outlet, and may measure five inches.

What is the transverse diameter of the outlet?

FIG. 4 .

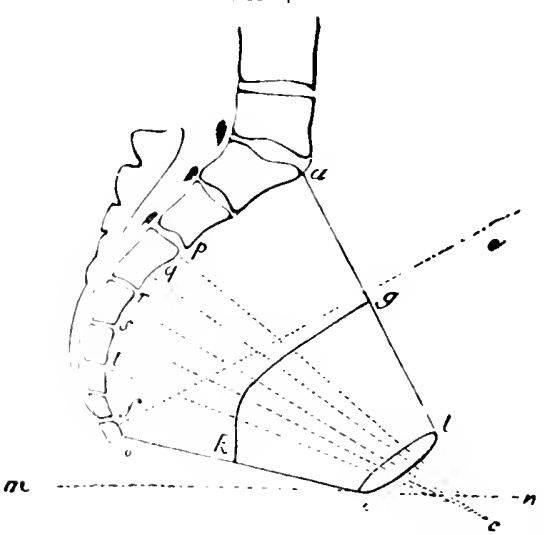

a b. Conjugate diameter of Inlet.

ef. Conjugate diameter of Outlet.
A line drawn from one tuberosity of the ischium to the opposite one, and meas. ures a little less than four inches in the normal pelvis.

What are the planes of the pelvis?

Imaginary levels, drawn through any part of the pelvic circumference (Ilayfair), to facilitate the description of the relations of the pelvis to the child, vertebral column or horizon. They may be illustrated by pieces of card-board cut so as to fit the pelvic cavity at any level. 


\section{What planes are important?}

The plane of the inlet and of the outlet.

\section{What is the plane of the inlet?}

A plane drawn transversely through the conjugate liameter of the inlet and limited by the circumference of the inlet.

\section{What is the plane of the outlet?}

A plane drawn transversely through the conjugate diameter of the outlet and limited by the circumference of the outlet. (For other planes see Appendix.)

How are these planes used to show the position of the pelvis in different postures?

In the erect posture the plane of the inlet makes an angle of $60^{\circ}$ with the horizon. In the semi-recumbent posture the same plane is directly horizontal, and in the recumbent posture it forms a reversed angle of $45^{\circ}$ with the horizon.

What is the axis of the pelvis ?

As usually given it is a line drawn from the centre of the conjugate diameter of the inlet, parallel to the face of the sacrum and coccyx, th the centre of the conjugate diameter of the outlet. (The line $s k$ in $\mathrm{Fi}_{5} .4$.)

\section{How is the pelvis lined within?}

By certain muscles, blood vessels, nerves and fascie.

\section{What muscles are contained in it?}

I. The Psoas-iliacus muscle on either side, consists, first, of the iliacus internus, which, in its origin, covers almost the entire inner appect of the wing of the ilium, uniting with the psuas magnus, which passes over the upper border of the sacrum. Their conjoined bolly passes ahng the border of the sacro-iliac arch, and by a common tendon passes wut of the pelvis to be inserted upon the femur.

2. The Pyriformis muscle on either sile, which covers with its insertion the face of the sacrum, and passes out of the pelvis unter the sacroischiatic arch, to be inserted upon the femur.

3. The Obturator internus muscle on cither side, which cover the ante. rior pelvic walls and passer out unler the suere ischiatic arch.

What obstetric uses have these muscles?

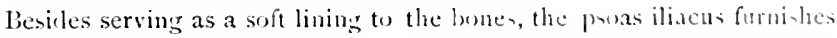
a cushion, or guard, for the iliac vesiels and nerves, preserving them from pressure, while the pyriformis performs the same office for the sciatic nerve, which lies along its border. 


\section{THE REPRODUCTIVE ORGANS.}

THE INTERNAL ORGANS.

What and where is the Uterus?

The uterus or womb is a hollow muscular organ, situated in the centre of the pelvin, letween the bladder and rectum.

What are its shape and dimensions?

It resembles a pear cut in two, the anterior surface being flat, and the posterior rounted. It is three inches long, two inches broad (above) and one inch thick, and weighs in the virgin about one ounce. S'

FIG. 5.

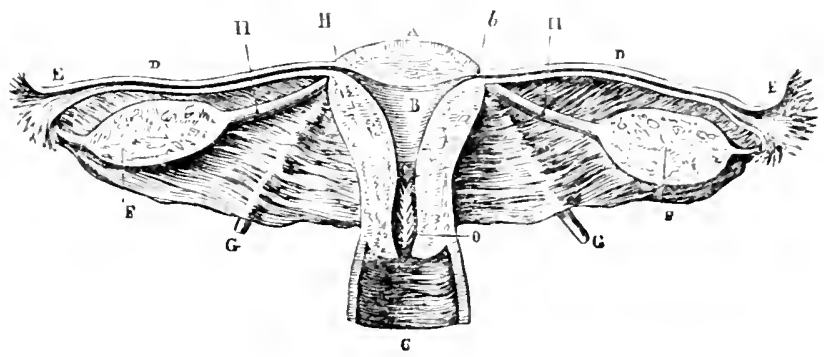

Into what parts is it divided?

Intu, Ist, the cervix or neck, about an inch long, and $2 \mathrm{~d}$, the body or FIG. 6.

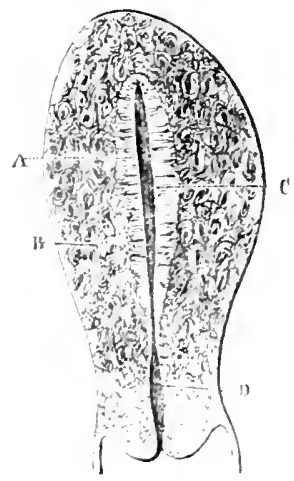
funlus.

\section{What are the cornua of the uterus?}

The upper and outer angles are called the cornua.

How is the cavity of the uterus divided?

Into the cavities of the cervix and body. The first is fusiform, and appears to he an antechamber to the main cavity; the latter is triangular in outline, but with its walls in apposition (see ligure).

What openings are found in the cervix?

The os externum, or os uteri, called alsu the os, is a small opening into the cavity of the cervix at the lower end of the cervix. The constriction between the cavities of the neck and budy is called the os internum. 


\section{What is the structure of the uterus?}

It is mainly composed of muscular tissue, with fibrous connective tissue, blood vessels and nerves. On the outside, it is mainly covered with peri. toneum, and on the insile, is lined with mucous membrane, called the endometrium.

\section{How are the muscular fibres arranged?}

For the most part they are irregularly and inextricably interlaced, but a circular arrangement of fibres is found in the cervix, while in the buily the m.jority are longitudinal.

\section{What kind of blood vessels are found in the womb?}

The arteries are mainly small, and helicine or spiral, while the veins are short, of large calibre, and freely communicating; peculiarities which warrant us in regarding the uterus as composed of a modified erectile tissue.

How is the uterus supplied with nerves?

Ist. The main nerves proceed from a well defined nerve centre in the lumbo-sacral region (the sexual brain).

2d. The sympathetic nervous system also furnishes fibres.

3 d. The vaso-motor apparatus has much intluence upon the womb.

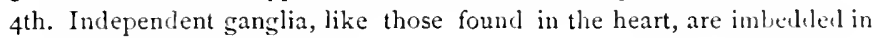
the uterine tissue.

\section{What kind of mucous membrane lines the uterus?}

The membrane lining the body is quite thick and vascular, and is composed-

I. Of a mesh of connective tissue containing many spindle-shaped celli.

2. Of many tubular glands, which give the surface of the membrane a perforated appearance. $=1117$, th

3. Of ciliated cylindrical epithelium cells, which line the glands and the outer surface of the whole membrane.

The membrane lining the cervix is continuous with that of the lexly, and is sulstantially the same, execpt in being thrown into numerous longiturlinal folds.

What distinguishing peculiarity has the uterine mucous membrane?

It has no hasement layer of connective tissue, and merges itregulaty into the muscular tissue.

What kind of mucus is secreted by the uterine mucous membrane?

A viscisl, alkaline mucus. 


\section{What are ovula Nabothi?}

The tubules in the cervical mucous membrane are sometimes occluded, while the secretion continues until the gland becomes quite large and globular. They are often a source of much irritation.

\section{How does the peritoneum cover the uterus?}

It completely invests the uterus above, in front as far as the junction of $=$ the body and cervix, where the bladder touches the womb, and behind as far as the junction of the uterus and vagina. $=a C l$

\section{What is the broad ligament of the uterus?}

The extension of the peritoneum over the uterus causes two folds of peritoneum to be brought together at its sides, and these extend across the pelvis, to be merged into the common abdominal peritoneum. These transverse folds are called the broad ligament, and divide the pelvis into two compartments; in the anterior one the bladder is situated, in the posterior, the rectum.

\section{What are the round ligaments?}

They are two rounded cords, composed of fibrous tissue, interspersed with muscular fibres, which extend from the cornua of the uterus to the top of the pelvis in front, where they pass through the inguinal canal to be inserted in the connective tissue of the labia majora.

\section{What are the utero-sacral ligaments?}

Bancls of fibrous tissue which pass from either side of the uterus to the sacrum, and are of considerable strength.

\section{What are the recto-uterine and vesico-uterine ligaments?}

Small folds of pcritoneum which pass between the uterus and the bladder and rectum respectively.

\section{What is the normal position of the uterus?}

The uterus is placed nearly in the centre of the pelvis; so that a line drawn from the top of the symphysis to the middle of the second bone of the sacrum would touch its top. Its long axis is ncarly parallel to the face of the sacrum and to the posterior wall of the symphysis pubis. But it must be remembered that the utcrus is movahle, and, ist, rises and falls with the respiratory movement, and, 2d, is pushed backward and forward by the varying conditions of fullness in the blarlder and rectum.

\section{What supports the uterus?}

Ist. The uterus is swung from the sacrum by the utero-sacral ligaments. 2d. It is slightly supported or belayed by the broad, round, recto- and vesico-uterine ligaments. 
3 d. The walls of the vagina act as a fleshy column of support, being in turn supported by the perineum.

4th. "The retentive power of the abdomen" (Duncan), due to the exist. ence of a partial vacuum in the abdominal cavity, aids in m.intaining the uterus in its normal position.

\section{What is a double uterus?}

A uterus containing two cavities separated by a longitulinal septum. Occasionally the whole genital tract is double, the septum extencling to the vulva, so that there are two vagine.

Sometimes a single cornu of the uterus is developed to such an extent as to be capable of containing a fatus during gestation.

\section{What are the Fallopian tubes?}

The Fallopian tubes or oviclucts are small tubes which extend from each cornu of the uterus.

\section{What is their structure?}

They are continuous in structure with the uterus, being mainly muscular, covered with peritoneum and lined with mucous nembrane, which is identical with that of the uterus. Their average calibre is one-sixteenth of an inch, and their length about five inches.

\section{How do they terminate?}

In an expanded or trumpet-shaped end. called the fimbriated extremity, because it is fringed with little prolongations of tubal tissue, one or mure of which is adherent to the ovary of the same side.

\section{What and where are the ovaries?}

Two glandular bodies imbedded in the posterior surface of the lroal ligament, one on each side of the uterus. They are of about the sice and appearance of blanched ahmonds.

\section{What is the structure of the ovary?}

It is mainly composed of a stroma of dense fibrous tissue, in the menties of which are found the ovisacs in different stages of development (see (1)ulation).

What is the parovarium?

The parovarium, or organ of Rosenuiiller, consists of several tulke placed between the folds of the loroal ligament. There is one mench sicle of the uterus. They are supposed to be the remains of the Wilfinin bodies, and have no known function. Very large cysts are sometimes developed from them. 


\section{What is the vagina?}

A tube which serves to connect the uterus and its appendages with the outsicle of the body. It is attached alove to the uterus and terminates below in the vulva.

\section{How is the vagina attached to the uterus?}

It is inserted upon the outside of the womb, at the junction of the body and neck, so that the neck of the uterus projects into the tube.

\section{What is the structure of the vagina?}

It is composed of fibrous connective tissue and of muscular fibres, for the most part circularly arranged. On the outside it becomes continuous with the ordinary cellular tissue or packing of the pelvis; within, it is lined with mucous membrane, which is reflected over the cervix uteri above, and below is continuous with the mucous membrane of the vulva.

How does the mucous membrane of the vagina differ from that of the uterus?

It is composed simply of flat or pavement epithelial cells, and has no proper glands. Numerous depressions or crypts in the membrane answer a similar purpose and sccrete a mucus of aeid reaction. In the virgin it is disposed in many transverse folds, called ruge. = vagine

\section{How long is the vagina?}

Its anterior wall is quite short, extending from the vulva almost directly to its point of insertion, a small pouch being formed above, called the anterior vaginal pouch. The posterior wall is longer, being prolonged upward to form a larger pouch belnind the uterine neck, called the posterior vaginal or retro-uterine pouch. The average length of the vagina is from 3 to 5 inches, varying in inclividuals and in races.

\section{Where is Douglas' cul de sac?}

It is situated in the abdomimal cavity, directly behind the posterior vaginal pouch, and therefore between the vagina and rectum. It is a very important space, because, being the most dependent portion of the abelominal cavity, effusions of blood or other fluid and tumors of various kinds are often to be found in it.

\section{How does the vagina terminate below?}

It terminates in a çircular fold of mucous memlrane, called the hr'men. From the fact that this fold is often more developed in its posterior half, it usually appears as a crescentic fold, stretching across the opening of the vagina. 


\section{What is an imperforate hymen?}

The membrane sometimes completely closes the opening of the vagina, and is then said to be imperforate.

What is the structure of the hymen?

It is composed almost entirely of nucous membrane, and is easily torn by the entrance of the male organ, but is sometimes firm enough to resist any ordinary pressure, and may cause delay in labor by its presence.

\section{What are the carunculæ myrtiformes?}

When the hymen is torn, its fragments undergo atrophy, and there remain little wart-like elevations in the line of the hymen, called carunculie myrtiformes. It is said, however, that these bodies sometimes coexist with the hymen, being placed a little distance behind it.

\section{What is the bulb of the vagina?}

A mass of erectile tissue, mainly composed of short, venous sinuses, shaped somewhat like a pair of saddle-bags, and placed over and at the sides of the vagina.

\section{What are the vulvo-vaginal glands?}

The vulvo-vaginal glands, or glands of Bartholin, are two small bodies situated just behind the hymen, one on each side. They are imberled in the cellular tissue around the vagina, and empty by a small duct on either side. They secrete a thin mucus, which is expelled freely, and even by jets, during venereal excitement and coitus.

\section{THE EXTERNAL ORGANS.}

\section{What is the vulva?}

The name given to the external organs collectively, but often used to denote the genital fissure, or chink of the vulva.

\section{What are the labia majora?}

Elevated folds of cutaneous tissue, which are found on either side of the genital fissure.

\section{What is the structure of the labia majora?}

They contain loosely arranged cellular tissue, with some fat. On their outer surface they are covered only with skin, which is characterized by a free growth of stout, curly hair, similar to that fouml in the axilla. (1) their inner surface the skin shades off into mucous membrane, which is finally continuous with that of the vagina, and is furnished with a considerable number of sebaceous follicles. 
What is the mons veneris?

An eminence of eutaneous tissue, situated directly upon the symphysis pulis, and is the anterior termination of the labia majora. It is well padicel with fat and covered with an abunclance of hair.

What is the anterior commissure?

The point just under the mons, where the labia meet in front. The anterior limit of the genital fissure.

\section{What is the posterior commissure?}

The posterior limit of the genital fissure, or the point where the labia meet posteriorly.

What is the fourchette?

When the genital fissure is made to gape by the fingers pulling apart the labia majora, a fold of mucous membrane is made to project behind the posterior commissure, which is called the fourchitte. The little dimple or cup between this fold and the commissure is called the fossa naticularis, but neither of them have any existence until artificially produced in this manner.

\section{What is the clitoris?}

A small cylindrical body, about an inch in length, which resembles and is the analogue of the male penis. It consists of two corfora caternosa, which are attached to the under edge of the pubic bone, and by their free end project slightly under the anterior commissure. The part which is visible is about the size of a pen.

\section{What are the labia minora?}

Called also the Nymphe. They are two folds of dartoid tissue, covered by mucous membrane, which cover the clitoris in a manner similar to the prepuce of the penis, and extend backward along the sides of the labia majora for about one-half their extent.

\section{What is their structure?}

It nearly resembles that of the male scrotum, inclosing also some erectile tissue.

What is the vestibule?

The space which extends from the clitoris to the opening of the vagina, and is bounded laterally by the labia minora.

What and where is the meatus urinarius?

It is the opening of the urethra, and is placed at the posterior limit of the restibule, and therefore, just above the opening of the vagina. It is situated in a tubercle or slight eminence. 
How long is the female urethra?

About one and one-half inches.

How is the urethra situated with respect to the vagina?

It lies directly over it, and can be distinctly recognized, by the finger introrluced into the vagina, as a tubular rilge above the anterior wall of the ragina.

What is the perineum?

The space between the vulva and anus, and bounded laterally by the tuberosities of the ischia.

What is the perineal body?

It consists of a wedged-shaped band of fibrous elastic tissue, which stretches across from one tuberosity to the other, and is interposed between the termination of the vagina and rectum.

What other structures of importance are found in the perineum?

The transversus perinei and levator ani muscles, and also fibres of the sphincter muscles, which are placed about the ends of the vagina and rectum.

\section{PHYSIOLOGY.}

OVULATION.

What is the function of the ovaries?

To furnish ova, or egss, which are the primitive germs of the human being, and the necessary female element in reproduction.

What is this function called?

Ovulation.

How early in life does ovulation begin?

In childhood. [Sinedy and Hausmann found evidences of ovulation in to per cent. of infants examined by them.] But it does not occur with much vigor until womanhood.

Where are the ova developed?

In small cystic bodies called ovisacs, or Graafian vesicles (or follicles), there being usually but one ovum in each ovisac.

How many ovisacs exist in each ovary?

They are variously estimated from 30,000 to 150,000 , but only a score or so can be observed at any one time.

Describe the ovum when fully developed.

The ovum, when fully developed, is a spherical mass of protoplasm, $I_{2}^{\frac{1}{2}}$ th of an inch in diameter. It is structureless, except that it containc, at one point, a small body, like a nucleus, called the germinal vesicle, 
which, in curn, contains a smaller borly, like a nucleolus, called the germinal spot. The ovum is surrounded by a thin envelope of albuminous matter, called the citelline membrane, the orum itself being called, also, the vitellus, or yolk.

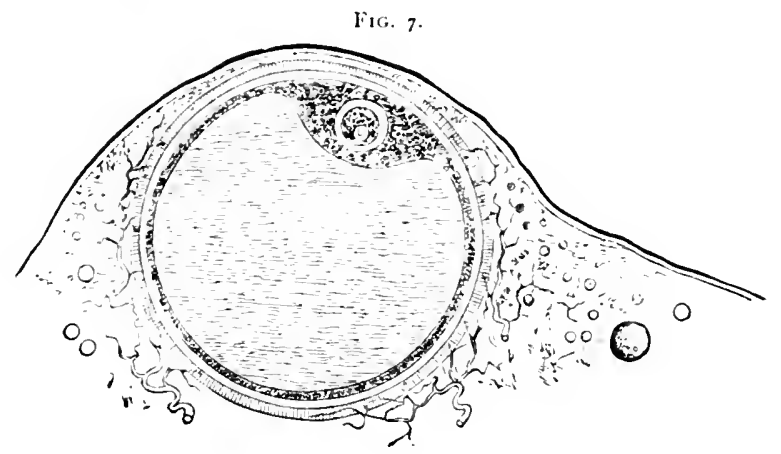

\section{Describe the process of ovulation.}

The ovisac, at first very minute, is imbedded in the stroma of the ovary. Its walls consist of several layers of cells, the innermost of which are called the proligerous disk, and in this the ovum is situated. These cells secrete within the ovisac an albuminous fluid. While the ovisac increases in sice, it also approaches the surface of the ovary, having then attained a diameter of one-fourth to one-half of an inch. At this point it stops grow$i n$, , while the fluid continucs to be secreted in its interior. This finally subjects the ovisac and the overlying covering of the ovary to a bursting pressure; the ovisac is ruptured, and the ovum, with some of the fluid and epithclium of the ovisac, is extruded upon the surface of the viary.

\section{What happens to the ovisac after the discharge of the ovum?}

Several things may occur-

I. The entire cuntents of the ovisac may be extruled, the walls collapse, and within a week or two a small linear cicatrix only is left to show that ovulation has occurred.

2. Some hlood may he effused into the sac at the time of rupture. A clot - is formerl, which is slowly absorbed; as its hematin becomes faded and yellowish, it is called the corpus lutiom.

3. Should the woman become pregnant, the walls of the ovisac may continue to secrete fluid. This is due to the increased blood supply which 
pregnancy occasions: and this leads to the formation of a large, yellowish body, called the cortus lutem of pregnancy.

How is the appearance of the ovary affected by age?

In youth it is smooth; after repeated ovulation it becomes fi-sured and wrinkled; in old agre atrophy takes place, and it returns to nearly its in. fantile appearance.

\section{What happens to the ovum after its escape from the ovisac?}

I. It may drop into the abdominal cavity and perish.

2. It is wafted toward the open end of the Fallopian tube by means of a current in the fluid bathing the tissues, which current is caused by the action of ciliated epithelium cells, and is always directed toward the tubes.

3. The end of the tube may, by a spasmodic movement, clasp the surface of the ovary and draw the ovum into the tube.

4. When in the tube it is passed on to the womb (a) by a ciliary current, and (b) by peristalis, and from the womb it is discharged with the mucus, etc., unless fecundated.

5. It may become fecundated and remain within the mother until devel. oped into a child.

How often does ovulation take place?

It is irregular in its occurrence. A number of ovisacs are constantly being developed, with greater or less rapidity, and the amount of the bluor supply of the ovary controls the rate of development. Frequent coitus leads to frequent ovulation, for this reason.

What is the usual interval between the discharge of successive ova?

Usually once a month, because the greatest increase in the bloorl supply occurs once a month, during menstruation.

\section{MENSTRUATION.}

\section{What is Menstruation?}

A periodical disturbance in the female. characterised by

1. An increase in the vascular tension throurhut the body.

2. A special determination of bloos to the pelvic organs (or pelvic hyper. amia j.

3. A renovation of the aterine mucous membrane.

4. A discharge of blood from the uterus. 
How often does menstruation occur?

(Ince every twenty-eight days; but the interval varies in some women, from three to six weeks.

\section{What is the first evidence of menstruation?}

An increase in the vascular tension, and a seuse of fullness in the pelvic region, which is accompanied ly pain, if there is any local disease.

\section{What effect has the pelvic hyperæmia on the ovaries?}

By increasing the blood supply it hastens the development of the ovisacs, and onc or more usually rupture at this time.

\section{What effect has the pelvic hyperæmia on the uterus?}

The uterus becomes larger and softer, and its mucous membrane under. goes changes as follows: 1. New cells are formed. 2. The outer layer or layers of epithelium are thrown off. 3. The membrane is turgid with bloml and thrown into folds. 4. There is increased functional activity in the mucous follicles, and a more abundant secretion of mucus. 5. Some of the superficial capillaries break down, and an oozing of hlood takes place.

\section{What is the clinical course of menstruation?}

1. The woman notices a leucorrhea for one or two days.

2. A discharge of blood for three days (average).

3. A continuance of leucorrhcea for one or two days.

\section{Is menstruation attended with pain?}

Not normally, but the majority of women experience some degree of pelvic pain, lecause the parts are hypersensitive, from some departure from the normal comlition. The pain is usually referred to the "small of the back;" also to the ovarian regions and to the hypogastrium.

\section{What peculiarities has the menstrual blood?}

I. It is mixed with mucus and epithelial scales.

2. It does not coagulate when moderate in amount, because it is made acil by the vaginal mucus.

How much blood is discharged during menstruation?

From $\bar{j}$ ss to $\bar{j}$ iij in all; but the amount varies. $X Y y^{\prime \prime}$

Is the blood during menstruation always discharged from the uterus?

No. The uterine mucons membrane sometimes fails to unlergo its usual changes, amel weakened eapillaries in any part of the body may lreak down unler the increased vascular tension. Thus we may have menstrual hemorrhage from the stomach, lungs, breasts, or any part whatever. 
What is this condition called?

Vicarious menstruation, or xenomenia.

What are the popular names for menstruation?

To be mwell; to see anything; to be regular; the periods; conrses; monthlies; turns; changes, and flowers.

What is the object of menstruation?

To insure the development of ora by a periodical increase in the ovarian blood supply, and to favor the detention of the ovum in the uterus by the changes in the nucous membrane.

When do women begin to menstruate?

As soon as they become women, which period is called puberty.

When does puberty begin?

It varies, from race, elimate and social condition. The average is at the age of tifteen years.

What physical signs attend the age of puberty?

The reproductive organs are fully developed, the breasts enlarge, the pubes is covered with hair, and the whole form of the girl becomes rouniled and womanly.

When do women cease to menstruate?

At about the age of forty-five years, which period is called the menopause or climateric, or " the change of life."

What happens to the reproductive organs at the menopause?

They gratually atrophy, but the possibility of child-hearing may continue until the age of fifty-tive years (F. liarker).

What is the main function of the uterus?

To receive the fecundated ovum, and to retain it until it is developect into a mature fotus.

What is the function of the oviducts?

To convey the ova to the uterus.

What is the function of the vagina?

It serves as the duct or outlet for the discharge of the uterine secretions, including the escape of the child in labor, and also to almit the mate organ, so that the semen may arain access to the ormm.

What is the function of the external organs?

They are endowed with great sensibility, and are mainly concemed with the function of coitus. The nymphe also serve to direct the stream of urine as it pas es from the meatus urinarius. 


\section{What is the structure of the breast?}

The bre:ast is compased of fifteen or twenty lobes of glandular tissue,

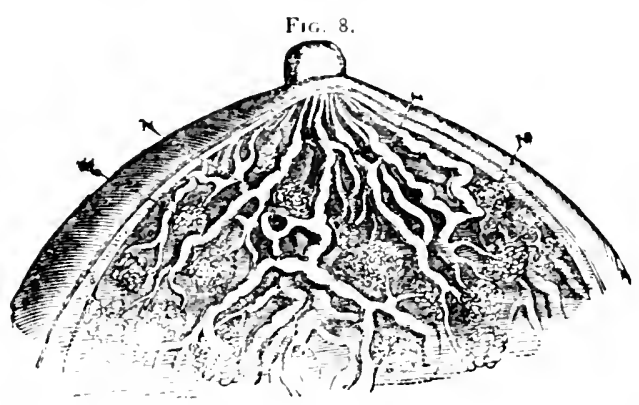
with a packing of arcolar and adipose tissue. The lobes are compounded of lobules produced by the aggregation of the terminal acini, in which the milk is formed. The ducts of each lolule unite with each other to form a terminal ca-

nal, called the galactophorous duct, of which there is one for each lobe (1'layfair). These empty upon the face or extremity of the cylindrical appendage called the nipple.

\section{What is the areola?}

A circular patch of cutaneous tissue around the base of the nipple, of pink color in vurgins, and darker in those who have borne children.

\section{PREGNANCY.}

\section{What is Pregnancy?}

The condition in which a woman contains a living and growing fietus.

What are the essential requisites for the occurrence of pregnancy?

Ist. That a fully matured ovum shall he recently discharged from the ovary.

2. That male semen shall come in contact with such an orum before it leaves the uterus.

\section{What is fecundation?}

The act by which the male semen imparts to the ovum the power of developing into a fretus.

What part of the semen has this property?

The spermatoroa ; each spermatoroün resembles a ciliated epithelium cell, except in being apparenty structureless or homogeneous. Wach drop of semen contains thousmols, all of which are in constant viluatile motion during life. 
How long do the spermatozoa retain their vitality?

They have been found in full vigor eight days after their introluction into the vagina.

How and where is contact between the spermatozoa and ovum brought about?

I. During coitus the semen is ejected against the cervix uteri and upper part of the vagina.

2. During the orgasm of the female the uterus sucks or pumps the spermatozoa into its cavity, after which their own vibratile motion causes them to ascend the oviduct until they meet the ovum.

3. Fecundation probably occurs most frequently on the surface of the ovary, but it can occur at any point before the escape of the ovum from the womb.

Is it necessary for the uterus to aid the entrance of the semen ? No; fecundation has occurred when the woman was perfectly passive, or unconscious, from drugs, drink, or sleep.

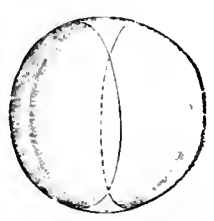

FIG. 9.
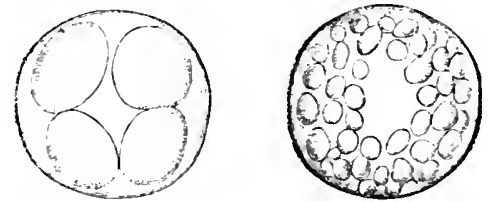

SEGMENTATION OF THE VITELLI'S.

What further means are provided for the retention of the semen?

I. During venereal excitement the round ligaments of the uterus pull it forward and upward. This permits the penis to glicle past the cervix and to deposit the semen in the posterior vaginal pouch. When the ligaments are relaxed, the cervix resumes its former position, and thus retains the semen in the pouch above; the spermatozoa may then, at their leisure, enter the uterus.

2. It has also been demonstrated that fecundation can take place when the semen escapes upon the vulva, so that the whole distance may he traveled by the spermatozoa unaicled.

What changes take place in the ovum after fecundation?

1. The germinal spot and vesicle disappear.

2. The segmentation of the vitellus; $i$ e. the vitellus splits into two masses, these into four, and so on until a large number of serments are formed. (See Fig. 9.) 
3. A clear thuid is secreted within the orum, which presies these segments to the surface of the ovmm, where they form a double layer of cells,

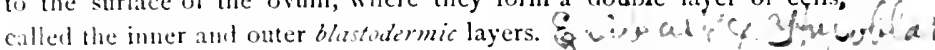

4. There then appears upon the outside of the viteltus a small oval eleratim, surrounded by a depression, which is called the area germinatiza.

5. There apprears in the area germinativa a small, dark line, called the frimitice trace. About this line will be grouped the various parts of the embryo, the rest of the ovum serving only as a covering and for nutriment. (Sice Fig. 10.)

6. A covering for this trace or embryo is now formed. Thus far the vitelline memlirane has been sufficient. The embryonic line sinks into the centre of the ovum, while the edges of the external blastodermic layer about the area close around it, inclosing it in a sac, called the amnion. (Sece Fig. 11.) The vitelline membrane then disappears.

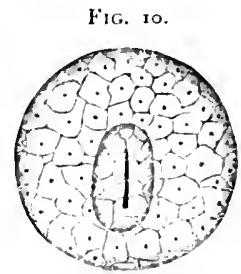

THE OUTER LAYEK OF CELLS (OMPLEl Fl).

The primitive srace in the centre of the area germinaliva.

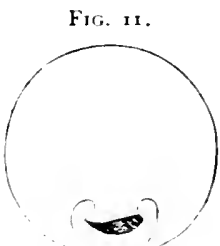

SECTION CF ONEM.

Shows emhryo sinking in Loward the centre of the ovum, and the woy in which the amnion is formed.

7. The rest of the external bla-todermic layer, or that part which did not follow the embryo within the ovum, now forms the outer covering, and is called the chorion.

S. the chorion develops upon its outer surface little hollow projections, callecl rilli.

9. I vascular mass, called the allantois, shoots out from the middle of the embryo, and when it has reaches the inner surface of the ovm, spreacls out, carrying forps of lolood vessels into the villi of the chorion. (Figs. 12 anl 13.)

10. Liefore the formation of the allantois, the nutriment neetled for growth is furnishet (a) by osmosis of fluids from the tissues of the mother into the wum, ant (h) by the thid materials of the orum contained within the interwal blastoclermic layer. While the allantuis is formerl, this in- 
ternal layer contracts, its shrunk bulk constituting the umbilical ivisicle, which tinally disappears. (Fig. I3.)

II. By the time the allantois is fully formed, if not before, the ovum has reached the womb. Its villi, thus provided with blood ressels, become enlarged and arborescent over that part of the ovum which is in cuntact with the uterine wall, and atrophy and disappear from the rest of its circumference.

12. When the orum has reached the uterus, it is detained in a fold of mucous membrane. The edges of the fold grow over the orum, so as to give it an additional covering of mucous membrane, called the decilua reftexa.

13. When the ovum is thus fastened to the uterine wall, the chorionic villi increase in size, and form attachments to the uterine wall under-

FIG. 12.

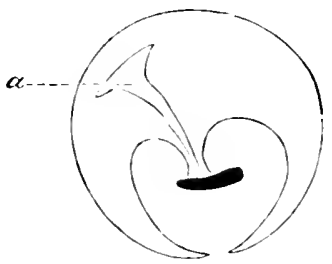

THE AMNION NEARLY COMPLETED.

The atlantois carrying llood vessels to the circumferance ( $a$.)
FIG. 13.

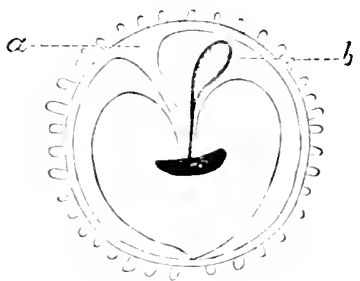

THE AMNION COMPLETED.

a. The allantois completed, having carried vescels into all the projections (villi) of the chorion. $b$. The umbilicail vesicle.

neath it, forming the placenta, by which a definite vascular connection is established between the embryo and mother.

I4. The placenta being formed, the embryo is suspended in the ammiotic sac by a cord reaching to the placenta, called the funis, or umbilical cord, and continues to develop to the end of pregnancy. It has now the following coverings: Ist, the amnion; 2 , the chorion; $3^{\text {th the }}$ decidua reflexa, besirles being covered by the uterine walls in general.

What changes in the mucous membrane of the womb follow fecundation?

1. The mucous membrane of the womb becomes hyperamic and hypertrophied; it develops new and soft connective tissue, and is thrown into folds. In this thickener state it in called the dicitua atro. (This occurs whether the orum enters the womb or not.) 
2. When the ovum enters, adjacent folds grow over the ovum, forming the derifur reflexa. As the ovum increases in size, the decidua reflexa becomes united or welded with the superficial layers of the general mucous membrane, or decidua vera (alout the fourth month.)

3. That part of the membrane directly under the ovum undergoes greater changes, and is called the dicidua serotina.

\section{What is the nature of the placenta?}

I. The villi of the chorion enter depressions in the decidua serotina, and bands of connective tissue unite the decidua and villi.

2. The venous sinuses under the serotina increase greatly in size, and the villi, by pressure and erosion, finally dip into them. As a result, we have a tlat, cake-shaped mass, mainly composed of blood ressels, which serve to convey nutriment from the mother to the child.

\section{Does the maternal blood enter the circulation of the child?}

No. The foetus derives nutriment by endosmosis, through the delicate walls of the villi floating in the maternal sinuses-like the rootlets of a plant-absorbing the elements needed for growth, and discharging effete products by exosmosis. According to some, the villi dip into crypts or depressions of the decidua seratina and not into the sinuses, and absorb a secretion called uterine milk, which is furnished by these crypts.

\section{What other function has the placenta?}

That of respiration. The fretal blool is oxygenated in the placental tufts.

\section{What is the funis?}

The veins of the placenta ultimately unite in a single vein, which parses to the umbilicus of the fretus. Two arteries pass from the fatus to the placenta, and are wound spirally about the vein. These three vesscls are imbedied in a substance called Wharton's gelatine, and covered by a membrane derived from the amion. The whole is called the funis, or umbilical corl.

\section{What are knots in the funis?}

The fotus in its active movements sometimes passes through a loop of the funis, and this, when drawn tight, forms a true knot. lalse knots are mere knobs or masses of Wharton's gelatine, formed at intervals along the corll.

What are the dimensions of the placenta and funis at full term?

The placenta is abrut nine inches in diameter, and weighs one pound. The funi, averages alont twenty inches, the extremes being from three to furty inclues in length. 


\section{Describe the fotal circulation.}

The blood is propelled from the left ventricle of the fretus through the aorta and iliac arteries to the point where the umbilical arteries are given off; through these to the placenta, and back again through the umbilical vein, which, passing through the liver, empties, by the ductus venosus, into the vena cava. From this it enters the right auricle, and is deflected by a membrane, called the Eustachian valve, through an opening, called the foramin ortale, into the left auricle, and then into the left rentricle. The blood, returning from the head and upper extremities, passcs from the right auricle to the right ventricle, and thence to the pulmonary artery, where a tube is provided, called the ductus artiriosus, which conducts the blood at once into the aorta. It will be noticed that the venous blood of the foetus is more oxygenated than the arterial. After birth the foimenen otale closes and the peculiarly fetal ressels disappear.

\section{What is the liquor amnii?}

A clear, slightly saline fluid, secreted from the inner surface of the amnion, and in which the embryo floats.

\section{How much liquor amnii is found at full term?}

From half an ounce to several pints. f $\tilde{z}$ iv on an arerage.

How large is the ovum (and fœtus) at different months?

By the end of the first lunar month of pregnancy the ovum is about the size of a pigreon's eggr.

End of ad month, size of a hen's egg; fortus an inch long.

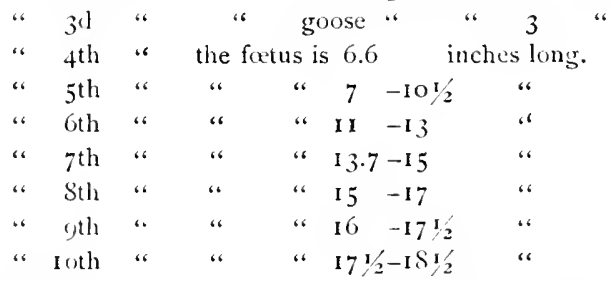

[According to Schroeder.] American children are usually larger at bith.

How soon can the sex of a child be recognized?

Not certainly until during the fourth month.

What is vernix caseosa?

In unctuous selaceous secretion covering the shin of the clilil, for the purpose of lubricating it for delivery. It does mot appear until the seventh munth. 
What is meconium?

The dark green, semi.fluid contents of the fietal intestine, corresponding to fecal matter in the adult.

What changes occur in the womb itself during pregnancy?

It greatly enlarges, to accommodate the growing ovum, and at the end of pregnancy has a weight of two pounds, and its cavity is a foot in diameter. The cervix enlarges but little (not more than one-half), and its carity remains separate until the last week or weeks of pregnancy, when the os internum is stretched open and the two cavities of the cervix and fundus become one. The tissue of the cervix becomes softer to the touch.

\section{What changes in position does the womb undergo?}

I uring the first month the increased weight of the uterus causes it to deseend somewhat in the pelvis, or become prolapsed.

End of $2 \mathrm{~d}$ mo. Still low in the pelvis, and usually anteverted. Bimanual touch shows it to be as large as an orange.

" $3^{\text {d } ~ " ~ T h e ~ s a m e, ~ b u t ~ a s ~ l a r g e ~ a s ~ a ~ c h i l d ' s ~ h e a r l . ~}$

“ $4^{\text {th } ~ “ ~ F u n d u s ~ c a n ~ b e ~ f e l t ~ j u s t ~ a b o v e ~ t h e ~ s y m p h y s i s, ~ a n d ~ b e i n g ~}$ too large for the pelvis, it now ascends.

“ $5^{\text {th }}$ “ Fundus midway between umbilicus and symphysis.

" oth " " a at level of umbilicus.

" 7 th " " 2 to $31 / 2$ finger brealths above umbilicus.

" Sth " " 1 to 2 " " below ensiform appendix.

" "9th " " touches the " “ "

" roth" " has descended to same position as in eighth month.

Why does the fundus of the uterus descend during the last month?

Because the cavity of the cervix is added to that of the fundus at that time, and the contents of the womb settle toward the pelvis, leaving more room above.

\section{ABNORMAL PREGNANCIES.}

\section{MULTIPLE PREGNANCY.}

How many children may a woman have at one time?

Two, or twins; three, or triplets; four, or quadruplets; five, or quintuplets.

How frequently do multiple births occur?

l'wins once in eigrty-nine cases; the others are rare, and any over five are apueryllial. 
How are multiple pregnancies caused?

1. Two or more ova may be fecundated and simultaneously developed.

2. Two primitive traces may appear on one ovun, and each develop an enibryo.

These two causes may be combined in the case of triplets, etc.

How may the cause be demonstrated?

Twins developed from separate ova will each have its own placenta and membranes; from a single orum will have a single placenta, and usually but one set of membranes, though there may be two amniotic sacs.

What is superfecundation?

The fecundation of two ova at different times, i.e., with an interval of several hours, or even days.

\section{How is this demonstrated?}

Fy cases in which a woman has bome twins, one white, the other a mulatto, from separate intercourse with a white man and negro.

\section{What is superfœtation?}

The fecundation of a second ovum after a first ovum has entered the uterus. It may occur during the first four months of pregnancy, or before the decidua reflexa and decidua vera have become united.

\section{How is this demonstrated?}

I. By cases in which the lirth of a fully developerd child has been followed by a second birth, after an interval of one, two, three or four months.

2. By the expulsion at one birth of a fully developed child and a futus evidently one or more months less advanced in development.

What is the clinical course of twin pregnancy?

I. Both children may be safely carried to term.

2. " " " prematurely expelled.

3. One twin may be prematurely expelled and the other remain until horn.

4. " " die in utero and be retained until the birth of the other.

What is a fætus papyraceus?

$A$ twin dying in utero at an early period may be partly dessicated, and compressed by the growth of the other twin, being llattened ant parchment-like in ajpearance.

What is a lithopædion?

A rlearl child may be infiltrated and incrusted by calcareous salts until it is stone-like in appearance. This occurs only after longr retention in extra-uterine cysts. 


\section{EXTRA.UTERINE PREGNANCY.}

What is extra-uterine pregnancy?

l'reguancy in which the fretus is developed in some other locality than in the uterus.

\section{How is it classified?}

1. The ovum, after fecundation, may remain in the ovisac, and be developed in the ovary, called ovarian pregnancy.

2. The fecundated ovum may be arrested in the Fallopian tube, and be there developed, called tubal pregnancy.

3. It may be arrested at the junction of a tube and the uterus (the narrowest part), and developed partly in the womb and partly in the tube, called tulo-uterine or interstitial pregnancy.

4. It may drop from the ovary into the abdominal cavity, and be there developed, called abdominal pregnancy.

\section{What effect has extra-uterine pregnancy on the womb?}

It enlarges, as in normal pregnancy, up to the fifth month, and its hrpertrophied mucous membrane or clecidua is cast off in one piece, in several pieces, or in flaky shreds, at from the second to the fifth month.

\section{What are the symptoms of extra-uterine pregnancy?}

I. The symptoms of pregnancy in general.

2. The presence of a cystic tumor in the abdomen, usually to be felt also in louglas' cul de sac.

3. The enlargement of the womb, and

4. The displacement of the womb by the tumor.

5. Irregular, sanguineous discharges from the womb.

6. The expuluion of the enlarged uterine mucous membrane (decilua).

7. Pain, irregular in occurrence, and of intense character.

What points are especially important in diagnosis?

A rapily growing tumor in Iouglas' cul de sac, with an enlarged but emfty womb, from which portions of decidual membrane have passed, can be nothing else than an extra-uterine cyst. The pain, if present, is characteristic. Abdominal pregnancy may proceed to term, without exciting any suspicions of its presence.

\section{What is the termination of extra-uterine pregnancy?}

1. Rupture of the cyst occurs in 35 per cent., followed by internal hemorrhage, shock, peritumtis, and usually death. 
2. The pregnancy may continue until full term, the chill lies and $(a)$ the tumor is partially reabsorbed, and remains innocuous, or ( $b$ ) inflammation supervenes, and the child is decomposed and evacuated by ulceration into the rectum, vagina, bladder, ablominal walls, or uterus-the woman running the gauntlet of peritonitis, septicamia, pyamia, etc.

When does the rupture of the cyst occur?

In the first half of pregnancy; selilom in second half.

What is the treatment where rupture has occurred?

If sure of the diagnosis, open the abdomen by an incision, ligate bleeding vessels, and remove all bloor and fluids.

What is the general treatment of extra-uterine pregnancy?

1. If discovered in the first half of its conrse, arrest it by destroying the vitality of the ovum.

2. If in the second half, operate as in ovariotomy, in hope of saving the child, and as near term as possible.

3. If the chill is dead, aw:ait developments, and interfere only when inflammation, absces;, or other complications demand treatment.

\section{How can it be arrested?}

By the faradic current of a battery.

I. An electrode, insulated except at its tip, is to be applied to the tumor, as felt in Douglas' cul de sac, per vaginam. The other electrode is applied to the upper part of the tumor through the abdominal walls. The choice of poles $(+$ or - ) is immaterial.

2. A moderate current is to be passed through the tumor, and gradually increased; the application to be made for an hour, and repeated every day for at least six days.

3. A large dose of morphia should be given before each application of the battery.

This treatment is certain if enough electricity is used, and for a sufficient length of time. No other treatment is either certain or safe.

\section{What becomes of the tumor after its arrest?}

It is rapidly absorbed, and becomes so small as to be inappreciable and innocuous.

What caution is necessary in operating surgically for the removal of the child?

The placenta must not be removed, because there is no contracting uterus to check hemorrhage after its detachment. It must, therefore, be allowed to remain, and become separated by the sloughing prucess. 


\section{HYDATID PREGNANCY.}

What is hydatid pregnancy?

Preguancy in which cystic degeneration of the chorionic villi occurs, giving rise to what is called a hydatiform mole.

I. 'The villi are converted into cysts.

2. The embryo dies and is absorbed.

3. The uterus is finally filled entirely with small cysts, whose average size and appearance is that of a white currant.

\section{What are its symptoms and termination?}

1. The pregnancy begins normally, but in the second or third month

2. A sudden and rapid increase in size of the uterus occurs, accompanied

3. By pain and irregular discharge of blood and water.

4. Labor supervenes and the mass of cysts is expelled.

It should be remembered that true hydatids (ecchinococci) may occur in the uterus, but not as a result or accompaniment of pregnancy.

\section{What is hydrorrhoa?}

A watery discharge from the uterus, from

I. Ilydatidl pregnancy.

2. A tear in the futal membranes, at a point remote from the os uteri, with gradual lealing of hipuor amnii.

3. l'robally from a watery secretion or transulation from the uterine mucous membrane.

\section{MOLE PREGNANCY.}

\section{What is mole pregnancy?}

1. At some time during the first three months of pregnancy a hemorrhage takes place in the ovum.

2. The embryo is destroyed and disappears, while the vitality of the chorion is maintained for several weeks or months.

3. Labor supervenes, and a fleshy, laminated mass or mole is extruded, in which close search will always reveal chorionic villi.and patches of the fartal membranes.

\section{SPURIOUS PREGNANCY.}

\section{What is spurious pregnancy?}

Called aloo preutocyesis, is a contition in which some of the symptoms of pregnancy are present, especially enlargement of the abdomen, changes in the breasts, and subjotiz' feeling of the fretal movements; the woman not being pregnant. It is to be distinguisherl from feignid pregnancy. 


\section{How may it be disposed of ?}

A vaginal examination shows the woml to be unenlarged, and the administration of ether will cause the abdominal enlargement to suddenly disappear. It sometimes terminates in spurious labor, a condition in which the clinical phenomena of labor are present in somc degree.

\section{PREMATURE LABOR.}

\section{What is meant by abortion, miscarriage and premature labor?}

Abortion is properly the premature expulsion of the fretus before it is viable; premature labor, its expulsion after viability, but before full term. The older writers restricted the term abortion to the period before guickiening (the child not being supposed to be living until then), and miscarriase to the period between quickening and viability. Now-a-lays, miscarriage is used as a euphemism for abortion, the latter word having fallen into disrepute, and become associated with the idea of criminality.

\section{What is meant by the term viable?}

A child born after seven lunar months of pregnancy may live, and is called viable-liveable.

\section{What are the causes of abortion?}

Disease or injury (I) to the ovum or fatus, citular,

Disease or injury (2) to the mother, maternal, $\}$ as

I. (a) Placental degeneration: amyloid or fatty (cystic, z'ide lydatids).

(b) Placental apoplexy and detachment, from hemorhage.

(c) Syphilis.

(d) Dropsy of amnion.

(e) Violence, either accidental or intentional, rupture of the mem. branes, etc. The death of the fietus from any cause is not always followed by its premature expulsion.

2. (a) IIypercmia of the pelvic organs from over excrcise, coitus, lifting, sewing machine, displacements of the uterus.

(b) Irritation of the uterus, as from tumors, mental shock, high temperature in [evers, and

(c) Emmenagogue drugs:

\section{What are the symptoms of abortion?}

- 1. Iain, more or less constant, felt in the back, hy pugrastrium or warian regions.

2. Uterine contractions.

3. Hemorrhage.

4. I)ilatation of the os uteri, with softening of the cervix. 
What are the dangers of abortion?

1. Hemorrhage; often great, because of the difficulty with which the orum is sepurated from the womb.

2. Retention of the placenta, in whole or in part, with subsequent septi. cemia, hemorrhage and other dangers.

3. The womb is apt to remain enlarged (set Subinvolution), and uterine disease may result.

4. Pelvic and peritoneal inflammations are more common after abortion.

When are the dangers of abortion most experienced?

In the middle third of pregnancy. In the first three months the ovum is usually expelled entire, and the chief danger is from hemorrhage during the slow process of dilating the os uteri. In the next third, the attach. ments of the placenta are fimer than at any other time; the fotus is first expelled, and the placenta often expelled with great difficulty and piecemeal, combining all the risks at their greatest. In the last three months the process differs but little from normal labor, except in being slower.

\section{What are the chief indications for treatment?}

I. To control hemorrhage.

2. To secure complete expulsion of the uterine contents.

How is hemorrhage to be managed?

1. By applying a tampon until the os is sufficiently dilated.

2. Hy securing complete delivery and stimulating uterine contractions.

How is retained placenta to be managed?

The placenta must be tetached by the fingers, or curctte, as soon as possible after the expulsion of the fretus. If pressure is male by one hand in the liypogastric region the womb can usually be forced down low enough to enable the finger to reach to the fundus.

\section{What rule should guide us in difficult cases?}

To persevere in efforts to remove the placenta as long as we are sure that our efforts are less injurious than allowing it to remain.

What is to be done when the placenta cannot be removed?

1. Use frequent antiseptic injections.

2. Employ remedies to guard against inflammation and septiciemia.

3. Renew the efforts to remove the placenta every dity.

\section{What preventive treatment may be used ?}

In threatened alontion from transient catses, absolute rest in bed, with full deses of morphia, may prevent. (2uinine is also useful in malarious 
districts, and in general, the removal of the cause, if possible, is always indicated. If preventive measures are not promptly successful, we should enteavor to promote the speedy termination of the process.

\section{THE SIGNS OF PREGNANCY.}

\section{What are the signs of pregnancy?}

The symptoms and physical signs caused by the changes taking place in the woman, and by which we recognize the occurrence.

\section{How may they be classified?}

I. Into certain and presumptive, or

2. Into objective and subjective, or

3. According to their etiology, viz:-

I. Signs due to the increase of vital activity.

II. " " " development of the womb.

III. " “ " " " "

IV. " " " unequal development of the general and generative systems, or seni-pathological signs.

\section{What are signs due to an increase of vital activity?}

The pregnant condition requires that the woman shall supply, not orily the needs of her own organism, as before, but shall also build up from ten to twenty pounds of highly organized tissue, viz: the child and its envelopes. Therefore, she will need more blood, and in general, all the vital forces must be increased. This is brought about by the stimulus of fecundation, and results in $(a)$ increase of appetite, $(b)$ weight, $(c)$ vigor, and $\left(a^{2}\right)$ sexual appetite. She must eat more in order to make more blood; the increased blood supply will increase her weight and general vigor, while locally, the hyperimia of the pelvic organs will cause, at first, an increase in the sexual desire.

\section{Is this class of signs always present in pregnancy?}

No. The general systen may fail to respond to the stimulus of fecun. dation, and these signs will be absent or defective, being replacel by the fourth class.

What signs are due directly to the development of the womb?

I. The descent of the womb, due to its increased weight, causes the alnomen to become smaller and flatter during the first month or two. Ilence the French proverb; "Qu en ventre jlit, enfant y"a." The umbilicus alsu become, deeper, for the same reason. 
2. Afterwards the womb enlarges at a farticular rati, differing from that of other tumors. (Siee page 34.)

3. Certain changes occur in the cervix, vagina and external organs.

What changes are found in the cervix ?

It hecomes sefter and a deeper red in color. The ascent of the uterus and renaction of the vagina gives the sensation of shortening, though in reality it becomes longer. Some increase in the mucous secretion of its carity is also noticed.

\section{What changes occur in the vagina and external organs?}

The increased blood supply causes the vagina to become deep red or violet in color; the external organs are somewhat enlarged, and the perineum is doubled in its antero-posterior measurement, during pregnancy.

With what other things may the pregnant womb be confounded ?

The enlargement of the abdomen may be due to fihroid, ovarian, and other pelvic tumors; to ascites, flatulence, or even excessive deposits of fat in the alilominal walls or mesentery.

What changes are due indirectly to the development of the womb?

Lines from distention, a median brown line, the cessation of menstruation, contractions of the nterine walls, and certain changes in the breast.

Are these signs found only in pregnancy ?

Each one of them is found to accompany other conditions, but when all or many of them are present, they furnish strong presumptive proof.

\section{What are lines from distention?}

Called also linei albicantes: are small patches of shining tissue, whiter than the surrounding skin, found on the lower part of the abdomen, especially in the iliac regions, upon the flanks, thighs, and sometimes upon the hreasts. They look like small "gores" inserted in the skin, or like cicatricial tissue. Average size one inch long and one-quarter inch broad.

Are they due to distention or stretching of the skin?

being fouml on the thighs, and also in young girls with rapid development of the hips, they are probably due only to rapid growth of the shin. They rarely disappear, and are, therefore, only of value in a first pregnancy.

What is the median brown line?

A narrow, brownish discoloration of the aldominal skin, extending from symplhysis to emiform appendix, in the median line, and of little value as a sign of fregriancy. 


\section{Is menstruation always suspended by pregnancy?}

In the great majority of cases. Some women continue to menstruate for a month or for several months; a very few menstruate throughout pregnancy; a few cases are recorled in which the woman menstruated only when pregnant. As the decilua retlexa is not usually united to the vera for the first three months, there may be a menstrual hemorrhage from the womb during that time. The real reason for the cessation of menstruation is the effeet which fecundation produces upon the system.

\section{Is menstruation stopped by other things than pregnancy?}

It often ceases for a few months in newly married women, and may be stopped for one or more periods by mental emotion, acute or chronic disease, and especially by phthisis.

What is meant by contraction of the uterus during pregnancy?

The walls of the uterus are always in a state of intermittent contraction. Hence the hand of the physician placed on the abdomen of a woman may detect them (the womb becoming harder) every twenty. to thirty minutes (Braxton Hicks).

\section{What changes occur in the breasts?}

I. They may become enlarged.

2. Pain or discomfort may be felt.

3. They may contain milk, which can be pressed from the nipple.

4. The nipple and areola become darker (sometimes almost black).

5. A circular ring of dark splotches may be developed at a short distance from the areola, called the secondary areola.

6. The sebaceous follicles about the areola become enlarged, and contain sebaceous matter.

7. Iinere allicantes may appear on them.

One or more of these changes are always present in pregnancy, though any of them may occur in other conditions. Their fresence, therefore, is of less importance than their absence, in settling a diagnosis.

\section{What are the signs due to the presence of a fœtus?}

I. The sounds of the futal heart.

2. Fatal movements.

3. The utero-placental souffle.

4. The funic souffle, and

5. Ballottemeut. 
What is meant by the fœtal heart sounds?

At any time during the latter half of pregnancy the beating of the fotal heart may be heard by placing the ear (or stethoscope) over the abdomen of the mother, being distinguished from the maternal pulsations by difference of rhythm.

\section{What does the sound resemble?}

The ticking of a watch under the pillow, with a rate of II $5-160$ pulsations per minute.

\section{Where and when are they best heard?}

They are most often heard by ausculting in the left iliac region, and may be heard from the fourth month of pregnancy, doubtfully before.

\section{What are the fœtal movements?}

The foetus moves about freely, and strikes out with feet and hands against the uterine wall. If the hand of the observer is placed upon the mother's abdomen, these slight blows may be felt. If not felt at once, they may sometimes be produced by wetting the hand in cold water, and applying it suddenly to the abdomen. This causes contraction of the uterus, which inconveniences the f(etus, and causes it to make demonstrations.

\section{When can the fœtal movements be first felt ?}

Not until after the fourth month, or until the uterine and abdominal walls have come in contact.

\section{Can the fœtal movements be simulated by anything else?}

Some women have the power to contract their abdominal muscles suddenly and irregularly, so as to simulate the foetal movements. Such instances are rare. Women often deceive themselves into feeling the fietal movements when they are not pregnant.

\section{What is the utero-placental souffle?}

$\Lambda$ bruit or whirring sound, which may sometimes be heard in the abdomen. It is variously supposed to be. produced in the uterine sinuses, the placental circulation, the uterine or hypogastric arteries, and elsewhere. It is probably produced in the vicinity of the placenta, but is heard also in some fibroid tumors.

\section{What is the funic souffle?}

$A$ similar, but less intense bruit, synchronous with the f(etal heart, and supposed to be produced in the ressels of the funis. It is rarely heard.

What is ballottement?

If, when the woman is in the erect posture, a finger (introduced into the vagina) is pushed against the anterior wall of the womb, the fuetus, if pre- 
sent, will first be pushed up into the liçuor amnii, and will then drop back. If the finger is held in position, the return of the fuctus to its resting place may be felt and recognized. The maneuvre is called ballottement, and may be practiced between the third and fifth montlss, inclusive.

\section{What is quickening?}

The time at which the mother first feels the fotal movements. The escape of the uterus from the pelvis (which is a requisite for feeling the movements) is sometimes sudden, and attended by peculiar sensations and faintness.

\section{What are the semi-pathological signs of pregnancy?}

1. When the general system fails, in whole or in part, to respond to the . stimulus of fecundation, the mother's blood has a double call upon it, and is either diminished in quantity or deteriorated in quality. This leads in turn to the imperfect nutrition and impoverishment of the nerve centres and of various organs, and as a result we may have such symptoms as-

(a) Morning sickness.

(b) Protracted vomiting.

(c) Neuralgia.

(d) Neuroses and mental disturbances.

(e) Dyspepsia.

2. Ordinarily the growing womb finds a sufficient amount of room to expand in, but sometimes, owing to natural defects, corsets, etc., it exer. cises injurious pressure upon its surroundings, causing-

(a) Difficulties in micturition.

(b) Constipation ancl hemorrhoids. -

(c) Albuminuria and odema.

(d) Dyspncea.

3. From excess of natural functions we may have (a) plethora, (b) salivation, (c) hirsuties, $(d)$ chloasma.

\section{What is morning sickness?}

Nausea and vomiting, just after rising in the morning. It is usually limited to the carly months of pregnancy, or when the volume of bool is not yet increased, although there is not enough for mother and chilk. It is, therefore, die to the want of sufficient bloorl, and the consecpent cerebral ancemia due to the sudden change in the circulation ujon awakening from slcep and resuming the upright position.

A similar form of vomiting is sometimes met with at other times of the day, after special exertion, and especially mental effort. 


\section{How should morning sickness be treated?}

It may be relieved by slowness in arising, and by taking a cup of coffee before rising, and may be cured by the use of nutrients and blood-making agents.

\section{What is the "vomiting of pregnancy ?"}

Continuous or protracted romiting in pregnancy depends-

I. On the deficiency and deterioration of the blood.

2. The irritable condition of the nerve centres, due to their impoverisls. ment from defective blood supply.

3. To an exciting cause, such as disease of the uterus, acting with the other sources.

It may be so grave as to apparently threaten life, and this being well known, the quack calls every fit of nausea by this name, and cures it!

\section{What are the indications for treatment in severe vomiting?}

I. To remove any sources of irritation which may coexist with the general state of the blood. Thus, inflammation and abrasions of the cervix uteri may exist in some cases, and their removal by proper applications may cure it.

2. To control the irritability of the nerve centres, which may be done by rectal encmas of cliloral and bromide of potassium.

3. To improve the llood supply, by administering nourishing fluids in small doses, frequently repeated, beginning with milk and lime water.

In mild cases any of the anti-emetics may be used, of which the best is the oxalate of cerium, with or without the subnitrate of bismuth.

\section{What forms of neuralgia are met with in pregnancy?}

Almost any form. The most common is odontalgia. Toothache is due (1) to the "cry of the nerve for healthy blood," and (2) to the fact that phosphate of lime is largely needed in the construction of the fictus, and when not sufficiently present in the food, may be absorbed from the teeth.

\section{What mental disturbances are met with in pregnancy?}

The woman may become irritable, peevish and capricious. She may have alsurd cravings for strange food (pica), or may even develop mania.

\section{How is difficulty in urination caused?}

I uring the first months the descent and anteversion of the uterus may callse pressure on the bladler. After the womb has ascended above the pelvis, there is rarely any lifficulty until its descent, during the last weel, when pressure is arain canted. 


\section{How are constipation and hemorrhoids caused?}

Constipation may be due to the deteriorated (hydremic) state of the blood, but is also due to direct pressure of the uterus upon the bowel, impairing its tonicity, or even acting mechanically. Hemorrhoids are caused in the same way.

What displacements of the womb may occur during pregnancy?

1. Early in the pregnaucy the increased weight of the womb may increase the natural tendency of the womb to fall forward (antatersion), causing some disagreeable pressure on the bladder. This will be relieved by rest in the recumbent posture, and will soon cease.

2. When the womb is about to ascend from the pelvis, a full bladler or unusual action of the abdominal muscles may push the funtus utir back and under the promontory, so as to incarcerate the womb in this position (retrozersion). This causes great pain and retention of urine. The woman is to be placed in Sims' position, or on her hands and knees, and the womb pushed up and a little to one side, so as to clear the promontory.

3. Prolipse of the womb sometimes occurs, but generally gives no troulle after the womb is large enough to rest above the inlet.

How are albuminuria and œdema caused?

Alluminuria may be due to the state of the blood, or to the pressure upon the kidneys or renal veins.

Iright's disease may coexist, or origginate with the pregnancy. Generally the disorder is transient and terminates with delivery:

(Edema, usually linited to the lower extremities and vulva, may be Consequent upon renal diseasc, or duc to pressure upon the alsluminal and pelvic venous trunks.

\section{How is dyspncea caused?}

liy pressure upon the diaphragm. It therefore appears late in presnancy, and is usually relieved dluring the last weeks by the descent of the uterus.

What is meant by plethora in pregnancy?

The natural increase in the bloori-making function is occanionally excessive, and too much blood is furnished, leading to attacks of vertion and other symptoms of that condition.

What are salivation, chloasma, hirsuties?

(a) Salivation is an increased flow of saliva, usually foumd only in the latter half of pregnancy, and often accompanicel by ulecrutions in the mouth. 
(b) Chloasma is an excessive deposit of pigment in the skin. Though usually contined to the mammary areolix and the brown line, it may occur un the face, the entire abdomen and flexures of the joints, suggesting Addison's clisease.

(c) Hinsuties is an excessive or abnormal growth of hair, usually on the face, and fortunately rare.

\section{Which of the signs of pregnancy are certain signs?}

Those due to the presence of the fortus, and of these but one is generally available, viz: the sound of the foctal heart. No other sign is more than suggestive or presumptive.

\section{Which of the presumptive signs are the most important?}

The cessation of menstruation; the regular and symmetrical development of the uterus; the changes in the breasts.

\section{At what date are the important signs available?}

I. The fretal heart, rarely before the fourth month.

2. Ballottement, third to fifth month, but its failure may be due to want of skill and other causes, besides the absence of pregnancy.

3. The cessation of menstruation, usually after the time for the tirst period, or immecliate. It is always a suspicious circumstance in healhy women, previously regular, whether married or not.

4. The increased size of the uterus may almost always be made out by bimanual touch, at from four to six weeks. If at a second examination, a month later, a further symmetrical enlargement, at the usual rate, is inoted, the fact of pregnancy is scarcely to tie doubted.

5. The changes in the breasts may begin in the second month, but are rarcly marked until the middle of pregnancy, which is true of most of the presumptive signs.

\section{What is the duration of pregnancy?}

It is somewhat variable, but it is sufticiently accurate to regard it as continuing through ten menstrual periods, ten lunar months, or 2 So days.

\section{What are the limits of variation?}

From 2.45 to 300 days, with possililities in either direction.

What method is usually employed to calculate the duration?

(inut nine cilendar months forward (or three backward) from the date of the lase menstruation; adh to this seven days. Fx. End of menstruation, Jan. 1ot! ; 3 months lack $=$ ()t. rot! ; add 7 days $=$ Oct. 17 th, as the frolutic date of confinement. 
What causes pregnancy to come to an end?

The important theories are-

1. Power's. The uterus is a peristaltic tube, witl circular fibres in the cervix acting as a splincter. As the chilel grows it presses upon this sphincter, and the sum of all successive irritations finally causes it to relax, and the uterus to expel the child.

2. King's. The uterus has a definite limit of growth. The fretus does not attain its limit of growth in utro, and therefore distends the uterus when the latter stops growing. This irritates the uterine filore, and causes it to contract and expel its contents.

3. The foreign body theory. The womb is always irritated into contracting upon a foreign body, and the foetus beeomes such a boly at the end of pregnancy. There is probably truth in each view of the matter.

Why is the ovum not a foreign body during pregnancy?

Because of the intinate vascular connections between the chorion and the uterine mucous membrane.

How does the ovum become a foreign body?

By the fatty degeneration and atrophy of the connections between the ovum and uterus, which occurs during the last weeks of pregnancy.

What effect has this upon the uterus?

It causes a gradually increasing irritation of the muscular fibres, until contractions are excited sufficiently powerful to expel the chill.

\section{What is labor?}

\section{LABOR.}

The process by which the child and its ovular attachments are expelled from the womb.

\section{What essential steps occur in labor?}

1. The enlargement of the os uteri until it is large enough to permit the passage of the child.

2. The expulsion of the child.

3. The expulsion of the placenta and nembranes, also called the alterbirth, or secundines.

Into how many stages is labor divided?

Into three. I. The stage of dilatation (of the os uteri).

II. The stage of expulsion of the chilil.

I1J. The stage of expulsion of the after bitth. 


\section{By what force are these occurrences produced?}

liy the contractions of the uterus, aided by the abelominal muscles.

\section{What are the contractions of the uterus called?}

Iabor-pains, because usually accompanical by painful sensations in the back or hypogantrium.

\section{How long does a contraction last?}

Each contraction lasts for from a few seconds to two minutes. Their duration increases with the progress of the labor, becoming longer and stronger as it allvances. The average duration is a little less than one minute.

\section{How long is the interval between them?}

At the beginning of labor they are from a half hour to ten minutes apart. The interval diminishes as labor advances, and towards the end may be from five minutes to only one minute apart.

\section{What effect have the contractions upon other muscles?}

When powerful, or when the second stage is half finished, they are accompanied by contractions of the abdominal muscles, which are almost entirely involuntary, and the woman strains or "bears down." The mu-cles of the extremities also become rigid during the expulsive effort.

\section{How much pain accompanies a uterine contraction?}

In an entirely normal labor in a healthy woman, the pain is sliglit ; in any case, during a bearing down effort, the consequent cercbral fullness causes some plyysiological anesthesia. But in perhaps the majority of labors there is some alnormal condition present which makes the contractious inconveniently painful.

\section{How is the dilatation of the os effected?}

I. The simultaneous contraction of all the uterine muscular fibres tends to pull apart the erlges of the os, since there alone the fibres are absent.

2. The uterus is longer than broad, and its longitudinal fil,res more numerous than the others; therefore, during a contraction it tends to become broader than long, which forees the contents of the uterus asrainst the os.

3. The circular fibres about the os undergo a spontaneous dilatation, and this appears to be increased by the free secretion of nucus from the cervical glands. 
What effect upon the contents of the uterus may be noticed during a contraction?

The force tends to move all the contents (child and li pur amnii) towards the os uteri; but fluids being more movable than solids, the li juor amnii is forced toward the os, while the child is driven away or recerles from it.

\section{What is the bag of waters and how formed?}

The gradual distention of the membranes by the liquor amnii, which is forced in advance of the child, forms a bag filled with fluid, in the us uteri. This becomes tense during a pain, and relaxed during the intervals, and by its even pressure greatly aids in the dilating process.

Is the bag of waters always formed in labor, and what variations occur?

I. Sometimes the amount of liquor amuii is so small that no bag forms.

2. The membranes may rupture prematurely, and thus prevent it.

3. The membranes may be so greatly distended that the barr of waters reaches to the rulva. Lsually it contains only a few ounces of fluid.

Of what service is the bag of waters after the os is fully dilated? Of none; and the progress of the labor is suspenterl until the contractions are powerful enough to rupture the membranes and permit the escape of the liquor amnii.

\section{What practical deduction follows from this?}

That the physician should rupture the membranes as soon as the os is fully dilated.

\section{How is the expulsion of the child effected ?}

By the contractions of the uterus, and according to a definite mechan. ism, depending upon the manner in which the child is placed. (See page $5^{8}$ et sic.)

\section{How is the after-birth expelled?}

Theoretically, the placenta becomes folled longitudinally, ground off the uterine walls by contractions, and then expelled. Practically this occurrence is so uncertain that it is found hest to leliver the placenta artificially.

What is the best method of delivering the placenta?

The method of Credé, so called, after its chief promulgator.

1. I'lace the hand upon the lower part of the ablomen and rub, strolie or knead the uterus. This will cause the womb to contrace energetically, and in so doing, to ascend and move forwart. Then- 
2. Grasp the uterus through the abdominal walls, with one or both hands, and sques $z$ the placenta from it. If successful, the escape of the placenta may be recognized, and the latter will be found at the vulva, or even shot out into the berl. If not, wait a few minutes, and repeat both mancuvres. If the placenta is dislodged as far as the vulva, remove it, taking care to twist the membranes into a rope, by rotating the placenta, in order to avoid leaving any strips behind. Seiver pull upen the funis.

\section{What other advantages has this method?}

It secures complete contraction of the uterus, and empties the uterine sinuses; preventing hemorrhage, inversion of the womb, uterine thrombosis, and almost all other complications.

\section{What is the normal duration of labor?}

It is variable. Collins, in over 16,000 cases, found that 84 per cent. completed labor within six hours, or less. It is probable that in strictly normal cases, three or four hours shonld suffice for the stage of dilatation, one hour for the second stage in first labors, and ten to thirty minutes in sulserquent labors. The third stage, being artificial, is terminated at the will of the physician, and should rarely be delayed longer than ten or fifteen minutes.

Define the terms primipara, multipara, etc.

A woman in her first pregnancy and labor is called a primifara; in sub. sequent labors a multifara, or if greater accuracy is required, the number may be given, thus: 2 para, 3 para, etc.; one who has had one child, and is not now pregnant, is called a unifara; a woman who is not a virgin, but has never had a child, is called a nullipara. Adjectives are formed from these words, as, a primiparous woman, etc.

\section{Why is labor longer in primiparæ than in multiparæ?}

There is no difference in the first stage, but in the second stage the vagina and external parts of the primipara dilate more slowly, and thus occupy a longer time.

What foundation is there for the statement that a woman who conceives late in life will have a difficult labor?

An oll primipara is apt to have, first, some inflammatory trouble of the cervix, leading to difficulty and delay in the first stage, and second, to have an unyicleling sacro-coccygeal joint, delaying the second stage. (therwise there is nothing to cause a difficult labor in these cases. 
What are the ordinary duties of the physician in a case of labor?

I. To examine the woman and ascertain the exact state of affairs.

2. To watch the progress of the case.

3. During the first stage, to encourage the woman, see that the bed is properly prepared, that due provision is made for the infant when born, and to keep others from mecldlingr.

\section{How should an examination be made ?}

Place the patient on her back, with the knees drawn up. Anoint the index and middle fingers with fresh lard, vaseline or other unguent, and introduce into the vagina, passing the hand under the thigh until the vulva is reached. Introduce the index finger alone at first; if necessary, the middle finger may be added, which will give an additional reach of about one inch.

\section{What should be learned from the first examination?}

I. If the woman is pregnant ;

2. If she is in labor;

3. The condition of the os uteri, as to dilatation and dilatability;

4. The state of the membranes, and existence or not, of a bay of waters;

5. The presentation and position of the child;

6. The condition of the soft parts generally, as to temperature, moisture and dilatability ;

7. The size of the pelvis.

The most important thing is the condition of the os.

How frequently should examinations be made?

Often enough to keep informed as to the progress of the case. As this will vary greatly in different cases, no rule can be made. Usually, it is proper to examine every hour or half hour luring the first stage. Meantime the physician need not be in the room, unless to encourage the patient; but may be in an adjoining room, or even absent himself from the house. When the second stage begins, his place is by the bedside. If progress is slow, examinations may be made, as in the first stage; if rapid, the finger placed on the perineum during a pain will warn lim as to the approach of the end.

How may it be known that labor has begun?

(1) By the disappearance of the cervix, (2) the dilatation of the os to some extent, (3) the presence of regular uterine contractions, $(t)$ a dis. charge of mucus tinged with hlood, which is called a "slow." "The first may fail in premature labors. 


\section{How should the bed be prepared?}

An oiled cloth, rubber blanket or thick comfort should be placed upon the mattress, to keep it from being soiled by the discharges. A sheet folled several times should be placed upon this, under the woman's hips, which may be withdrawn when soiled, and replaced by another.

When should the woman be placed in bed?

There is no special need until the os is nearly dilated, unless the labor is tedious, when her strength will be conserved by lying down and keeping quiet.

How should she be dressed?

The chemise should be tucked up, well above the hips, to prevent soiling, and therefore the need of changing it after delivery. A night robe may be worn over this, and she should be covered with bed clothes adapted to the temperature of the room.

\section{What preparations should be made for the infant?}

Its cluthing should be made ready and aired. Several ligatures for the funis shoull be provided and a pair of scissors. Both hot and cold water should be in readiness.

\section{What hygienic measures are to be cartied out?}

I. To see that the bowels are moved by an enema, if there has not been a recent passage.

2. To reguire the woman to urinate occasionally.

3. If thirsty, give her water to drink.

4. See that the room is properly ventilated.

5. If there is any deviation from the normal course of labor, ascertain and remove it by appropriate treatment.

\section{What things are to be prevented?}

Crowling the room by unnecessary conpany. Medllesome practices of old women, such as giving "teas," and in general angthing which will disturb the woman, mentally or physically.

What objections exist to giving anæsthetics to make the labor painless?

1. The pain is not great, unless some abnormal condition is present, which should he sought for and treated.

2. Natural labor lasts but a short time.

3. Anasthetics protract the labor.

4. They increase the risk of hemorrhage (post partum). 
5. From the same cause (imperfect contraction of the womb) they increase the liability to all the puerperal discases.

6. They endanger the child's life (especially chtoroform).

\section{What disturbances often attend the end of the first stage?}

I. The woman is very apt to vomit, which relaxes and prejares the soft parts and increases the uterine contractions.

2. A rigror sometimes occurs, temporarily suspending labor, but with hot applications to the feet and a lot drink it usually speedily cuases.

\section{What duties are required during the second stage?}

I. To rupture the membrane, if this does not occur spontaneously.

2. To observe the descent of the child, and to be ready to remedy any departure from the normal course.

3. To prevent laceration of the perineum.

4. To complete the delivery of the child.

\section{How are the membranes to be ruptured?}

by pressing the finger against them while they are male tense by a contraction. If they are too thick and strong to yield to this, the mail of the midlle finger may be prepared as follows: First, make a straight cut in the free border of the nail and in the middle line of the finger. Second, pare away the free border on one side of the cut, which will leave a sharp, linife-like colge.

If the bag of waters is large, it is well to place a cloth in front of the vulva before rupturing, in order to soak up the liquor amnii when discharged.

\section{What occurrences often attend the end of the second stage?}

1. The woman wants to sit on the chamber, even when the bowel is cmpty; due to the pressure of the child's head on the bowel. Of course, she is not to be allowed to sit up at this time.

2. Cramps in the legr often occur from pressure of the descending head arainst the sciatic nerve. Rubbing the leg affords relief.

\section{How is the perineum to be guarded?}

By bringing out the head in the absence of a pain, if possible. When the head greatly distends the perineum, and a part of the occiput protrudes, pass two fingrers into the rectum, and place then on the brow, malar bones or chin of the chill, as may be convenient. l'lace the thumb on the occiput. The head may then be controlled and prevented from passing through the vutra during a pain. If, when a pain has subsibed, the head be now pushed over the perineum, laceration will be prevented. It is also necessary that the woman shall not bear down at this time. 


\section{What is episiotomy?}

An operation desirned to save the perineum, by making small incisions into its margin, on either sile of the median line.

What is to be done when the head is born?

1. Ascertian if the funis is around the child's neck, and if so, unwind it.

2. If no uterine contraction appears to be forthcoming, pass a finger into the vargina, below the child's neck, and hooking it into an axilla, withdraw the child, taking care that the shoulders do not lacerate the perineum.

\section{What is the first attention to be rendered to the child?}

1. Pass a finger into its mouth to remove any mucus which may be there.

2. If it does not at once cry, give it a slight spank on the buttocks, or use other means of resuscitation, until it gives a good cry.

3. When it has cried well, tic the cord.

\section{How is the cord to be tied?}

A ligature of several strands of sewing threarl or other material should be tied two or three finger-breadths from the child's navel. A second ligature should be applied several inches from this, ant the cord cut between the ligatures with scissors. If there is much Wharton's gelatine in the cord it is well to hold it firmly at the navel, and endcavor with the finger and thumb, to squeeze out the gelatine or "strip" the cord. After cutting the cord see that the ligature is firm, and that no bloor is escaping, and hand the child to the nurse.

\section{How is the cord to be dressed?}

The physician is usually expected to dress the stump of cord attached to the child. Take a piece of linen or muslin (old and soft) about four inches syuare; cut a hole in the middle large enough for the cord to pass through; slip it over the stump and fold it so as to thoroughly cover it.

\section{How may a child be resuscitated when apparently still-born?}

If it cloes not at once respond to spanking or dashing water upon its chest, resort at once-

I. To Sylvester's method of artificial respiration, or,

2. To mouth to mouth insuflation. Wije the bahy's face, compress the nostrils with the fingers of one hand and press the other hand upon its epigantrium. Then apply your mouth to the child's, and blow ints it. The pressure of the sccon! hand prevents the air from entering the intestines.

3. A galranic battery may be used.

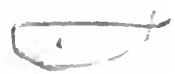




\section{What attentions are to be rendered to the woman?}

1. The plicenta is to be delivered after the manner of Crede (ridt' l) 5 I).

2. The soiled clothing is to he removed and a napkin placerl at the vulva to receive the dischareses.

3. A lroad handige or "binder" should be applied aroumb the almbmen.

4. The uterus shoukl occasionally be felt through the abdominal walls, to be sure it remains contracted.

\section{What is the position of the womb after delivery?}

Just after the delivery of the placenta the womb shoulsl be in the hypo. gastrium, its fundus reaching half way to the umbilicus, and reeling as bart as a stone. In a short time (generally within the hour), the aluluminal muscles regain their tonicity, and the "retentive power of the abdomen" draws the womb upwarl, its fumlus reaching nearly or quite to the umbilicus.

\section{Why does a rigor often occur just after labor?}

I. The bedding and clothes are ajt to be wet with the discharges.

2. The withrlrawal of the child takes away a source of bolily heat, its temperature being nearly a degree higher than that of the mother.

\section{When may the physician leave, and when should he return?}

lle may leave within half an hour, if the woman has heen cared for as above, and is in good case. Ile shoull return within from twelve to twenty-four hours; and in general those who watch their patients lent will have the least trouble.

\section{What are after-pains?}

The pain sometimes experiencel after labor, due to the contractions of the uterus. They are rarely felt ly primipare, and usually increase in severity with each sulsequent lakmr. They may aceur only a few times, or ma keep up for screral days. If severe enongly to need treatutut, opium and camphor, in poweler, or as in paregoric, will be the prefuer remerly.

\section{What is the caput succedaneum?}

An rerlematous swelling formed on the part of the presentation in

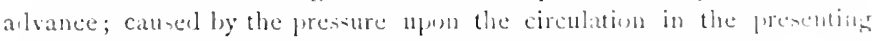
circumference, by the grip of the cervis, vayina, or pelvic wall, It forme only when the head is arrested at any point for sine time.

\section{How long does it remain?}

Fin several lays after lirth, if not interfererl with. 


\section{THE MECHANISM OF LABOR.}

\section{What is meant by the mechanism of labor?}

The purely mechamcal movements involvet in the passage of the chilu] through the pelvis, in distinction to the vital and clinical conditions connectel] with the process.

With what is the mechanism of labor concerned?

With three things. 1. The borly to be projelled.

2. The tube throush which it is propelled, and

3. The propelling force.

What is the propelling or motive force in labor?

1. The contractions of the uterus, principally. aided by

2. The contractions of the abdominal muscles.

3. The clantic resintance of the perineum.

When is the first or uterine force exerted?

Thronghom the entire labor, and is the main and necessary force.

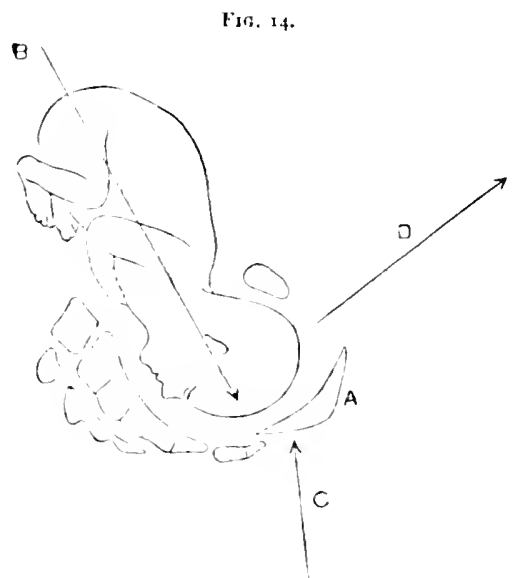

A. Perineum: $B$. The directin of the uterine f.....: 6 : the direction of the perineal force: $D$. the re-ultunt of the two forces, in which the heal mises.

After the child has reached the outlet, it can so no further without pasting thromb or over the perinenm. The uterine force is mable to
When is the second or abdominal force exerted? It may be voluntarily exercised at any time, but usually is reflexly excited when the hearl is low in the pelvis, hecoming almost in. voluntary.

What effect has the abdominal force?

1. It aids the uterine force drectly, by purhing the child onward, amd

2. Indirectly, hy holding the womb down and preventing it from leing polsherl upward by the pelvic resistance to the passage of the child.

When and how is the perineal force exerted? 
propel it in any direction except arainst or through the perineme. A new force is therefore provisted in the clastic resistance of the perinemm. which tends to push the head back in neurin the opposite direction (a litte forward as well). Therefore the heal moves in the resultant of the wo forees, and oe'e the perineum.

What form does the child assume when packed in the womb?

It is substantially an ovoil, or egg-shaped figure, the extremities leing flexed and pressed against the trunk.

What relations may it assume to the pelvic inlet?

Fither end (the head or lreech), may be opposite the inlet, or it may lie transversely across it.

What is the presentation of the child?

That part of the child in advance, or, more accurately, that part of the chilil included within the circumference of the inlet at the beginning of linor.

\section{How many presentations are there?}

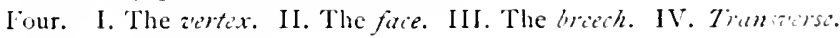

\section{Which is the most common?}

The rertex presents in over 90 per cent. of all labors.

\section{What distinguishing marks exist upon the head?}

I. Sntures. II. Fontanclles. III. Protulerances.

I. The sagittal suture and its continuation, the bi-fiontal, extends antero-posteriorly between the parietal and fromtal bones.

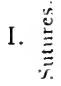

2. The lambdoidal suture extends from the posterior linit of the sagittal suture, letween the occipital and parietal buncs, making a V-shaped line.

3. The coromal suture extends letween the parietal and front.ul bones, crossing the sayittal at right angles.

1. The fosterior fontanille, a small, tri.mgular enlarisement of the sutural membrane at the junction of the saytlat and lambedoidal sutures.

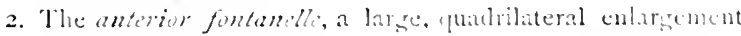
of the sutural membrane, at the junction of the sagthal want coronal sutures.

3. The pesterolatiral fontanelles, one on each sile, at the inferior limits of the lambiloidal suture. 
1. The farictal frotuberances, called also eminences or bosses, situated in the centre of each parietal bone.

2. The fromal protuberances, situated in the centre of the fronta\} bones.

3. The occipital protuberance, situated in the centre of the occipital bone.

\section{What is the object of the sutures and fontanelles?}

They admit of the molility and overlapping of the bones, so as to liminisl the size of the head in labor. Incidentally they furnish us with important "landmarks." The overlapping edge of bone is usually felt, rather than the suture itself.

\section{What are the diameters and planes of the fotal head?}

The diameters are lines drawn from one point to another; the planes are imaginary levels drawn transversely through different points of the hearl; each for the purpose of facilitating the description of the relation of the head to the pelvis in labor.

\section{Name the diameters and planes.}

I. The occifito-fiontal diameter, drawn from the mildle of the bi[rontal suture to the occipital protuberance, and measures a little over 4 inches, or $4+$ in.

2. The cerrico-frontal dianeter, drawn from the apex of the forehead to the occipital ridge or nape of the neck, and measures a little less than 4 inches, or 4 - in.

3. The covico-brematic diameter, drawn from the posterior borler of the anterior fontanelle to the mape of the neck, and measures $3 \% 2$ inclies.

4. The li-parietal or transverse diameter, drawn from one parietal protuberance to the other, and measures $3 \mathrm{t} / 2$ inches.

5. The ocifito-mental diameter, drawn from the occipital protuberance to the point of the chin, and measures $5 \frac{1}{2}$ inches.

1. The occifitofrontal plane, drawn transversely through the occipito-frontal diameter for through the occipito and frontal protuberances); when the liead is neither flexed nor extended (the borly being erect), this plane is exactly horizontal (corresponds to the plane of the horizon).

2. The cervico-frontal plane, drawn transversely through the cervico-frontal dimeter. When the head is half flext, this plane is horizontal, and therefore may be called the plane of remi-flexion. 
3. The cervico-bregmatic plane, drawn transversely through the cervico-bregmatic diameter. When the lead is complitely' flexel, this plane is horizontal, and therefore may be called the plane of complete flexion.

What outline is intercepted by these planes?

In the occipito-fromtal an elliptical outline; long diameter $4+\mathrm{in}$. Transwerse diameter $3 \frac{1}{2}$ inches.

In the cervico-frontal an elliptical outline; long diameter $4-\mathrm{in}$. Transverse diameter $3 \frac{1}{2}$ inches.

In the cervico-bregmatic, a circular outline; long diameter $3 \frac{1}{2}$ inches. Transterse diameter $3 \frac{1}{2}$ inches.

What important deduction may be drawn from these facts?

The more the head is fixed the smaller is the outline presented.

In how many ways may the vertex enter the pelvis?

The elliptical outline of the heal may enter with the occifut in from and to the left or right, and behind and to the right or left. There anc, therefore, four positions of the vertex, named as follows :-

I. Left Occipito-Anterior.

2. Kight Occipito-Anterior.

3. Right Occipito-Iosterior.

4. Left Occipito-Posterior.

How many positions are there of the Face presentation?

Since the face has also an elliptical outline, with the mutum or chin at one end, we have the same arrangement as in the vertex, or-

c. Left Mento-Anterior.

7. Right Mento-Anterior.

3. Right Mento-Posterior.

Left Mcnto-Posterior.

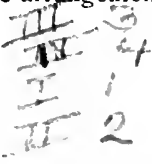

How many positions are there of the Breech presentation?

Since the breech has also an elliptical outline, with the sucum in a direct line with the occiput, we have the same arrangement as in the vertex, or-

I. Left Sacro-Anterior.

2. Right Sacro-Anterior.

3. Right Sacro-P'osterior.

4. Left Sacro-Posterior.

How many positions are there of the Transverse presentation? For the sake of uniformity we may assume an elliptical outline for the

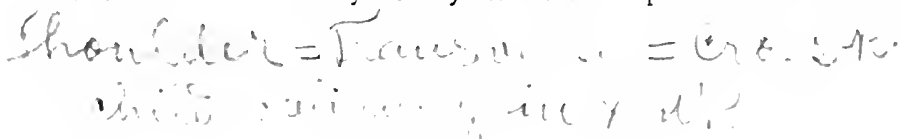


shouller, with the dorsum, or back of the shudler, as the name-point. This gives us the same arrangement as in the other presentations, or

1. Leff forso-Anterior.

2. Right Dorso.interior.

3. Night 1),rso-Posterior.

+. I.eft Dorso-Posteriur.

How may the positions be more briefly designated ?

by initials, as 1. U. A. for left occipito-anterior, R.S. P., for right sacropostcrior, and so on.

How may these sixteen positions be represented in a single scheme?

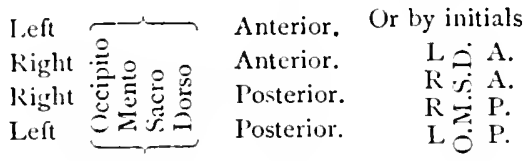

How is the head situated at the beginning of labor in the $L$. $O$. A. position?*

The occiput points to the left ileo-pectineal eminence; the bi-frontal suture is olposite the right sacro-iliac symphysis, and the sagittal suture lies in the riglit oblique diameter.

What is the mechanism of delivery in the L. O. A. position?

1. Hixim occurs, whereby the cervico-frontal, or even the cervico-Jregmatic diameter is sulstituted for the oceipito-frontal, thus reducing the ontine presenting in the pelvis.

2. The hearl discents in the pelvis, and at the same time a letelins movement occurs by which the forebead descends more rapidly than the occiput, and becomes level with it.

3. While the head descends it also rotates, so that the sagittal suture is finally brought into the median line by the time the head reaches the jelvic outlet.

4. When the heal reaches the outlet the occipnt or nape of the neck remains fixed under the sub-pubic arch, while the forehead and face sweep wer the perineum by a movement of extcrsion.

5. Ifter the heal is born it undergoes a movement of external rotation, or restitu'ion, lecause the shoulders descend in the left oblique diameter, so that the oceiput is again turned toward the left side.

"The mechanin here given is mainly from Cazeaux and Playfair; the author's views my tre funt in the Apremlix. The student is earnestly advised to study the mechanin with the fortal skull and the pelvis before him. 
What variations occur in the mechanism of the L. O. A. position?

If there is not a close fit between the head and pelvis there may be less flexion and rotation, but no substantial difference in the mechanism occurs. The shouklers may vary greatly, due usually to the length of the neck and the time when they are compelled to follow the hearl. Thus, they may enter the pelvis directly transiersely and rotate indifferently into either canal, and at any level, which will also control the movement of restitution.

What is the mechanism of delivery in the R. O. A. position?

The same as in the first, or L. O. A position, except that the sagittal suture is in the left oblique diameter, and the occiput directed toward the right pectineal eminence; and in general the same description will apply throughout, substituting right for left, and vice versa.

\section{How often does this position occur?}

Very seldom, owing to the infrequency of left lateral obliquity of the womb, and the presence of the rectum on the left side of the pelvis.

\section{How is the head situated in the R. O. P. position?}

The occiput is opposite the right sacro-iliac symphysis, the forehead opposite the left obturator foramen, and the sagittal suture lies in the right oblique diameter.

\section{What is the mechanism of delivery in R. O. P. position?}

There are four different processes by which it may be terminated,

1. Anterior rotation at the inlet.

2. Anterior rotation at the outlet, or during descent.

3. Anterior rotation on the perineum, and,

4. Posterior rotation throughout.

\section{What is meant by anterior rotation?}

The rotation of the heall so as to bring the occiput in front, thereby converting the position into a R. O. A.

\section{How does anterior rotation occur?}

I. From the fact that the foramen magnum is nearer the occipital end of the head, the shoulders are thrown further back in this position, and therefore the right shoulder impinges upon the vertebral column or promontory. If it should be pushed off on the right side the child's back will be brought in front. This twists the neck, and the untwisting force of its clastic structure tends to rotate the head with the occiput in front. This occurs most easily at the inlet, next at the outlet or churing descent, and rarely, even when the heal has reached the perineum. 
2. The resintance of the pusterior pelvic wall w the occiput is greater than that of the anterior wall upon the forehead, owing to the narrowing of the pelvis under the sacro-iliac arch, which also aicls in anterior rotation, and accorling to some, is the only catuse.

\section{What must occur before anterior rotation?}

firion, continued until the circular cervico-fregmatic outline is reacheel.

\section{Under what circumstances does posterior rotation occur?}

If the child's hack is turned toward the mother's lack, and remains so, the heal cannot rotate anteriorly, and is delivered with the forchead under the sul, - julic arch.

\section{What difficulties are encountered in posterior rotation?}

1. The labor is more prolonsed, hecause the uterine force is transmitted throngh the pusterior and narrow portion of the pelvis.

2. The perineum is endangered, because the head cannot be fully flexed while passing over it.

\section{How may we recognize the R. O. P. position?}

1. It the hegriming of labor the anterior fontandle (usually large) will be found very accessible in front, and to the left.

2. A. llovin occurs the fontanelle will move upward and become less accesilule, which is directly the reverse of the course followed by the proterior fontanclle in the 1.. (). A.

\section{How should the R. O. P. position be managed?}

Is sonn as cliscovered a reasonalole effort should be made to rotate the shenliles with the lack in front, by external manipulation. This may be aibled ly two fingers placel mon the vertex, and similarly employed in enleavorin: to rotate the heal. If these efforts fail, we may leave the calie to the uterine efforts, until it is evilent that natural delivery will take too loner, when we should employ the forceps.

\section{What is to be avoided?}

Attempts to rotate the heal without reference to the position of the shoulers. It enlungers the child's life, from over-twisting of the neck, aul is rarely successul.

What is the mechanism of delivery in the L. O. P. position?

The same as in the thirl or k. (). P., except that anterior rotation converte it into an 1. (). 1., ant in general left is to be substituted for right, and vice versa, thoughout the description. 


\section{What are the causes of the Face presentation?}

I. From a mistirection of the uterine axis (due to pendulous abdomen and the like) the contractions may propel the head, originally presenting the vertex in such manner that its uccipnt is arrested at the brim, while the facial end, being free, descends. Thus an L. O. A. may be converted into an R. M. P., and an R. O. P. into an L. M. A.

2. External violence or jarring may listurb and change the presentation.

3. The child may, by reflex movements, extend its head.

What plane and diameters are described in the Face presenta. tion?

A plane drawn through the anterior limit of the anterior fontanelle, the malar bones and the junction of the chin and neck, is called the trachelobrematic plane.

It is of elliptical outline, and nearly parallel to the cervico-bregmatic plane, but smaller. Its long dianeter is ealled the trachelo-bregnatic; its transverse diameter, drawn from one malar bone to the opposite, the bi.malar.

\section{How is the head situated in the L. M. A. position?}

The chin is opposite a point in front of the left acetabulum; the anterior fontanelle is opposite the right sacro-iliac symphysis. The features of the face (eyes, nose, mouth, ete.) may be felt between these points.

\section{What is the mechanism of delivery in the L. M. A. position?}

The head descends with its trachelo-bregmatic diameter presenting in the right oblique diameter, and without difficuity, until the cervicol,regmatic plane has entered the pelvis. By this time the diameter of the neck or upper part of the ehest is added to the cervico-bregmatic diameter, and this constitutes too large a bulk to pass. Delay therefore oceurs.

\section{How is this difficulty overcome?}

As soon as the head can reach far enough to be acted on by the perineum, the perineal foree (see page 58 ) will cause the head to be flexerl, and allow it to sweep easily over the perineum. Therefore, if the head is small, or the neck long, there may be no delay in flexion and delivery. Otherwise the head must remain stationary until it is moleled and wiredrawn, so as to enable it to reach to the perineum.

\section{What effect has this delay, etc., upon the child?}

I. It is endangered by the pressure upon its cervical structure.

2. The caput succedaneum forms easily upon the face, and the prarts inay ve perilously swollen and infiltrated. 
What treatment is demanded, and why?

Since the telisery can te reatily accomplished by securing flexion after the face has reached the inferior strait, we should assist the mechanism--

1. Liy attempting to llex the heart with the fingers, and

2. With the forceps, if the fingers fail, or traction is necessary to bring the heal low enough to be flexed.

\section{What is the mechanism of the R. M. A. position?}

The face enters the pelvis with the chin in front and to the right, and in general the same description will apply, substituting riglst for left and vice versa, throughout.

\section{What is the mechanism of the R. M. P. position?}

I. The trachelu-bregmatic plane enters the pelvis with the chin opposite the right sacro-iliac symphysis. The forehearl remains stationary at the front part of the l,rim, while the base of the skull and upper part of the chel attempt to atvance unter the sacro-iliac arch, which is impracticalle.

2. The shoulters will thus be mate to impinge upon the vertelral column, and will have a tentency to be pushed to the right of the promontory, with the back in front. This will twist the neck, and tend to rotate the hearl into an R. Y. A. position, when the labor is teminated as in that l"sition.

The key to the mechanism, therefore, is anterior retation at or near? the inlet. If this fails to occur, the hat and chest leceme tightly werlged, and unless the head is very small, or the pelvis large, delivery is impossille.

\section{What is the mechanism of the L. M. P. position?}

- The face enters the pelvis with the chin behind and to the left, and in greneral the same description will apply, substituting left for right and vice versa, throughout.

\section{What is the Brow presentation?}

$A$ varicty of the lace presentation, the upper part of the face presenting. It is either comverted into a full face or into a vertex presentation, or camot be delivered naturally unless the head is very small.

What plane and diameter are described in the Breech presentation?

A flane drawn transwersely through the ilia and sacrum, called the liviliac, from its long liameter, drawn between the crests of the ilia. It is of elligtical ontline and almost ilentical with that of the shoulders. 
How is the breech situated in the L. S. A. position?

The sacrum is in front of the left acetabulum; the right ilium unter the left sacro-iliac symplyysis; the left ilium in front of the right acetabulum, and the pubes in the free space in front of the right sacro iliac symphysis.

What is the mechanism of the L. S. A. position?

The bis-iliac diameter enters the pelvis in the left oblique diameter, rotating during descent, so that when it arrives at the vulva, the left ilium is directly in front and the sacrum directly toward the left side. Since the breech is quite compressible, advantage is taken of this to enable it to pass out of the vulva with less distention of the perineum, by one of the hips passing in advance of the other. The breech being born, the body and legs emerge, next the shoulders, following the same mechanism, and finally, the head, which enters in the right oblique diameter, and passes down strongly flexed.

What is the mechanism of the R. S. A. position?

The same as in the first, substituting right for left, etc.

What is the mechanism of the R. S. P. and L. S. P. positions?

So far as the breech is concerned, the mechanism is the same as in the sacro-anterior position (making allowance for change in direction). But when the head enters the pelvis it will be in an occipito-posterior position, and there will be the same need for anterior rotation as in the corresponding vertex positions.

\section{What dangers are connected with the breech presentation?}

I. Compression of the funis.

2. Premature respiration.

3. Inhalation of mucus, etc.
4. Extension of arms over head.

5. Extension of the head.

6. Rupture of the perineum.

How may the funis be compressed?

If there is any delay in the birth of the head after the body is born, the funis may be compressed between the hear and pelvic walls, thus asphyxiating the child.

\section{What is premature respiration?}

After the birth of the body, the contact of air may excite respiration, and abolish the placental circulation. Delay after this may result in asphyxia.

\section{How may inhalation of mucus occur?}

The child may respire while the head is detained in the passages, and may draw mucus or fluids into the lungs, causing either asphyxia or pneumonia after birth. 


\section{How may the arms be extended?}

The arms are naturally flexed upon the child's boty, and pass out with it, lut if arrested by the pelvic walls, they may be extended alongside of the head, increasing its diameter, and making delivery impossible until they are bronght down.

\section{How are the arms to be brought down?}

Une or two fingers are to be passed by the child's head and laid upon an arm from behind. The arm is then to be pushed across the child's face, and so on until brought down ly the site of the body. This may be repeated with the other, if buth are extended.

\section{How may the head be extended?}

The head is unually so tightly grasped by the utcrus and vaginal walls as to be kept flexed, but if the pelvis is small, or improper traction is made ufon the body, it may lee extended, and will then present a larger outline in prosing through the pelvis. This makes its advance more difficult, and may callse a laccration of the perincum.

\section{What is the fætal mortality in the breech presentation?}

lirom thirly to fifty per cent.

\section{How should a breech case be managed throughout?}

$A s$ a rule it shruld not be interfered with until the breech is born. The physician should then-

1. As the shoulders are coming down, endeavor to secure anterior rotation if it is in a pesterior position.

2. As swon as the body is hom, bring down the arms, if extended.

3. If the hearl is not at once horm, pass two fingers to its mouth, to secure as suply of air and atmit of respiration.

4. Iraw the horly dewn arainst and parallel to the perineum (to flex the heall). Then elevate the body, turning it over upon the mother's abdomen, while making traction. An assistant, if possible, should press upon the hyponastrium, to force the head down. Repeat the manceuvre, if necessary.

What caution is nccessary in pulling upon the child's body?

The neck lreaks with a weight of 100 pounds, and decapitation occurs whit 120 pronds. (Natthews I Huncan.)

\section{Under what circumstances is earlier interference indicated?}

When the lalur in unisly protracted we may suspect that the soft breech in spe:aling wut :nd being wedged in the pelvis, rather than being molded into a shape suitable for passing. We may then- 
1. Carefully introduce the hand and bring down one or both legs to use in making traction, or

2. We may use a fillet. Pass a silk handkerchief or roller bandage over the child's groin, to use in making traction. A "blunt hook" or other metallic instrument should never be used on a living child.

What varieties of the breech presentation occur?

One or both feet or legs may come in advance of the breech, which is called a lireech footling.

How does the descent of one or both feet affect the mechanism ?

Very little, except by offering a temptation to pull upon them, and thus to extend the arms and head. The first stage of labor may be longer, from the want of an even dilating werge in the os.

How is the ehild situated in the L. D. A. position?

The right shoulder presents in the os uteri, the head lying in the left iliac fossa and the breech in the right iliac fossa, or a little higher.

How is the ehild situated in the R. D. A. position?

The left shoukler presents in the os, the head lying in the right iliac fossa, and the breech in the left iliac fossa, or a little higher.

How is the child situated in the R. D. P. position?

The right shoulder presents in the os, the head lying in the right iliac fossa, and the breech in the left iliae fossa, or a little higher.

How is the child situated in the L. D. P. position?

The feft shoukler presents in the os, the head lying in the left iliac fossa, and the breeeh in the right iliac fossa, or a little higher.

What are the modes of delivery in the transverse presentation? There is no natural mechanism, but

I. The child, if very small, may be doubled up and expelled. (Rare.)

2. The ehild may be spontaneously turned in utero, so that it becomes either a vertex or breech presentation. (Rarer.).

3. After the child has been doubled up the breech may be pushed down after great efforts. This is ealled spontaneous evolution. (Rarest.)

How should transverse presentation be managed?

We should not await any of the spontaneous methods, but turn the cliid to a vertex or breeeh presentation. (See Version.) If this is impossible, we will have to perforate the chest and reduce the size of the elilul. (fiee Embryotony.)

What variety of the transverse presentation oceurs?

The hand or arm may be in advance of the shoulder, and may present

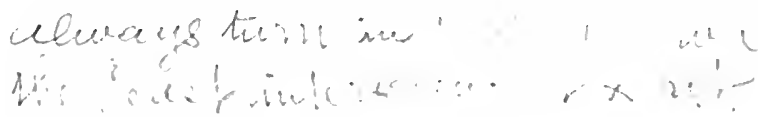


at the vulva. Care shoull be taken not to confound the hand and foot will each other.

What anomalous presentations are occasionally observed?

1. The hody of the child may be so doubled that the feet present with the vertex or face. 2. One or hoth hamls may be added to the vertex or fice presentution. 3. The funis may present with any of the others.

\section{PATHOLOGY OF LABOR.}

\section{What is dystocia?}

\section{DYSTOCIA.}

The technicil name for labor which departs from the normal stantaril.

\section{How is labor rendered abnormal?}

13: disease, defect or accident affecting-

1. The motive force. 2. The futus and its attachments. 3. The mother's tinsues or general condition. We have, therefore, three classes of dystwein: 1. Uterine; 2. (Tular; 3. Maternal.

In what way may the motive force be affected?

It may be: I. Excessive. 2. Deficient. 3. Irregular.

\section{What evils may excessive uterine action occasion?}

3. Precipitate labor, involving a too sudlen enptying of the womb, with laceration of the cervix and perineum.

2. kiugture of the womb when there is much resistance. Opium, chloral or aniesthetics will control it.

\section{What is deficient action?}

literine inctia, or any deficiency in the power, length or frequency of the uterine contractions.

\section{What evils may uterine inertia occasion?}

The principal one, and which involves many evils, is dilay in the labor. I hlay is hurtful, more or less, according to the stage in which it occurs.

1. It all times the protraction of labor beyond its normal limits enfechles the mether ant endangers the child's circulation.

2. In the secoml stage athlitional dangers arise, from pressure upon the maternat tisoues, with possibilities of sloughing, fistulas and septic procenses.

3. In the thirel stage incitia may leat to fatal hemorrhage, thrombosis in ut.rine sinuses, wh subsepuent septiciemia and other diseases.

What are the causes of uterine inertia?

1. Infective innervation or circulation of the uterus. 
2. Paralysis of the uterus from over-divention.

3. Organic lefects in the uterine muscles.

In what ways may the innervation and circulation of the womb be affected?

The nervous supply of the uterus being spinal, cerebral (vaso-motor) and ganglionic, it may be affected by mental emotion, the shrinking from pain of the hysterical temperament, improper ventilation, or from either direct or indirect disturbance of the uterine centre. The latter may he occasioned by malarial poisoning or by reflex influences from other disturbed organs. Premature rupture of the membranes is frequently associated with inertia, probably as cause.

\section{How may the uterus be paralyzed from over-distention?}

The walls of the uterus may be mechanically over-distended by twins or dropsy of the amnion, maling the contractions feeble.

\section{What organic defects are met with?}

The uterus which has frequently gone through the processes of pregnancy often has its fibrous and uncontractile element increaserl at the expense of the muscular tissue. This decreases the power of the uterus; hence, old multipare frequently have protracted labor from this cause. It is said that fatty degeneration sometimes occurs.

\section{How should uterine inertia be treated?}

If sufficiently great to unduly prolong labor we should-

I. Endeavor to ascertain and remove the cause.

2. Place the woman under the best hygienic conditions.

3. If the source of reflex disturbances cannot be removerl, we may guict the nerve centre by chloral, opium or the bromide of potassium, after which the inertia is commonly reliever.

4. ()uinine is always useful in malarious districts.

5. Massage and stroling of the uterus through the abdominal walls may he tried.

6. If orer-distention exists we should early rupture the memliranes.

7. In the second stage we may suthlement the uterine force (a) ly kisisteller's methorl, (b) ly the forceps.

What is Kristeller's method?

I'lace the han ls on the ablomen (facing the woman's feet). Firleavor at intervals to fush the child through the pervis. Cilled also expression.

What should be avoided in treating inertia?

The use of axytricies. 
What are oxytocics?

Irus crented with the power of directly affecting the uterine muscle, anl of cauning or strengliening contrations, such as ergot, cinnamon, burax, and many others. Of these the one most used is ergot.

\section{What objections exist to the use of ergot in labor?}

It is uncertain in action, and when it cloes act, causes tonic contraction

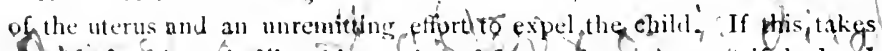
faceliof ore the of is rlitated laceration of the cerbix mayocur's if the head is large, rupture of the womb may occur; in any event, the placental circulation witl he contisuoudy compressed, gand the chill in tonger of arphyxi. Erot should neser be given before the birth of the chld, and

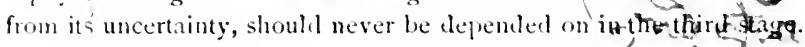

\section{What objections exist to the use of stimulants?}

A lluse of whiskey is often given, increasing the woman's courage, and the contractions of the abdominal muscles. liat if labor is not speedily Icrminated, reaction follows, and the labor will be retarded.

\section{What is irregular action of the uterine force?}

Irresular contraction of special fibres instead of general contraction of all. It typical form is called "ante-partum hour-glass contraction." In this comlition, a circular band of fibres, usually a little above the cervix, contracts irmly anl tonically, while the rest of the womb remains inert. This holds the child tightly in the womb, and suspends normal contracti.ns.

\section{How should this be treated?}

Reluxation should be attempted by anesthesia or by cmetic doses of ipencen These failing, our only resource is in artificial delivery by forceps, (ir conlingtomy.

What obstructions to delivery are encountered in the maternal tissues?

1. It the os uteri; risidity, relema, atresia, or displacement.

2. In the vatrina; filmous Innds, atresia, persistent hymen.

5. An unyieltiner jetineum.

4. Thums, including a disten led liduder or rectum.

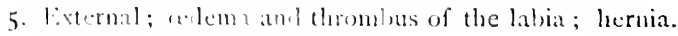

1. Defomities of the pelvis.

What is rigidity of the os (or cervix) uteri?

An unyedling and undilutale conlition, due-

1. To orguic clanges, and 2, to temporary spusmodic contraction of the

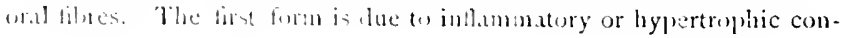


ditions by which the cervical fibres have become thickened and fibrous. The second form may occur at any time during the first stage of labor, ancl is usually associated with uterine inertia.

How may organic and functional rigidity be distinguished?

1. In organic rigidity the edges of the os are thick and dinse, and the cervix has not entirely disappeared.

2. In rigidity from spasm the edges of the os are thin and tense, giving the sensation of sharp, wiry resistance. It is also associated with some constitutional disturbance, the woman being nervous and fidgety and the vagina hot and less moist than usual.

\section{What treatment is indicated?}

1. In organic rigidity the uterine contractions should be allowed ample time to force open the os; this failing, incisions should be made with a bistoury. The patient should be placed in Sims' position, the speculum introduced, and the incisions made radiating from the os, to a sufficient extent to allow the head to come through with or without the forceps. The condition is rare, and such extreme measures are rarely called for.

2. Functional rigidity depends upon much the same causes as uterine inertia, and demands similar hygienic treatment. Chloral, gr. $\mathrm{xv}$, every hour, will be found effective. Over-stretching may be used. This is accomplished by inserting the inclex and middle fingers within the os, and spreading them forcibly, so as to stretch the oral fibres. The fingers exert so little real force that no judicious person can do harm with this procedure. It may be repeated in an hour, or with two or three succcssive contractions. If necessary, Molesworth's or Barnes' dilators may be used, to dilate with more force and rapidity.

What is œdema of the cervix?

An infiltration of serum, especially into the anterior lip of the ccrvix, which impairs its dilatability. It is due to pressure from the child's head.

What is the indication for treatment?

To remove the cause; as long as the head remains the swelling will continue; hence deliver with the forceps before it becomes too extensive.

\section{What is atresia of the os uteri?}

Entire closure of the os, duc to inflammatory adhesions of the cervical lips. It is very rare, and demands similar treatment to organic rigitity.

What is displacement of the os uteri?

Removal of the os from its usual place in the vagina, usually dlue to a forward displacement of the fundus. 'This in turn is due to a relaxed 
condition of the aldominal muscles. [Cases are recorded in which the fundus of the womb rested on the woman's knees, in the sitting posture, throwing the os so far hack as to make it inaccessible.] The same condition is sometimes caused by tumors, displacing the womb in any direction, but the usual displacement of the os is backward, toward the promontory.

\section{What are the dangers of this condition?}

1. The child's head is pressed against the anterior wall of the cervix, and is unalile to leave the womb, unless through a rent in the anterior wall.

2. The incautious examiner may mistake the thinned wall for the membrancs, and make the rent himself. This condition is common enough to warrant every one in making the discovery of the os and the condition of its edges the first duty in labor.

\section{What treatment is indicated?}

Replace the womb by pushing the fundus backward, while, if possible, the finger is hooked into the os and it is pulled forward. If the displacement has been great, a bandage should be applied around the abdomen, to) retain the uterus in position.

What treatment is indicated for a small vagina, obstructive bands, etc.?

$A$ vagina small enough to impede delivery will require the forceps to be used. Pands or a persistent hymen may be incised. While the hend di-tends and makes tense the band, a knife placed between the head and bant is allowed to be pushed through. Care should be taken to cut as little as posilile, and to tear rather than cut after the edge is severed.

How may the perineum obstruct labor?

I. The perineum may be congenitally defective in structure, or have been imperfectly developed during pregnancy, constituting organic rigidity. 2. (1) its muscular fibres may be in a condition of spasm, or functional rigillity. The same measures may be used which are applicable in rigidity of the cervix, lut the forcejs may be used instead, which render us incle. pendent of the perineum.

What is to be done when tumors obstruct delivery?

The treatment of a distended bladder and rectum is obvious. Empty them. No rule can be laid down for other tumors. If the tumor is safely remuvalile or can be diminished in size, it may be done. If not, the child must he lesseneel in size. 
What treatment do the external tumors (œdema, thrombus and hernia) require?

I. When adema of the labia is extensive enough to obstruct delivery, a number of punctures should be made with a fine bistoury, which will speedily drain and remove it.

2. A large thrombus occasionally distends the labium obstructively. A free incision should be made, the clot turned out and hamostatics applied if necessary.

3. IIernia rarely complicates labor. If irreducible, it requires avoidance of bearing lown.

\section{DEFORMED PELVIS.}

\section{In what parts is the pelvis deformed?}

It may be generally contracted throughout, or the deformity may be limited to the inlet or outlet.

What is the generally contracted pelvis called?

The pelvis aquabiliter justo minor.

\section{What difficulties does it occasion in labor?}

$A$ small head will pass through it with the normal mechanism. A large hearl will be unable to pass unless aided by the forceps.

In what ways is the inlet deformed?

1. Inflammation of a sacro-iliac or hip joint occurring during the developmental period, may so affect one sacro-iliac arch as to practically obliterate the pelvic canal of that side. This may not affect the opposite canal, or there may be a flattening of the whole inlet, contracting the conjugate diameter, and lessening the calibre of the remaining canal.

2. Rachitis may so affect the pelvis as to cause a flattening of the inlet and contraction of the conjugate diameter, entirely obliterating the normal condition of the canals.

3. Osteo-malacia, or softening of the bones, may distort the inlet in a variety of ways, always diminishing its effective diameters.

4. Curvature of the spine may, by kyphosis, scoliosis or spondylolisthesis, so rlisplace the promontory as to cause, in effect, the same deformities as in the other classes.

\section{What is kyphosis?}

Posterior curvature of the lumbar spine. Its usual effect is to lengthen the conjugate diameter and diminish the transverse diameter ly tilting the sacrum backward. Such a pelvis is called "funnel-shaped," a name also given to a pelvis of male type resuiting from imperfect development. 
What is scoliosis?

Lateral curvature of the spine. It may only impair one side of the pelvis, but, if great, may cause serious deformity.

\section{What is spondylolisthesis?}

$A$ slipping forward of the last lumbar vertelora on the sacrum, so as to greatly contract the conjugate diameter.

Do deformities of the inlet affect the whole course of delivery?

Generally the trouble is over when the head has passed through the inlet, the rest of the pelvis being undeformed.

What effect upon delivery is occasioned by deformities of the inlet?

I. The presentation is apt to be irregular.

2. The agreement between the axes of the uterus and pelvis being disarranged, the uterine force is deflected, which protracts both the first and second stage.

3. The normal mechanism of delivery is perverted.

4. The inlet is made too small to admit the child to pass readily.

5. The maternal tissues are more apt to suffer from pressure due to the misdirection of the uterine force.

In what way is the mechanism altered?

I. The hearl is usually more transversely placed, and rotation has to be made through a longer arc.

2. The head has to make a curved passage around the promontory before it can enter the inlet.

3. The narrowing of the pelvis delays the head until it can be compressed and moulded to a suitable size.

\section{How are degrees of deformity estimated?}

liy the length of the conjugate diameter, as determined by pelvimetry.

\section{How may the conjugate be measured?}

Various instruments called pelvimeters are in use, but the most availalle is the finger of the physician.

( ) ne or two fingers are passed into the vagina, and extended so as to reach the sacral promontory. The point at which the anterior commi-sure of the vulva touches the hand may then be noted, and the reach measured. This is the diagonal conjugate. Deduct an inch from this for the thickness of the pubes, and we have the hypothenuse $(x)$ of a right-angled triangle, in which the real conjugate $(y)$ is one leg, and the inmer face of the pubes ( $\%$ ) is another-(Then $x^{2}=y^{2}+z^{2}$ ). 
In a normal or slightly deformed pelvis the promontory cannot usually be reached, but in all cases where it is a practical matter, the length of the conjugate can be cletermined in this manner.

\section{What degree of contraction is compatible with delivery?}

Much will depend upon the skill of the physician, but in general terms, it may be said that with a conjugate of three inches or more, a living child may be extracted, with or without the forceps; three to two and a half inches, may be delivered by forceps or version, or at worst by craniotomy; two and a half or less, may be delivered by craniotomy, but the statistics show that the Cresarean section is as safe. (Parry.)

\section{How may the outlet be deformed?}

By a narrowing of the transverse diameter, due to a too close approach of the ischia; or of the conjugate diameter, due to anchylosis or rigidity of the sacro-coccygeal joint. The first is rare, and the second common, in old primipare.

\section{What treatment is indicated?}

Sufficient additional force to enable the head to pass, which is best furnished by the forceps.

\section{OVULAR DYSTOCIA.}

What departures from the normal condition occur in connection with the foetus and its envelopes?

I. The membranes (a) may rupture prematurely;

(b) may be too tough;

(c) there may be an extra amniotic sac;

(d) there may be hydrops amnii.

2. The funis $(a)$ may prolapse; $(b)$ may be too short.

3. The child may be enlarged or deformed by $(a)$ hydrocephalus; $(b)$ hydrothorax; (c) ascites; (d) cedema; (e) putridity; $(f)$ by anchylosis of joints.

4. Parts of the child may be displaced; (a) prolapse of arm or foot by head; (b) arm behind the occiput.

5. There may be more than one child, called multiple labor.

What effect has the premature rupture of the membranes?

I. No bag of waters is formel to assist in dilating the os.

2. The uterine walls close upon the irregular projections of the child, instead of upon the evenly pressing water-sac, and irregular contractions may occur.

3. The first stage is prolonged.

4. The child is subjected to greater pressure, and may be injured. 


\section{What harm is occasioned by too thick membranes?}

I Iours may elapse in fruitless efforts of the womb to rupture them ; and they repuire to be artificially punctured.

\section{What is a "caul?"}

In rare cases, where there is little liquor amnii and the membranes are elastic, the child is born with its head enveloped in the membranes, which is called being born with a caul. [The nembranes, when dried and preserved, are said to be a charm against denth by drowning.] The practical point is to tear or cut open the sac as soon as possible, to prevent asplyyxia of the child.

\section{What is an extra amniotic sac?}

An effusion or secretion of fluil which sometimes occurs between the amnion and chorion. When the bag of waters is formed during labor, the sac will be formed by this fluid, and when the chorion is ruptured the Aluid will escape, giving the impression that the true bag of waters has ruptured. A new loag will then form, enclosed only in the amnion. It is of no importance, except in the matter of diagnosis.

\section{What is hydrops amnii?}

I Hopsy of the amnion or over-secretion of Auid by the amnion. This may take place to the extent of over a gallon, distending the uterus, enfechling and sometimes destroying the child. If the amount of fluid is great, it is well to pass a bandage around the abdomen before evacuating it, and stimulants should also be at hand.

\section{What is prolapse of the funis?}

The funis, or rather a loop of the cord, may fall in advance of the head. There may le only a small knuckle or several inches may prolapse, so that the cord even reaches to the vulva. This endangers the childis life, from pressure, lut is rarely an impediment to delivery.

\section{With what may the funis be confounded?}

With a loop of intestine, which also may be met with after rupture of the womb. The finger may be passed entirely around the funis; with the intestine, the mesentery will prevent.

\section{What treatment is indicated?}

The funis should be pushed up above the inlet in the interval between pains, and when the presentation is forced down by a contraction, it will frothahly he retained. This can be dune by the fingers or by repositors inventerl for the purpose, and may be aided by placing the woman in the lince-chest posture. If the alvance of the presentation clos not retain it, 
a small piece of sponge passed between the head and the inlet will often succeed. If the cord is surely pulseless it may be left alone, but if the child is alive and the funis camnot be retained, prompt artificial delivery is indicated.

In what way does a short funis impede delivery?

By preventing the child from descending completely through the pelvis. It may be only five inches long, and if of normal length, may become shortened by being wrapped in one to four coils around the child's neck.

\section{How may a short funis be recognized during labor?}

I. The head is arrested low in the pelvis; it then advances slightly with each contraction, and is abruptly jerked back by the tension of the cord.

2. Constant pain is felt in the womb, over the placental insertion. Fortu. nately the occurrence is rare, since the diagnosis is not easy unless the head is born, and aid is difficult to render.

\section{What treatment is required?}

Delivery loy main force until the cord can be reached and cut, or is ruptured.

What is hydrocephalus?

Enlargement of the fotal head by excessive development of the cerebrospinal fluid. It may be so great as to double the length of the head diameters. The bones are thin (in extreme cases expanded and parchment-like in texture), and the sutures and fontanelles greatly enlarged. It is often associated with spina bifida.

\section{How may it be recognized?}

By the softness of the head and the enlargement of the sutures and fontanelles. Moderate degrees are not recognized with certainty until the forceps are applied, when the wide divergence of the handles shows the increased bulk of the head.

\section{How should it be managed?}

Simple perforation of the skull will allow the fluid to escape, and permit the collapsed cranium to be withdrawn. The brain should also be broken up before the child is withdrawn.

How may hydrothorax and other enlargements of the fœtus obstruct delivery?

Effusion of serum in the chest (hydrothorax), abdomen (ascites), external cellular tissue ('edema), may enlarge the bulk of the child and obstruct delwery. The joints may be anchylosed in such a position as to increase its bulk. A child dying in utero and becoming putrid may be swollen, but usually causes trouble only by poisoning the mother. 
In any of these cases it may be necessary to reduce the bulk of the child by embryotomy.

How is prolapse of the hand or arm by the head to be treated?

The prolapsed nember is to be pushed up, as in the case of jrolapse of the funis. If the arm is behind the head (Simpson) and the diagnosis can be made, turning is indicated.

In what way may the foot or feet complicate head presentations?

One or both feet may jresent alongside of the head, in which case the child must be more or less doubled up. It may be noted that these accidents often occur together, feet, arms and funis, in varying proportions, prolapsing at the same time.

\section{How is this complication to be treated?}

If recognized before the rupture of the membranes the feet may either be pushed up or the child turned. If at any time we find turning to be very difficult or impossible, we may know that the child is dead (because difficult to turn and doubled), and at once perform embryotomy.

How may the shoulders give trouble in delivery?

By not entering the pelvis, but catching on the inlet, thus preventing the head from advancing.

\section{How may this be recognized and treated?}

liy the manner in which the head advances and is retracted, as in the case of a short funis, and by external palpation. Ly external pressure the shoulders may be pushed into their proper place.

\section{TWIN LABOR.}

\section{What is the usual course of twin labor?}

After the first child is born a short rest occurs; the pains recur (usually within fifteen minutes) and the second child is born, and so on, if more than two.

\section{What difficulties may occur in twin labor?}

I. lioth chiluren may attempt to enter the pelvis at once, and become wetgred.

2. After one head has reached the outlet the second may enter the pelvis, with the same result.

3. Head locking may occur.

\section{What is head locking ?}

When the first child is born by the breech, its chin may catch upon the chin of the sccond child, prescuting by the head. 
What general rules may be laid down for these complications?

1. To pusl up one child and allow the other to come down, if possilble.

2. When one child is partly born and the other wedged in with it, the first child is to be sacrificed in order to save the second.

What forms of twin monsters complicate delivery?

The principal forms are-

I. Two nearly separate bodies united in front by the thorax or abdomen (ex., Siamese twins).

2. Two nearly separate bodies, united back to back by the sacrum and lower part of spinal column (ex., North Carolina sisters).

3. Dicephalous monsters; the bodies single below, but the heads separate.

4. The bodies separate, but the heads are partially united.

The two latter are almost invariably still-born. (Playfair.)

\section{EFFECT OF MATERNAL CONDITIONS ON LABOR.}

\section{What maternal conditions may affect labor?}

1. Syncope. 2. Hemorrhage. 3. Rupture of the uterus. 4. Eclampsia.

How does syncope affect labor?

Usually by only temporarily suspending the uterine contractions. If associated with organic heart disease it may prove fatal. The treatment is the same as inclicated at any other time.

\section{What forms of hemorrhage are met with?}

I. From detachment of a normally implanted placenta, before the birth of the child, or accidental hemorrhage.

2. From detachment of an abnormally implanted placenta, before the birth of the child, or unavoidable hemorrhage.

3. During and after the third stage, or fost partum hemorrhage.

What causes premature detachment of the placenta (accidental hemorrhage)?

External violence and irregular contractions of the womb.

What symptoms does it cause, and why?

Hemorrhage and colicky pains in the abdomen, but either may be absent. The hemorrhage may be concealed, $i . c$, the blood may dissect up the placenta and membranes without escaping from the woml, or in small quantity. This will cause distention of the womb and pain. If there is no external hemorrhage the symutoms of loss of blood internally will be present. 


\section{What treatment is indicated?}

Prompt dilizery, on behalf of the child, which, after all, is usually destroyed by the impairment or total stoppage of the placental circulation; and alio on account of the mother, if the hemorrhage is at all extensive.

1. The os uteri should be dilated sufficiently to allow the child to pass.

2. The membranes should be ruptured, and the child at once delivered by forceps or version. The membranes should not be ruptured until we can deliver, for the evacuation of the linjuor ammii gives just that much more room for the effusion of blood, without any gain in uterine contraction.

3. The woman's strength must be maintained by whiskey or hot milk, and inertia guarcled against.

\section{PLACENTA PREVIA.}

\section{What is placenta previa?}

The implantation of the placenta upon the lower third of the uterine wall. The placenta may be centrally placed over the os uteri; its edge may reach to the edge of the dilated os; or any degree between these extremes may be met with. It is, therefore, divided into central and

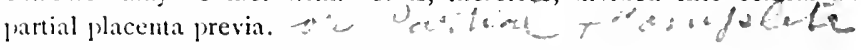

\section{How and why does placenta previa occur?}

The orum should be, and usually is, arrested as soon as it enters the womb, by a fold of the mucous membrane.

If these folks are not prominent enough, it may advance until it arrives at the os internum, where the placenta will then be formel. It is, therefore, found principally in nultipare, and in those whose organs are in a relaxed conclition.

\section{What is the source of hemorrhage in placenta previa?}

The blood pours from the openings in the uterine simuses when the placenta is detached, and not from the placenta itself.

How soon does placenta previa cause trouble, and in what manner?

Rarely before the sisth or seventls month of pregnancy.

About this time the cervical segment, which is smaller than the fundal region of the womb, has nearly reached its limit of growth. The placenta then grows faster than the womb, and its edge is liable to become detached. later in presnancy the os uteri becomes patulons, and this again causes some separadion of the placenta. As a result, hemorrhige occurs, more 
or less profusely. Usually, if rest is enjoined, the opened sinuses are closed by a clot, and the hemorrhage is arrested until further separation takes place.

\section{What are the dangers in placenta previa?}

Death of the mother from hemorrhare, and of the child from asphysia. The maternal mortality is one in four; fotal mortality one in two to three.

\section{What treatment is demanded when it occurs before fulhterm?}

Rest in bed, with or without a tampon, will grrest bemorkage, for the time; the sinusest are closed by thrombi, and the case may go on to term orowhet hemorrhage. If the hemorpage is great it is safer, to intuce labor at once, than to wait. Occasionally no henorrhage occurs during pregnancy, nor even in labor.

\section{How should delivery be managed at full term?}

I. Introduce one or two fingers within the os (the hand being in the vagina), and dissect the placenta from the uterine wall for about three inches from the os uteri in all directions, pushing it to one side, if necessary.

2. Rupture the membranes, and if there is an unfavorable presentation, turn the child and make the breech engage in the os; or if the head presents, the forceps may be used, if speedy delivery is necessary.

This partial detachment of the placenta will almost inevitably arrest hemorrhage (Barnes). The strength of the woman is then the main point to be cared for, and if in a reasonable time the uterus seems to be incompetent, the child may be delivered by art.

What complication may interfere with this procedure?

A rigid and undilatable cervix, which is often present, because of the thickening of the tissues under the placental insertion.

\section{How is this to be overcome?}

In prentature cases, or-when we are not prepared to dilate, the tampon may be applied for. some hours. Otherwise the Molesworth or liarnes' dilators may be used to mechanically dilate the os, if the fingrers camnot do it.

\section{What is a tampon, and how applied?}

A tampon is a plug made of pieces of cotton, soft rags, or similar mate. rials, packed into the vagina so as to restrain hemorrliage.

I. Place the woman in Sims' position and introduce Sims' speculum.

2. With a pair of dressing forceps introduce a small wad of cotton batting within the os uteri. Continue to add similar picces until the whole uper part of the ragina is packed with them. 
3. Gradually withdraw the speculum, continuing to add cotton until the whole vagrina is packed.

4. Apply a compress and T-bandage over the vulva.

A roller bandage or lamp-wick (recommended by Fuster) may be used, and will be casier to withdraw.

\section{How long should a tampon be left in place?}

Sellom over twelve hours, and in placenta previa it may be necessary to remove it within an hour or two.

\section{What effect has the tampon besides restraining hemorrhage?}

It excites uterine contractions, and aids in dilating the os. This should always be considered where these results are not desirable.

\section{What cautions are to be observed with the tampon?}

1. The upper pieces should be moistened with a one or two per cent. solution of carbolic acid or other disinfectant.

2. Never introduce it when the membranes have been ruptured, except in the early months of pregnancy, lest bleeding occur above it, distending the uterus.

3. Watch it after it is applied, to see that blood does not flow past or through it. There is no dlanger if it is properly applied.

What complication may occur in placenta previa after delivery?

The exposed sinuses in the cervical region may not be efficiently sealed, and hemorrhage may continue. The management will be as in postfartum hemorrhage generally.

\section{POST-PARTUM HEMORRHAGE.}

\section{What is the cause of hemorrhage post-partum?}

An uncontracted or incompletely contracted uterus, wherely the opened sinuses of the placental site are not compressed, and bleeding is allowed. It is also favored by the retention of the placenta, cluts (incomplete delivery), and by fibroid tumors. In a slight form, may be due to laceration of the cervix, vagina and perineum.

\section{What are the symptoms of post-partum hemorrhage?}

I. Livally the blood pours out so freely as to readily attract attention; if concealed or retained in the uterus, it will occasion the symptoms of internal hemorrhage.

2. The hand placed on the abdomen will not find the womb hard and in the hypergatric region, but soft and at a higher level. 
What are the indications for treatment?

I. To empty the womb.

2. To make the womb contract.

3. To cause clots in the opened sinuses, if the womb fails to contract.

4. To support the woman's sirength.

How is this treatment to be carried out?

I. The hand should be introduced into the womb, and clots or other contents removed.

2. The hand is re-introduced and moved about, stroking the uterine walls, while the other hand is similarly engaged on the abdomen. This will often succeed in arousing contractions, and lead to the expulsion of the hand from the womb. If not,

3. A handkerchief, soaked in vinegar, may be carried into the womb and squeezed out; or a peeled lemon; or a piece of ice.

4. Injections of hot water $\left(110^{\circ} \mathrm{F}\right.$.) may be used.

5. The faradic current may be useful, if at hand.

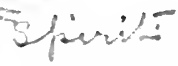

6. As a last resort, and to cause clots, injections of tincture iodinii, or liq. ferri perchloridi, diluted one-third, or even of full strength, may be used.

How may post-partum hemorrhage from inertia be prevented? By delivering the placenta by the method of Credè.

\section{What internal medication is proper?}

Stimulants, opium and ergot, but no dependence is to be placed upon anything but local treatment. Hot milk is both stimulant and rapidly absorbed.

\section{What is the operation of transfusion?}

Injecting into the circulation blood, milk or other fluid, to replace the blood lost by hemorrhage. To inject blood requires special and costly apparatus and great skill. Milk may be injected with little tronble. Care must be taken to avoid injecting air, and not to inject so rapidly as to distend the right side of the heart. For this reason it is safer to expose the radial artery and inject toward the hand, slowly and gently.

\section{What is secondary hemorrhage and its cause?}

llemorrhage occurring after an interval of several hours or even days, after delivery; it is usually preceded by ordinary post-partum hemorrhage, and may be due to a return of uterine inertia; the detachment of thrombi; retention of pieces of membrane, or clots; displacement of the uterus, from a too tight bandage; an impacted rectum; sitting up too soun. 
What treatment is indicated?

The same in principle as in immediate hemorrhage, with due attention to the exciting canse.

\section{RUPTURE OF THE UTERUS.}

\section{What is rupture of the uterus?}

A tear or laceration in the substance of the uterine body, usually permitting the escape of the child into the ablominal cavity.

\section{Under what circumstances does it occur?}

Generally during the second stage of labor, the rent beginning in the cervix and extending toward the fundus. Rarely the peritoneal covering escapes laceration; also it occasionally occurs early in the labor, or even in premature labors.

\section{What is the cause of rupture?}

l)uring labor there is a tendency for the anterior wall of the cervix to be pullect upward, and for the posterior wall to be pushed downward (I). Perry Hart). If the head becomes packed in the inlet early, so as to prevent the anterior wall of the cervix from being pulled up, the anterior wall just above the head becomes greatly thinned, owing to this upward pulling, and rupture almost invariably begins at this point. The thickened ring of filres just above the point of thinning is known as liandl's ring.

\section{What symptoms denote its occurrence?}

l) bring or just after a labor pain the woman is seized with an acute and firsitint pain. The form of the uterine tumor is changed and the presentation is retracted. As blood is effused from the rent, symptoms of internal hemorrhage and shock are added. The fingers passed into the vagina readily recognize the rent, and if the child has altogether escaped into the abdominal cavity the intestines will have prolapsed through the rent.

\section{What treatment is indicated?}

1. I'reventive; a prompt resort to the forceps when the occurrence is feared.

2. Afterwarls, if the presentation is not entirely retracted, an attempt may be mate to deliver per aias naturales.

3. In any case, unless it can be demonstrated that the peritoneum is unbreken, the aldomen should be opened by an incision, the uterine wound closed ly sutures, and all blood and fluids removed from the alstominal carity. 
What is the mortality from rupture?

I. In cases abandoned to mature nearly all die.

2. When the child is clelivered without gastrotomy a few more recover.

3. When gastroiomy is at once performed, 60-70 per cent. recover.

\section{ECLAMPSIA.}

What is puerperal eclampsia?

A form of convulsions occurring before, during or after labor, which resembles epilepsy in clinical appearance and uremic convulsions in cause. The typical form occurs during the second stage of labor.

\section{What is the clinical history of an attack?}

1. The patient is suddenly seized with a tonic spasm, involving the muscles of the face and thorax, usually of the upper extremities, and occasionally of all the muscles. This tonic spasm lasts for about one minute and-

2. Is succeeded by clonic spasms or twitchings, lasting for sezeral minutes. The convulsions subside and-

3. Are succeeded by coma, with stertorous breathing. The patient may become conscious or the convulsions may be renewed in the same order, keeping up until the patient is exhausted or recovers.

The masseter muscles are contracted tonically throughout the seizure. The interference with respiration causes the face to become red or livid. The duration of each seizure and the interval between, depend upon the severity of the attack.

\section{What prodromic symptoms warn us of an attack?}

I. Severe and persistent headache is often complained of before an attack.

2. Albumen in the urine should also put us on our guarcl.

What is the cause of puerperal eclampsia?

The cause is complex, the main factors being-

I. I) ill-supplied nerve centres becone more irritable or convulsable (barnes).

2. The processes of elimination, especially through the kitneys, become defective, and urea (including other excrementitious matters) is retained in the blood. Therefore the nerve centres are supplied with poisonous or irritating substances, as well as impoverished.

3. Vascular tension is increased during pregnancy, and especially during labor, which intensifies the action of the foregoing factors.

4. During labor the interference with the cephalic circulation (from lear- 
ing down, ctc.,) causes hyperemia of the brain and of the nerve centres specially concerned with eclampsia.

Which of these factors is the most important?

The uremia, as shown by the fact that go per cent. of eclamptics have albumen in the urine.

Wherein does puerperal differ from uræmic eclampsia?

The temperature in the former is high (has been observed as high as I0 $9^{\circ} \mathrm{F}$. (Busey); in uremia it may even be subnormal. The clinical history also differs.

Wherein does puerperal eclampsia differ from other forms of convulsions?

I. In hysteria the spasms are altogether irregular and consciousness is never entirely lost.

2. In apoplexy the condition of coma is permanent, and there is a difference in the size of the pupils.

3. In epilepsy, the history will distinguish, except in labor in epileptics, who rarely have convulsions in labor (Parry).

\section{What point in the etiology is disputed?}

The conlition of the brain, as to anemia or hyperiemia.

Traube and Rosenstein assert that hydramia causes cedema of the brain, which in turn leads to anemia from pressure upon the capillaries from without. Others assert that anemia of the brain is essential in eclampsia, and that the base of the brain is anemic, even when the convolutions are hyperamic.

What effect upon the cerebral circulation have the bearing. down efforts of the second stage, when eclampsia mostly occurs?

The cervical veins are obstructed and blood accumulates in the brain.

Does this occur when eclampsia takes place before or after labor?

Not demonstrably; and in these cases we conclude that the other factors, notably uremia, preclominate.

What are the indications for treatment in puerperal eclampsia?

1. To relieve the irritability of the nerve centres.

z. To reduce vascular tension.

3. To reluce cerelural hyperiemia.

What preventive treatment is indicated?

I. To eliminate urea, etc., by cathartics, ancl,

2. To ruiet the nerve centres by chloral and bromide potass. 
What treatment should be employed during the attack?

I. Venesection, as the quickest and most powerful means of relucing the vascular tension, cerebral liyperemia, and secondarily the nerve irritability.

2. Chloral and bromide of potass. by the month, if the patient can swallow, or in double doses by the rectum.

3. Ether or chloroform may be given until the chloral, etc., can he arministered and take effect.

4. The labor, if in progress, should be terminated as soon as possible, without violence.

5. Purgatives may be given, especially after delivery.

6. A warm pack, to promote diaphoresis, may be used.

What objections are urged against venesection?

That it is out of fashion, and does. not reduce vascular tension in a healthy log.

Veratrum viride may be used instead, if there is time to wait upon its action.

What drug was especially used before the discovery of chloral and the bromide?

Opium, which relieves the irritability of the nerve centres.

What objections exist to its use?

It allays nerve irritability at the expense of all other indications; when the kilneys are seriously crippled it may, itself, cause death; it is no better than other less dangerous remedies.

\section{MISCELLANEOUS COMPLICATIONS.}

What complications may exist during or after the third stage of labor, besides hemorrhage?

1. Placental dystocia, or difficulties in delivering the placenta. 2. In. version of the womb. 3. Emphysema of the neck. 4. Lacerations of the cervix, vagina, and perineum.

What forms of placental dystocia occur?

I. Adherent placenta. 2. IIour-glass contraction. 3. A placenta too large. 4. Clots behind an inverted placenta. 5. Utero-placental vacuum. 6. Placentee succenturixe and other anomalies of form.

\section{What is adherent placenta?}

The term is properly applied to one that has contracted firm allhesions o the uterine wall, from inflammation during pregnancy. There is usually 
a listury of fixed pain in the uterus. This is rare, but improper traction upon the cord may delay the separation of an otherwise normal placenta.

How is adherent placenta to be treated?

Pass the hand into the uterus, find a detacherl edge of the placenta, and by a sawing motion with the fingers break through the adhesions.

\section{What is hour-glass contraction?}

Irregular or tetanic contraction of a part of the uterine walls, the rest being relaxed, wherely the placenta is grasped and held as if in a sac. It may be complicated, if not caused, by adherence of the placenta.

How may it be recognized?

The hand, introduced into the womb, finds apparently a second os internum, high up, caused by the constriction of the muscular filbes of the womb below the placental site.

How is it to be overcome?

The fingers, little by little, and finally the hand, are to be insinuated within the constricting band and its resistance overcome. This may be facilitated by ancesthetics or chloral. The best reliance is upon patient and continuous manual efforts.

How may the bulk of the placenta affect its delivery?

A very large placenta which has fallen centrally upon the os, instead of enlgewise, may be too bulky to pass without assistance. The same may occur wilh a placenta of moderate size, if clots have formed tehind it to such an extent as to prevent it from being (loubled up).

How is such a placenta to be delivered?

It should he perforated centrally by one or two fingers, which will enable us to hook into and drag it down.

What is a utero-placental vacuum?

$\Lambda$ rare occurrence, in which the placenta being detached, a pull upon the funis mahes a vacuum between the placenta and uterine wall, convert. ing it into a sucker, resembling in action the leather disk by which the small loy raises bricks from the pavement.

\section{How can it be detected and remedied?}

It resembles at first the large placenta, or one enlarged by clots, but as som as perforated and the vacuum destroyed, it is delivered with great ease, or even spontancously expelled at once.

What irregular forms of the placenta are met with?

1. The huttledore placenta, in which the funis is inserted at the margin, in-teal of centrally. 
2. The vessels of the cord may not unite, even at the margin, but ramify over the membranes before uniring to form the funis; known as the a'lamintous insertion of the cord.

3. The subdivision may extend even to the placenta, and result in there being two or more placenta, situated at different points on the uterine walls; called flacente succenturis.

These anomalies are uncommon, but sometimes lead to perplexities in the delivery of the after-birth.

\section{INVERSION OF THE UTERUS.}

\section{What is inversion of the uterus?}

A turning inside out of the womb, so that the fundus-

I. May present at the os uteri (partial inversion), or-

2. lasses through the os and extends to or through the vulva (complete inversion).

\section{What is the cause of inversion?}

Partial and irregular contraction of the uterus is the main factor, often aided by traction upon the cord in delivering the placenta. No one can invert a healthy womb by traction upon the cord, but if the fibres under the placental site are not contracting, inversion will be very likely to occur. It may happen either before or after the placenta is detached.

\section{How may inversion be recognized?}

I. The woman usually complains of great pain at the moment of the accident (a sensation as of something tearing loose within her). 2. $11 \mathrm{em}$ orrhage and more or less shock follow. 3. The hand, placed upon the ablomen, fails to find the womb in its natural place, and when introlucerl within the vagina finds it there (unless external). It can then be mistaken for wothing but a fibroid tumor, which, of course, could not occupy the vagrina just after delivery.

\section{How is inversion to be treated?}

I. The placenta, if adherent, is to be detached.

2. The womb should then be squeezed within the hand, to raluce its bulk, and an attempt made to replace the fundus, with the hand grasping it, while the other hand presses downward in the hypogastric region, making counter-pressure.

3. If this fails, endeavor to inclent the uterine globe with a knuckle or the finger tips and thus reinvert it. The indentation is said to be best effected at the opening of a Fallopian tube. l'ressure should be firmly and patiently continued, and if employed just after the accident, rarely fails. 
4. After the fundus is replaced the hand should remain within the uterus for some time, or until expelled.

What is to be done in case of failure?

If called too late, or if replacement cannot be effected without violence, the fundus should be bathed with somewhat diluted tincture of iodine, to restrain hemorrhage, and allowed to remain inverted for one or two months, or until involution has taken place, when the reposition may be attenipted by the method of White.

\section{What is emphysema of the neck?}

During the bearing-down efforts of the second stage it sometimes happens that a few air vesicles in the lungs are ruptured, and air escapes by way of the mediastinal space to the cellular tissues of the neck and face. It is usually limited to one side, the tissues being swollen and crackling unler the fingers. It may cause great alarm, but is innocuous if left alone, sulsilling in a few days without any ill consequences.

What ill consequences attend laceration of the mother's tissues?

The only immediate consequence is or may be hemorrhage, easily controlled.

The remote consequences may be serious, especially when the perineum or cervix are badly torn.

What is to be done when the cervix is lacerated?

Some anthorities recommend that sutures should at once be inserted; luat the general practice is to let it alone until the womb has passed through the preriod of involution of the womb.

What is to be done when the perineum is lacerated?

Nost anthorities recommend that it should at once be uniter with sutures, muless of very slight extent.

\section{OBSTETRIC OPERATIONS.}

\section{What are the capital operations of midwifery?}

1. The use of the forceps. 2. Version. 3. Embryotomy in varions forms. 4. The Ciesarean section and modifications. 5. The induction of premature lalur.

What are the obstetric forceps?

Two separate and similar pieces of steel, each fashioned into a blacle and hamlle, intended to cross each other in the mildle and be temporarily united at that print ly a lock. 


\section{What is the object of the forceps?}

1. They are used to seize the child's head and to make traction upon it.

2. They are used to compress the head and diminish its diameters.

3. They are used to flex or extenil the head, as may be required.

Why is a fenestra or open space made in the blades?

To allow the parietal protuberances to project, therely permitting the forceps to be applied to the head without at all adding to its bulk.

\section{What curves exist in the blades?}

1. The pelvic curve, so that they can be applied at any point in the pelvic canal with equal ease.

2. The head (or capital) curve, by which they are bowed outwardly, so as to enable them to grasp and hold the head.

How many forms of lock are in common use?

The mortise, or English lock; the pivot, or French lock, and the button, or German lock.

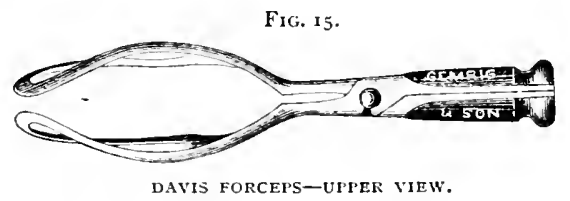

How are the blades distinguished and named?

The blade to the right is called the right blade, or when provided with the pivot or button, the male blade (see Figure I5).

The blade to the left is called the left blade, or when provided with a slot, the female blade.

\section{When should the forceps be applied?}

In any case where the head presents, and where prompt delivery is necessary (cither for mother or child), or to be regarded as preferable to waiting upon the natural efforts.

\section{May they be applied during the first stage?}

There are few circumstances which warrant us in applying them before full dilatation of the os. The necessity for prompt delivery should be very clear, since bruising and laceration of the cervical tissues are almost incvitable.

\section{What preliminaries are requisite to their application?}

The consent of the woman being ubtained, she should be placed in a suitatle prosition and the forecps be placed in warn water. 
In what position should the woman be placed?

Lying crosswise in the bed, the vulva overhanging the bed's edge, and with her feet placed upon two chairs. The knees may be held apart by an assistant, and the legs covered.

What station should the physician occupy?

Seated upon a chair, directly in front of the vulva, the forceps placed within reach.

How should the forceps be applied to the L. O. A. position at ${ }^{\circ}$ the inlet?

I. The physician should take the male blade in his left hand, holding the handle securely, and having greased both the blade and his right hand, pass the latter into the vagina, high enough to enable him to feel the rim of the os uteri (on the left side of the mother). Two fingers will often suffice, instead of the whole hand.

2. Pass the blade along the palmar surface of the right hand or fingers, aiming to place the blade under the left sacro-iliac arch, and, therefore, along the left side of the child's head. 'This is usually very easy, as there is a free space at that point. Care should be taken to pass it between the cervix and head.

3. When the first blade has been adjusted to the head, its handle should be pressed well against the perineum, so as to keep it out of the way.

4. The right hand is now cleansed, and takes up the female blade, which, with the left hand, is anointed, and the fingers of the latter passed into the vagina, to guard the rim of the os uteri.

5. The female blade is then introduced upon the palmar aspect of the fingers, with the view of insinuating it between the child's head and the pelvic walls, behind the obturator foramen, and, therefore, upon the right side of the head.

6. When the second blacle is fully introduced, it should lie upon the first blacke, with the slot just opposite the pivot, and the handles being now compressed, the instrument is locked and fully applied.

How should the first blade be held at the beginning of introduction?

As the tip of the blade enters the vulva, the handle should be held nearly perpendicular, with its tip above the inner limit of the right groin. The rest of the introduction resembles the passage of the catheter in the male. 
How should the second blade be held at the beginning of its introduction?

As the tip of the blade enters the vulva, the handle should lie in the line of and almost touching the left groin. The handle is then brought almost directly to the median line, and the blade pushed onward and upward, as soon as the handle is free from the left leg.

What should be done if the instrument cannot be locked?

The second blade should be withdrawn, and more carefully reapplied. Locking can often be effected by simply pushing the handles well back upon the perineum.

How should the forceps be held in making traction?

The handles should be grasped with the right hand, and gently compressed; the left hand should be placed over the lock, with a finger upon the top of each blade.

\section{How is traction to be made?}

1. The left hand presses or pushes the blades downward and backward (and slightly to the right), while the right hand ptils the handles partly in the reverse direction and partly in the line of the handles.

2. As the head descends, the direction of traction is changed, being made in the curve of the obstetric canal at all times.

\section{How long should traction be made?}

For about a minute at a time, with an interval of the same or greater length, during which the handles should be partly unlocked, to remove the compression of the forceps from the child's head.

Should traction be made during a labor pain?

The contractions may be disregarded until the head presses upon the perineum, when traction should be made only in the absence of uterine contractions, and if the operator is not sure of his skill, he should with. draw the forceps at this point.

How may the forceps be withdrawn?

liy reversing the motion used in applying them, and with the same deliberate carc.

\section{How are the forceps applied at the inferior strait?}

The head having rotated, the blades will be on opposite sides of the pelvis, when on the sides of the head. Therefore, both blades are passerl in the same manner, and nearly as the first blade is passed in the high uperation. 
How are the forceps to be applied to an $R$. O. $\Sigma$. position at the inlet?

I'reciscly as in the L. O. A. position.

How is traction to be made in the R. O. P. position?

I. The hamdles should be grasped firmly, so as to hold the head securely while,

2. The handles are elevated, with scarcely any traction, so as to fex the he'al; this being a necessary part of the natural mechanism.

3. Traction should then be made in the axis of the eanal, and with as littic comforssion as possible, in order not to interfere with rotation.

4. If the twisting of the handles shows a tendency to rotate, this may be aided; but rotation should not be forced.

How are the forceps to be applied in the R. O. A. and L. O. P. positions?

The position of the head being the reverse of the L. O. A. and R. O. P. positions, the right side of the head is behind and at a distance, the left sicte in front, and near. Therefore, the female blade is first applied, under the right sacro-iliac arch, and in the same way as the first blacle in the other position. The male blade is then introduced in a manner corres. ponding to the second blade, in the L. O. A.

What difficulty is then encountered?

The shank of the male blade will lie oz'er the female blade, and the instrument cannot be locked.

How is this to be remedied?

Talee holl of the handles separately, and bring each handle to the merlian line and beyond, until the handle of the female blade can be lifted over that of the male blade. They will then be in position for locking.

How are the forceps to be applied on the face presentation?

In the lirst and third positions, precisely as in the vertex, first and third. In the sceond and fourth positions, precisely as in the vertex second and fousth.

May the forceps be used on any part but the head?

They have been used upon the breech, but are of doubtful utility as compared with other procelures, and not free from danger when so applicel.

What are the indications for the use of the forceps?

1. Int kituy in the sceoml stage of lakner, arising from (a) uterine inertia;

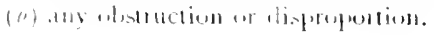


2. For delay in the first stage, rarely, as in (a) placenta previa; $(b)$ organic rigiclity; (c) absence of a natural dilating agent.

3. For rapid delivery, when required, by such complications as, $(a)$ convulsions; $(b)$ prolapse of the funis; $(c)$ excessive utcrine action menacingr rupture.

4. For secondary purposes, as for, (a) extraction of the child in the Caesarean section; $(b)$ after rupture of the uterus; $(c)$ for removal of tumors or foreign bodies from the maternal passages.

\section{What is the principal circumstance demanding their use ?}

Uterine inertia, or insufficiency of the uterine contractions to complete the labor.

How long should the second stage be allowed to continue before resorting to the forceps?

Rarely over one or two hours. It is irrational to subject the woman to long-continued pain and effort, when we can harmlessly deliver by art.

What alternatives do we possess to the use of the forceps? Version and embryotomy-

1. If prompt dclivery is indicated in any case, and we clo not possess the forceps or the skill to use them, we may employ version.

2. If the forceps fail to extract the child, or the pelvis is so deformed as to rencler their use impracticable, we may perform version (according to some authorities), or resort to embryotomy.

3. The last generation of physicians used a substitute, the victis, which is simply a single blade of the forceps. It was used to slip over the head to flex it, or by alternately pressing on one side and the other to malie traction. It can do nothing which cannot be better done by the forceps.

\section{What is version?}

\section{VERSION.}

The operation by which the presentation of the child is changed; called, also, turning.

How many kinds of version are there?

I. As regards the choice of presentation there are two-

(a) ccphalic, in which the hearl is male to present, and,

(b) podalic, in which the brech is makle to present. = . . in:-

2. As regards the mode by which it is effected, we have three-

(a) incrmal, in which the hand is prassed inte the womb to effect the change, 
(b) external, in which the change is effected by manipulation through the abdominal walls only, and

(c) bifolar, in which one land upon the abdomen and two fingers (or more) internally are used.

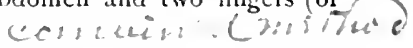

What are the indications for version?

1. To convert a transverse presentation into one of the vertex or breech.

2. When rapid delivery is required, and the use of the forceps is not feasible, podalic version is indicated.

3. According to some authorities, to render delivery easier in deformed pelves.

\section{How is internal version performed?}

I. The hand is cautiously passed into the uterus until a foot is reached and seized. As this foot is pulled down the child is turned until the breech presents. According to some, version will be easier if we seize the foot which is furthest from us. 2. The head may be seized and brought duwn in some cases.

\section{What cautions are necessary?}

1. To introduce the hand slowly and gently, lest the womb be lacerated. Inxsthesia is sometimes of service in promoting uterine relaxation.

2. Not to mistake a hand for a foot.

\section{What posture assists in version?}

When a transverse presentation is impacted the woman may be placed in the knee-chest posture, which will aid in introducing the hand.

\section{How is external version performed?}

1. Hy careful palpation we ascertain the exact position of the head and breech.

2. (Me hand placed over the head (on the abdomen) and the other over the breech, push the head and breech in opposite directions until one or the other is brought into the pelvic inlet.

This is rarely practicable after the liquor amnii is evacuated.

\section{How is bipolar version effected?}

1. (ne hand is introduced into the vagina, and two fingers made to press against the presenting part.

2. The other hand is applied on the abdomen and pressed against the heat or breech of the child, while the fingers of the other hand press the presenting part upward and to one side or the other.

This methorl slould always be tried before internal version is resorted (1), since, if successful, it removes the necessity of introducing the hand into the womb. 
Under what circumstances is version easy or difficult?

1. When there is much liquor ammii, and the uterus is uncontracted, it is easy of performance.

2. When the liquor amnii has drained away for some hours, when the womb is tonically or tetanically contracterl, and when the child has been dead long enough for post-mortem rigidity to supervene, it is difficult, and sometimes impossible.

When version fails in a transverse presentation, what alternanative operation have we?

Enbryotomy.

\section{EMBRYOTOMY.}

What is embryotomy?

The operation by which the size of the child is reduced by cutting and mutilation. It is now restricted to mutilation of the body; when applied to the head it is called craniotomy.

What are the steps in performing embryotomy on the transverse presentation?

I. An assistant places his liands on the abdomen and presses the child downward, so as to steady it.

2. A perforator is introduced into the vagina, and made to perforate the chest, and to divide several ribs. Care should be taken to guard the sharp edges of the perforator with two fingers, while introducing and using it.

3. A blunt hook, crotchet or other instrument, is introduced into the chest through the perforation, and the viscera broken up and removed piecemeal. This is called evisceration.

4. The body may then be doubled up and drawn down by a blunt hook or embryotomy forceps.

5. In a few cases it is necessary to decapitate the child before it can be extracted. This may be done by instruments invented for the purpose, or by improvised methods, if the operator is ingenious.

What is craniotomy?

The operation by which the head is lessence in size.

I. The head is pressed down and steadied by an assistant.

2. The hearl is perforatel.

3. The lrain is broken up completely, and if necessary removed by syringing out the cranial cavity.

4. Traction is made upon the head by a finger hooked into the perfora- 
tion, by craniotomy forceps, or by any suitable instrument, and the head collapses, and is drawn out. If not sufficiently reduced in size by these stcps, we proceed to cranioclasm.

What is cranioclasm?

The operation by which the vault of the cranium is removed.

I. Craniotony is performed as above.

2. The cranioclast (or craniotomy forceps) seize an edge of bone at the perforation, and wrench off as large a piece as possible, which is then cautiously withdrawn. This is repeated until the vault of the cranium is removed.

3. The head is then tilted, so that the craniotomy forceps can seize the face, and the thin base of the skull is drawn down through the pelvis.

What cautions are necessary?

1. To preserve the scalp, so that the sharp edges of bone may be covered while it is withdrawn. Therefore, the scalp is to be dissected up before using the cranioclast, and its blades placed, one insicle the skull, and the other between the scalp and outside of the skull.

2. To guard the edges of fragments of bone with two fingers while withdrawing them.

If even the base of the skull is too large to pass, what alternative have we?

Cephalotripsy, in which a powerful pair of forceps (the cephalotribe) is applied, and matle to crush the base. Cephalotripsy may also be used before resorting to cranioclasm.

\section{CAESAREAN SECTION.}

\section{What is the Cresarean section?}

Gastro-hysterotomy, or the removal of the child through an incision marle in the abrominal walls and uterus. It is sometimes incorrectly applied to simple gastrotomy (laparotony) after rupture of the utcrus.

What are the indications for the Cæsarean section?

1. A pelvis contracterl to two inches in the conjugate, or obstructed by tumors, or other insumountalule olsstacles to delivery by the natural way.

2. For the rapid delivery of a supposed living child after the death of the mother. (bilatien have been saved when the mother has been dead 1., more than an homs. 
What are the steps in the Crsarean section?

1. The woman is prepared by anesthesia and the emptying of the bladder.

2. The operator stands by her side, with his face toward her feet, and begins to make his ineision near the symphysis. (To avoid eutting early into the placental site.)

3. An incision is made, layer by layer, in the linea alba, from near the pubes to the umbilicus, and, if necessary, continued further up, and to the left of the navel.

4. The womb is eautiously incised.

5. The ehild's feet are grasped, or the head seized by forceps, and the ehild extraeted.

6. The afterbirth is delivered.

7. The uterine incision is elosed by a few sutures. 20

8. The abdominal eavity is earefully cleanserl of all blood and fluids.

9. The abdominal ineision is closed by suture.

What is Porro's method?

A modification of the Cesarean section, in which the uterus is removed after the child is delivered, and the stump treated as in ovariotomy.

\section{What is gastro-elytrotomy?}

A modification of the Cexsarean seetion, in which the vagina is opened instead of the uterus, thus escaping the risks of opening the abdomen.

I. An incision is made parallel to and just above Poupart's ligament.

2. When the peritoneum is reached it is dissected up until the fingers reach the upper end of the vagina.

3. A small incision is made into the vagina, and enlarged by tearing with the fingers (to prevent hemorrhage).

4. The os uteri is hooked into this incision.

5. The ehild is turned, or the foreeps applied, and extracted through this opening.

6. The upper wound is closed by suture.

It is difficult to avoid injuring the bladder, and the entire operation demands great skill.

\section{What is symphyseotomy?}

The section of the symphysis pubis, for the purpose of pulling open the ossa innominata and enlarging the pelvic eavity. It is called also the Sigaultian operation, after its inventor $(1777)$. The operation was thoroughly tested when first introduced, and alandoned beeause it dit not materially increase the effective diameters and dicl inflict injury, sometimes irreparable, upon the mother. Its recent attempted revival is lue to a craving for notoriety. 


\section{INDUCTION OF LABOR.}

\section{What is the induction of premature labor?}

The operation by which labor is lorought on at any time before full term.

\section{What are the indications for its performance?}

I. In deformed pelves, a child may be clelivered alive if labor is induced at seven or eight months of pregnancy, which would have to be sacrificed by craniotumy if allowed to develop until full term.

2. If the mother's life is endangered by vomiting, convulsions, or other causes, the operation is sometimes performed.

\section{How is the operation conducted?}

(Barnes' method). I. Pass an elastic bougie six or seven inches into the uterus; coil up the remainder of the instrument in the vagima, to keep it in place. Do this in the evening.

2. Next morning proceed to dilate the cervix by Barnes' (or, Molesworth's) dilators, until it will almit several fingers.

3. Kupture the membranes and reapply the dilator.

4. Allow the natural efforts to complete delivery, or use the forceps or version.

5. (Thomas). Pack the chill in cotton or wool as soon as born, and maintain a suitable temperature by artiticial heat, applied in various ways.

\section{THE PERIOD AFTER DELIVERY.}

\section{What is the period after delivery called?}

The lyins-in period, the puerperal state, or the period of involution, because after labor the uterus undergoes the process of involution.

\section{What is involution?}

The process by which the womb returns to its original size and condition. The tissues of the womb undergo a form of fatty degreneration. As the products of this change are partly alsorbed and partly transuled ant discharged from the body, the structure of the uterus becomes conlensed until it has becone nearly of the same size and conclition as before pregnancy. 'The same change takes place in all the structures (ligaments, etc.,) enlarged by pregnancy.

How long a time is required for this process?

by the tenth day the womb is so climinished as to lie entirely within the pelvis, and the funclus is not to be felt above the inlet. After this, involution combinues at a sluwer rate, being completed in about six weeks. 


\section{What irregularities are met with?}

I. Sub-involution; it may be protracted by intlammation or other concurrent disease, and remain permanently enlarged, or for a long time.

2. Sufer-inzolution: it may be rapid and excessive, leading to atrophy of the womb; but this is very rare.

What outward or clinical manifestation of involution exists?

The lochia (plural), or lochial thow ; or, popularly, the flow, or cleansings.

\section{What are the lochia?}

The "flow" is the discharge from the uterus and vagina which occurs after labor, and, to some extent, until the womb is completely involuted.

\section{What are its properties?}

It is a rather thick, albuminous fluid, containing oil globules, epithelial cells, blood corpuseles, and granular debris from the uterus. During the first day after labor it is of a red color, from the presence of blood in excess (or it may be blood alone immediately after labor). This may continue for several days, especially if any clots have been retained in the uterus, after which it becomes straw-colored, and finally clear and culor. less.

\section{What is the nature of the lochial fluid ?}

It is an excrementitious product, and readily decomposes at the temperature of the lody or a little higher. If retained and reabsorbed it may poisun the blood, as any other excrement, thus causing septicimia.

\section{What is the amount of the lochia?}

At first varies from one-half ounce to several ounces per diem. It is gralually diminished, and after the tentls day is scarely perceptible, being little more than the natural secretion of the parts.

\section{What is the normal condition as to health after labor?}

The majority of women feel in good health, being only a little tired and sore, and in a few days feel competent to arise and resume their avocations.

\section{Should they be permitted to do so?}

No. liest and 'puiet are essential, to guarl against the dangers inciclent to this period.

How long should the woman be kept in bed and at rest?

Until the womb has retreated within the pelvis, and not allowed to work until involution is complete. before this, the womb is enlarged and sofened, and is sulject to displacements and flexions. 


\section{What physical peculiarities are noted in this period?}

I. The pulse becomes slow, falling to 60 beats per minute, or less.

2. The temperature is elevated from $.5^{\circ}$ to $x^{\circ} \mathrm{Fahr}$.

3. The skin is more active and perspiration more free.

4. The urine is increased in amount.

5. The bowels are constipated.

6. The breasts secrete milk.

\section{How soon after labor is milk secreted?}

To a slight extent during pregnancy, and some is to be found in the breasts just after labor. But the secretion is not fully established for from thirty-six to seventy-two hours, beginning suddenly in some and gradually in others.

\section{What is the nature of milk?}

It is an emulsion of oil globules in an albuminous fluid, containing salts in solution. When of good quality it is rather thick (a drop adhering to the finger nail when inverted), of a bluish tinge and sweetish taste. The milk found in the breasts just after labor differs from the sulisequent secretion, in being richer in fatly matters and slightly purgative to the chilı. It is called colostrum.

\section{What is weid, or milk fever?}

An irritative fever, lasting from several hours to one or two days, and occurring in women in whom the secretion of milk is sudienly established. It is due to reflex irritation, from the sudden development of secretory changes in the breasts. Clinically, it is distinguished by a sudden rise in temperature, precelled by a slight rigor and followed by free diaphoresis, and camot be distinguished from an attack of intermittent fever, except by its nun-recurrence.

\section{What rules should be observed concerning lactation?}

I. Juring the first month the baby should nurse REGULAR LY, every two hours during the day and once or twice at night; during the next month the intervals may be lengthened to three hours, and afterward to four hours. Observance of this rule will save much trouble.

2. The nipple should he clean, drawn out and erect, when offered to the child, especially at first.

3. After mursins, the nipple slould be washed and dried, and, if tender, batherl in whiskey or some astringent wash.

4. If the breants are large and pendulous they should be supported by a hamlare whenever the woman is in the upright posture. 


\section{What attention does the urine require after labor?}

Retention is apt to occur after long labors, from temporary paralysis of the bladder and urethra, from pressure. The catheter should then be passed, within twelve to twenty-four hours after labor, and, if necessary, twice daily, thereafter, until recovery. Ilot cloths are also useful when the retention is due to local swelling and spasm.

\section{How should the catheter be passed in the female?}

I. Place the woman on her back, with the knees drawn up.

2. Introduce a finger into the vagina.

3. Partially withdraw the finger until its tip arrives at the end of the vagina.

4. With the other hand pass the catheter along the finger to the tip, immediately above which is the meatus.

If this fails, the meatus must be sought for by the tip of the finger, which is to be depressed as soon as the catheter arrives at the vestibule.

Do not try to pass the catheter by the sense of touch alone, if not promptly successful, but remove the bed clothes and look for the meatus.

\section{What attentions do the bowels require after labor?}

Owing to the constipation, it is usually necessary to give a purgative on the third or fourth day after labor. This will not be needed if the bowcls move spontaneously, and if there seems to be a slight inclination to a movement, an enema will be preferable.

What rectal difficulty is common at this time?

Hemorrhoids. These should be carefully replaced if extruded, after labor, and during convalescence an attempt may be mache to cure them by medication (Barker's pills).

\section{What diseases are especially liable to occur in this period?}

The lying-in woman is hable to septicemia, peritonitis, and pelvic inflammations, thrombosis, phlebitis, pyrmia, and mastitis.

\section{What is puerperal septicæmia?}

I. A fever produced by the absorption of septic matter into the system (Playfair).

2. It may occur in a severe and acute form, or in a mild and subacute form.

3. It is often associated with inflammations, by which its course is greatly modified.

4. The various conılitions resulting from the union of septiciemia and inflammations are grouped by some under the name of puerperal fever. 


\section{What are the causes of septicæmia?}

1. Silfinfection, from,

I. Retention and decomposition of bits of placenta, or membranes, or clots.

2. Retention and decomposition of the lochial discharge.

3. Non-xcretion of the lochial discharge, which, being an excrement, poisons the blood if not eliminated (auto-sepsis of barnes).

11. Infection from without, by

1. Septic matter conveyed by the physician or nurse.

2. Erysipelas, scarlet fever, diphtheria and the zymotic fevers, may originate it.

\section{What are the symptoms and course of acute septicæmia?}

I. Slight chilliness; no rigor, unless complicated by inflammation.

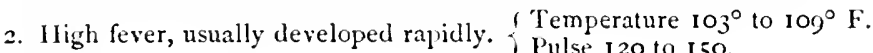

\{ Pulse 120 to 150.

3. No pain or slight tenderness in hypogastrium.

4. Suppression of the lochia or a fetid discharge in some cases.

5. Hind usually unimpaired, and the patient either cheerful or indifferent.

6. Face anxious.

7. The typhoid statc usually precedes a fatal termination, which occurs within a week, unless recorery takes place.

What are the symptoms of chronic septicæmia?

1. The patient remains weak, and has little appetite.

2. The tongue is pale and flably, and lightly coated, if at all.

3. Slight fever, of intermittent type, is prenent.

4. The urine is high-colored, and constipation exists.

How is septicæmia influenced by peritonitis and other inflammations?

1. The symptoms of peritonitis, and other inflammations (metritis, cellu. litis, etc.) are but little different in the puerperal period and at other times, and in all, except peritonitis, a mere mixture of symptoms is present when occurring with septicrmia.

2. In peritonitis with septicemia, the septic symptons predominate, and a remarkable difference between the pulse and temperature rate is observel.

The pulse is frequent, 120 to 150 , while the temperature is slishtly elevates, or even subnormal.

The abdomen is tympanitic, yet the patient complains little of pain. 
What are the indications for treatment in acute septicæmia?

I. Antiseptic injections. These should be made into the uterus, and any retained fragments of placenta, etc., removed.

2. Whiskey alministered with a frec hand.

3. The salicylate of soda or potassa, and quinine, are also useful in full doses.

\section{How are antiseptic injections to be given?}

1. The material to be injected may be (a) a two per cent. solution of carbolic acid; (b) tinct. jodine one-fourth, to water three-fourths; (c) corrosive sublimate one part to 1000 or 2000 of water. Each of these has its adrocates, and there are others less used.

2. A tule attacherd to a syringe is to be carried into the uterus. (A flexible catheter without its stylet will do very well).

3. The fluil is then to be injected without force, and care taken that the os uteri is kept open, so that fluicl can get out as rapidly as it gets in.

4. Continue the stream until it comes away clear.

5. Lse every few hours, or often enough to keep the uterus free from putrescible matters.

What are the indications for treatment in chronic septicæmia?

I. Antrsptic injections, if there is any reason to suspect the retention of putrescible materials in the uterus.

2. To improve the action of the excretory apparatus by such agents as calomel, ipecac, and saline laxatives.

3. The salicylates or quinine, in small doses.

What are the indications for treatment in inflammations, complicated with septicæmia?

The septicumia is to be regarderl as the chief trouble, and the inflam. mation combated as a secondary matter.

What is uterine thrombosis?

The formation of clots in the uterine sinuses, due to imperfect contrac. tion of the womb after delivery.

\section{What results may follow from thrombosis?}

I. Hetachment of fragments, and formation of emboli in other structures, as in the lungr, hrain, etc., learling to inflammations in the ohstructed organs and metastatic alscesies.

2. Jurulent liquefaction of the thrombus and subse puent escape of pus intor the circulation, causing pyemia.

3. Extension of the thrombus into consecutive veins, causing phletitis. 


\section{What is phlegmasia alba dolens?}

Also called " milk leg," is an inflammation of the cellular tissue of the thigh and leg, usually associated with femoral or crural phlebitis. Thrombosis of the vein may precerle or cocxist, but is not always present.

\section{What are the symptoms of "milk leg?"}

It begins usually in the secont week, with-

I. Irregrular chilliness and malaise for several days.

2. Pain in the leg and abdomen, of a Iragsing character.

3. A distince rigur, and swelling of the leg.

4. Fever of a remittent type, changing to intermittent as recovery advances, or becoming continuous in grave cases.

\section{What peculiarities attend the swelling?}

r. The slin is white and tense.

2. A red streak marks the line of the vein when phlebitis is present.

3. Later, the vein feels like a hard cord when palpated.

\section{What are the results of "milk leg?"}

I. It may end in crmplete resolution.

2. An aliseess is formed alonis the vein, and lischarges.

3. Gangrene and septicamia may be developed.

4. If thrombosis is present, emboli and yicmia may occur.

In all cases recovery is slow, and the leg is apt to remain weak and become cedematous, from permanent olstruction of the vein. 3 i:

\section{What is the treatment indicated in " milk leg?"}

I. To control inflammation.

2. To relieve pain.

3. T'o support the patient's strength.

The lirst can be best effected hy the use of atropia, in a one per cent. solution, applied to the parts with a cloth, or by belladonna ointment. Wam fomentations are also useful, and a lotion of learl water and laudanum, applied warm, is also useful in relieving pain. Anoclynes may be given as neeterl. Absolute rest is cosential. If an alscess forms it may le evacuated, and applications of tinct. iodinii are useful in promoting resolution.

\section{What is mastitis?}

Inllammation of the lareast. It is divicled into: r. Ciandular; 2. Interstitil. and 3. Sub-glamelular. In the lirst the lobules of the gland are

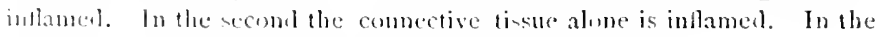
thin the connective tisste leneath the ghand is involved. 


\section{What are the symptoms of mastitis?}

I. In interstitial and sub-glantular mastitis the symptoms are those of abscess in the cellular tissue anywhere; slight constitutional disturbance, except in large sub-glandular abscess, and the pain is not increased by suckling the child.

2. In glandular mastitis there is a rigor and high fever, preceded by a hard lump in the lreast, and suckling causes severe pain.

\section{What is the treatment of mastitis?}

1. When the connective tissue is involved suppuration is almost inevitable, and is to be treated on general surgical principles, poultices and early incision being usually indicated.

2. In glandular mastitis various measures have been employed; massage or stroking, rubbing and knearling the breast; endearoring to empty engorged milk simuses, and to remedy the bluod stasis. An ice bag is strongly recommended; also compression by strapping with arlhesive plaster, or with a plaster-of-Paris dressing. To rirectly affect the blool supply and functional activity of the gland, belladonna is used, in. ternally and externally. The sulphide of calcium internally, and iolide of lead externally, are used, and many other remedies have adrucates.

In all cases the breast should be suspended in a sling. When incisious are necessary they should be marle in a line radiating from the nipple, to avoid severing milk ducts.

\section{What are the chief causes of mastitis?}

Coll, ubstrnction of milk ducts, septicemia and sore nipples.

\section{What affections of the nipple are met with?}

The nipples may le simply tender, or inflamed, with resulting abrasions. excoriations and fissures. The inflammation may be simple, aphthous or ečematous.

\section{How are sore nipples to be treated?}

I. Stop suckling, and have the milk removed ly a pmmp or massage.

2. Apply astringent remedics, or such as act ly excluding the air. The best applications are tannin and glycerine, tinct. lenzoin, collodion; lut all treatment will be uncertain if the child is allowed to nurse while the nipple is sore.

\section{What are agalactia and galactorrhœa?}

I. Agalactia is a suppression or greatly diminished flow of milk. The secretion of milk may be augmented by free use of Muils, especially milk. Attention to the greneral licalth is important. 
2. Cialactorrhra is an excessive secretion of milk. This may be remedied by the use of coffec and belladonna. The name is sometimes used to denote incuntinence of milk from want of muscular tone in the nipples. This is to be treated with astringents.

What are the principal congenital defects in the child which require attention?

llare lip; imperforate anus or turethra; spina bifida; elub-foot; cephal. hamatoma; patulous foramen ovale.

\section{What general rules are applicable to these affections?}

I. Hare-lip is to be operated on at once, if it interferes with suckling; otherwise we may wat a few months, until the child is stronger.

2. Imperforate anus and urethra are to be operated on at once.

3. The treatment of other malformations should be begun as soon as practicable.

\section{What is a cephalhæmatoma?}

A swelling upon the parietal bone, consisting of bload effused uncler the periosteum. It legins usually within an hour or so after birth, and is important only in that it may be confousded with a caput succedaneum.

\section{How is the diagnosis made?}

In cephalhematoma the swelling never extends beyond the edges of the parictal bone. Aspiration will show that the contents consist of blood, which is very finely clotted, and which remains fluid. The cephallianatoma becomes larger as the effusion dissects up the periosteum, ant the edges are sharply defined, giving the impression that the skull is fractured.

\section{What treatment is indicated?}

It dees best when left alone; if the swelling is great, an incision may be necessary, to rclieve tension. The only danger is from irritation of the scalp and erysipelatous inflammation. It gencrally disappears after four or five weeks.

\section{What is a patulous foramen ovale?}

A failure of the foramen in the auricular septum to close after lirth. Hence the blom is divented from the lungs. The child is sulject to spells of partial asphyxia (rarely continuous) and the face becomes dusly or livirl ; hence the mane a "blue child."

\section{What is to be done?}

Treatment by posture; the chill is to be kept on its risht sille, that the action of sravitation may hinder the escape of the blood through the frianen. 


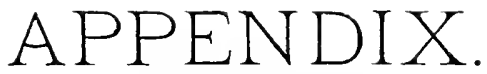

believing that the common statements as to the mechanism of lalwn are erroneous in fact, and that the proper study of the pelvis throws light both upon the cause and nature of the mechanism, the author has added his own teaching in an appendix. The mechanism of the L. O. A. position alone is given; the changes required in the statement of the other positions being sufficiently obvious.

How is the pelvis arranged to permit the head to pass?

It contains two canals, each of the same outline or calibre as the fretal head, and a little larger. These canals are partly divergent above and entirely identical at the outlet.

How may this be demonstrated?

In Fir. 16, the ellipse A D B C represents the ontline of the fretal head, and the ellipse F B D F is another identical outline. But, disregarting the dotted lines, the figure A D B F represents the outline of the pelvic inlet.

In Fig. I7, the outhine represented is that of the fetal head, and also that of the pelvic outlet.

If we combine these two figures as in Fig. Is, and draw lines to indicate the pelvic walls, we see that there are two canals in the pelvis, as have been defined, in either of which the head may enter and be propelled.

\section{How is this clinically shown?}

In the great majority of labors the head enters the pelvis with its long diancter conciding with the right oblinue dianeter (a line drawn from $A$ to 1 , in Fig. I6), and when it reaches the outlet its long diameter coincides with the conjugate diam. eter of the ontlet (a line drawn from $J$ to 1 ), FIg. I6.
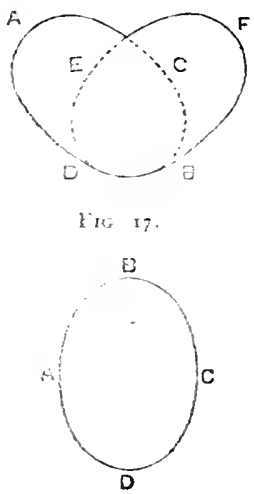

FIG. 18 . lïg. 17 ). 


\section{What are these canals named?}

The one containing the right obligue diameter is called the right canal;

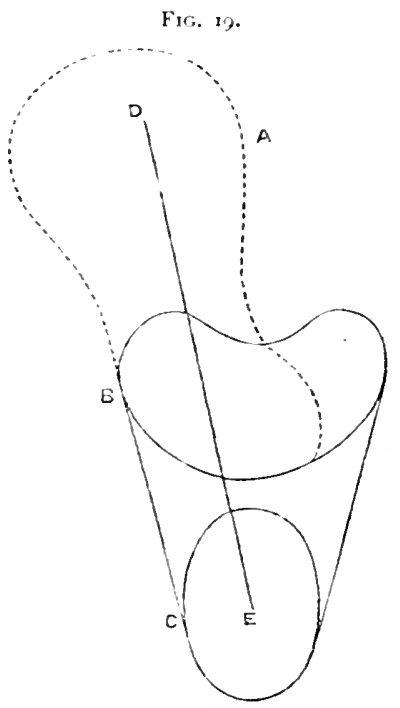
the orposite one the left canal.

Why does the head enter the right canal in the majority of labors?

lecause the uterus does not lie in the median line, but with equal frequency its axis is to the right of the merlian line, as in Fig. 19.

What is the initial plane of the right canal?

$\Lambda$ plane passed through the ileopectineal line of the right side, from the promontory to the symphysis, and continucd until intersected by a similar plane on the opposite side (the initial plane of the left canal).

\section{What appearance does the pelvic cavity present on an antero-pos- terior section?}

A simple curved tube, which shows $A=$ the Uienss. $\quad B=$ the Inlet. $\quad C=$ us that the pelvic canals are curvel as she Gutler. If Ethe Axis followed by well as divergent, and hence their axes
the ticad in habor (rememlering also that it is curved from before backward). are sfiral.

FiG. 20.

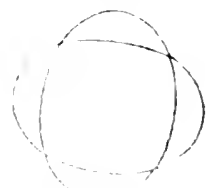

Why are there two canals in the pelvis?

'To permit the shoulders to follow the head with the least amount of space.

\section{How may this be demonstrated?}

I. The oulline of a section through the shoulders is almost illentical in shape and size with the ontline of the occipinto-frontal plane of the head, hut with its long diameter at right angles to the long diameter of the head (1.ivg. 20).

2. The formen magnum (and attaclment of head to neck), being nearer the aceipital end of the head, the shouklers follow the head in labor, as in rigs. 21.

3. While the lodly of the child is in the womb, with its long axis coinciclunt with the axis of the womb ( see lig. 19), the head is engaged in 
the pelvis horizontally, or in other words the head is thexed laterally toward one shoulder, causing the outline of the shouluers to follow the head, as in Fig. 22, which is also the ontline of the inlet.

4. The shoulders enter the opposite canal, but before descending far the head is already born, and there is need of but one canal, except near the inlet.

How is the head situated at the beginning of labor in the L. O. A. position?

The occipital protuberance is placed opposite a point a little in front of the left acetabulum; the bi-frontal suture opposite the right sacro-iliac symphysis; the right parietal protuberance just over the right obturator foramen; the left parietal protuberance is in the free space in front of the left sacroiliac symphysis.

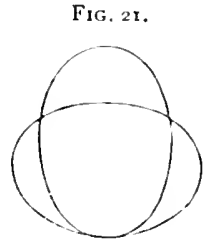

Fig. 22 .

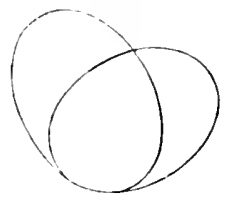

How may this be expressed by a comparison of pelvic and head diameters and planes?

The occipito-frontal diameter is coincident with the riglit oblique diam. eter, the occipital end being in front ; or the occipito-frontal plane is coincident with the initial plane of the right canal.

What follows from this as to the obliquity of the head?

The right side of the head is lower than the left, and the occipito-frontal plane is obliquely situated with reference to the plane of the conjugate diameter or of the inlet.

What is the mechanism of delivery in the L. O. A. position?

I. The head undergoes a compound movement of fexion and synclitism. This brings the two silles of the head upon the same level, namely, in the plane of the inlet, and substitutes either the plane of complete flexion or demi-flexion for the occipito-frontal plane.

2. The head then descends flexed, and a movement of rotation occurs during descent, whereby the long diameter of the head comes to be coincident with the long diameter of the outlet by the time the hearl has reached that point.

3. The hearl passes over the perincum by a movement of extension, and is then born.

4. As the head passes ont of the vulva, the shoulders, engaged in the left canal, go through a similar meclianism of rutation during descent. 
Hence, when the head is born, its occiput turns to the left, which is called restitution.

\section{What is synclitism?}

A lateral flexion, or the movement by which the head is made level with the plane of the inlet.

\section{What is the cause of synclitism?}

The whole right side of the hearl, and particularly the right parietal protuberance, is closely applied to the pelvic walls, while the left side is free. The uterine contractions, therefore, are resisted on the right side of the head, while the left side, being free, is moved downwarl. This movement is comparatively unimportant, and may not occur if the head is small or the pelvis large.

\section{What is the effect of flexion?}

To present a smaller outline of the head to the pelvic canal; it will therefore be great or little, accurdling to the tightness of the fit of the head and pelvis.

\section{Why does the head rotate during descent?}

lecause it is descending in a spiral canal exactly fitted to its calibre.

\section{Why does extension of the head take place?}

When the head has reached the pelvic outlet, it has gone as far as it can, without the body entering the pelvis and following it. The hingelike arrangement of the neck now allows the head to pass over the perineum by this movement, without further descent of the body.

How may we recognize the occurrence of flexion and synclitism?

At the beginnins of labor the posterior fontanelle is at or above the pelvic brim, and barely accessible to the finger. The right branch of the lambloidal suture is on a line with and parallel to the inlet at the symphysis.

As the uterine contractions continue, we may observe the fontanclle becoming lower and more accessible, while the lambdoidal suture becomes more oblifue. Neantime the central part of the head has not descended.

This is lirect proof that the head has lecome flexed and leveled.

\section{How may we recognize the occurrence of rotation?}

At the beginning of labor the posterior fontanelle is found well upon the left sile; when the heal has reached the outlet it will be in the merlian line. 
How may we recognize the occurrence of extension?

When the heat has reached the outlet, the posterior fontanelle remains nearly stationary uniter the sub-pulic arch, while the forehead, face, ctc.. sweep over the perineum.

What movements do the shoulders and body undergo?

After the descent of the heal, the shoulders enter the left canal with the right shoulder in front and to the right. 'They descend, rotating, until at the outlet the right shoulder is directly in front. They may then emerge together, or, as is more common, the right shoulder remains stationary unler the sub pulic arch, while the left sweeps over the perineum, and is born first. The whole body follows the same course as the shoulders, ani being smalier, is rapidly expelled as soon as they are free. 
1 


\section{INDEX.}

ADOMEN ENLARGED PAGE

A 1 flattencd....................... $4^{3}$

Abdominal muscles, action of........... 57 pregnancy ........................ 36

Abortion, catses of....................... 39

- dangers.............................. 40

- treatment.......................... 40

After-birth.................................... to

delivery of............................. $5 \mathrm{~s}$

After-pains................................. 57

Agalactia................................. 109

Albuminuria in pregnancy................ 47

- eclampsia.......................... 88

Allantois................................... 30

Amnion .................................... 30 - water of ........................... 33 dropsy of ....................... 78

Anasthetics in labor........................ 54

- eclampsia......................... 87

Anchylosis of fretal joints................ 77

Anteversion .............................. 47

Antineptics............................... 107

Apoplexy of placenta....................... 39

A reola..................................... 28 changes in ......................... 43

Articulations, pelvic ...........................

Asphy xia ...................................... 56

Atresia of os uteri .......................... $7^{2}$

Attentions to the nother.................. 57

— to the child .......................... 56

BAG OF WATERS................ 51

Balluttement ...................... 43

Bandatge, after labor......................... 57

l3andl's rinet.............................. 86

Partbolin, gland of.......................... 21

l:attledore placenta....................... 9n

Verl, how prepared......................... 54

Finder, obstetric........................... 57

Pipnlar version............................. of

blastodermic layers....................... 30

I'lood, alteration in pregnancy....... $4^{1-45}$ circulation in foetus............... 32 transfusion of ........................ 85

blood-lettins................................. $\delta_{i j}$

Brody of Kosemialler..................... is

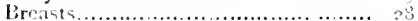
changes in ....................... 4 ?

- inflammation of ..................... 1 8

Breech presentation........................ 59.6 7

liregma, vile liuntanclle................

lirim of pelvis........................ is
P'ACE

Broad ligament.......................... 18

Brow presentation ......................... 66

lirown line, median..................... 12

CAESAREAN SECTION......... I.

Cimals of the pelvis................ it

Caput succedaneum..................... 57

Caruncule myrtiformes ................. 2 I

Catheter, mode of introducing......... 105

Caul........................................ $7^{5}$

Cephalhæmatoma........................ 1 10

Cephalic version......................... 97

Cephalotribe............................... 100

Cephalotripsy ............................. roo

Cervix.................................... I6

Crigidity of ......................... $7^{2}$

Child, congenital defects.................... 1 10

Cattentisns to..................... 56

Chill, during labor........................ 55

- after labor......................... 57

Chloasma ...................................... is 45

Chloral ................................... $7_{1}, 89$

Chloroform, vide Anasthetics.......... 54

Ghorion .................................. 30

- villi of............................. 30 cystic degeneration............... 36

Circulation in fretus........................ 32

Clitoris.................................... $2_{22}$

Coccyx................................ 10

Colostrum .............................. 104

Commissures of vulva..................... 22

Conception................................ 28

Confinement, to predict.................... is

Congenital defects ...................... 110

Conjugate diameter of inlet............. 14

- diameter of outlet................. It

- diagonal.................................. $7^{6}$

Constipation............................... 45

Contractions of uterus .................... 4)

C hour-glass...................... 72, g0

Convulions ............................. 79

Cord, umbilical, vide Funis.............. $3^{\mathrm{I}}$

Corpus lutenu........................... 25

Cramps ................................. 55

Cranjoclasm............................. 100

Craniotomy ............................ Ioo

Credé, method of .......................... 57

Crotchet............................... git

Decapitation of foetus ivo l)ecidua, retlex.................... 31 serotinit.......................... iz

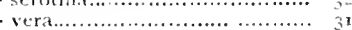


1) furingies uf Irelvis .

Thelivery, mecthuism of ................... 72

— atublor's statement............... rit

Hianteters of petris...................... I $_{3}$

- of fortat head .................... 6 o

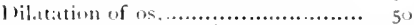

bisplicement of uteris.................. \&7

- of os mteri ......................... 72

bistention, lines from..................... 42

I) unl,le uterus ......................... Iy

boumlats cul de sac.........................

1) ropsy of ammion...................... $7^{3}$

luctus arterionms....................... 33

Wenosus............................ 33

Duratiost of labor.......................... 52

- of pregraticy................. 48

1) nties of the fllyysicitn............. 55,57

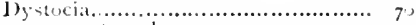

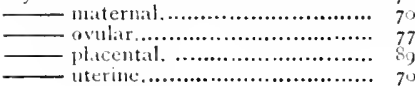

FCLAMP $=I A \ldots \ldots \ldots \ldots \ldots \ldots \ldots, \delta_{7}$

lilectricity $\ldots \ldots \ldots \ldots \ldots \ldots \ldots \ldots \ldots, 37,85$

Embryotony.............................

limpliy $>$ ema if neck....................... 02

Endonietim........................... 17

Enena in labor........................ 54, 105

Episiotumy................................ 56

Ergot .................................. $7^{2}$

Eustalchian valve........................ 33

livisceration............................. 99

Fvolution, spontaneous................... 69

Fxaminations, in lator.................. 53

I.xpression of clitd....................... $7^{1}$

F. of placenta ........................ 5I

Fxternal organ $\ldots \ldots \ldots \ldots \ldots \ldots \ldots \ldots \ldots \ldots$ 2I

Extra-uterine pregnancy................ 36

Face presentation.

Fallopian tubes.............................. In

Fecundation................................. 28

l illet ..................................... 6

Fetus, diameters of ..................... 60

- dimensions of.......................... 33

- frowtl of ......................... 33

- muvements of.................... is

- untrition of ...................... $3^{2}$

- respiration of.................... 32

- proyraceus ........................ 35

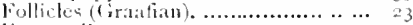

Furtituelles.............................. 51)

Furamen oliturator....................... is

- ovite............................ 33, irm

Forceps ................................... (1)

when to apply................. y $3^{-1 y 7}$

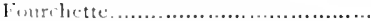

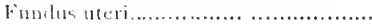

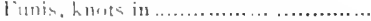

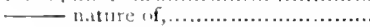

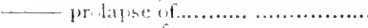

— ittiture of..........................

-

7 ')
IAC.E

Funis, to tie............................. 56

- souffle ef.......................... +3

Funnel-blatped petris..................... 75

GALACTORRHCEA............... 109

Gastro-elytrotomy................. 1ut

Gastro-hysterutomy...................... 100

fiastrotomy............................. 10u,

Germinal vesicle and spot.............. 23

Ciclatin of Wharton..................... 32

filands of vagina.. ..................... 20

- vulvo-vaginal ................... 21

if uterus.......................... 17

Graafian vesicles.......................... 23

HEAD, FCETAL, DIAM-

1 eters of ......................... 60

Head and font presentation.............. 70,80

llead-fucking of twius ................... 80

Heart, somds of fortal................. +3

Ilenurrhage, accidental................... 8 is

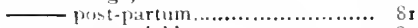

- unatroudable......................... $8_{4}$

Hemorrhoidi.. ............................ ws

1 Jertia.................................... 75

Hour-glass contraction..................... gn

- ante-partum ..................... $7^{2}$

Hydatiform mole.......................... 38

Hydatid pregnancy..................... $3_{3} 8$

Hydrami.l.............................. 47

Hydrocephalus........................... 79

Hydrop annii ............................... $7^{8}$

Hydrorrlica .............................. 38

Hydrothorax............................. 79

Hymen. .................................... $2 \mathrm{~J}$

TLIUM $\ldots \ldots \ldots \ldots \ldots \ldots \ldots \ldots \ldots \ldots \ldots$ io

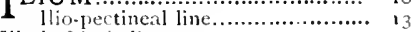

Ilik-ischiatic line........................ 13

Induction of labor ..................... I02

Inertia of womb .......................... $7^{\circ}$

Injections, antiserptic.................... I 7

Inlet of pelvis ......................... 13

Intestine distinguislied from funis..... $7^{8}$

Intr.tuterine injections................. 107

Inversion of uterus...................... gi

Iotine, hamostatic....................... $\delta_{5}$

- antiseptic........................ 107

Ischium................................... 10

KRISTELLER'S METHOD... 7r $^{\prime}$

Kyphosis........................... 75

I ABIA MAJORA.................. 21

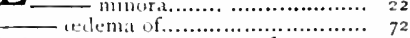

fabor, determining cause of............ 49

- duration of....................... 52

- mechanism of ........................ 58

— pains ............................. 50

- phemonemat of ................... $55^{-5}-55$

- premature ....................... 3)

- incluction of .................... $1+12$

— ctitgtes of ......................... t9

1.efcraturl of cervix.................. 84,85

— of perinewm. ................. 55, 92

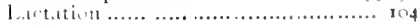


PAG:

Lapa rotony......................... 86, r

Liganents of pelvis.................... 117

L of uterus........................ 18

Lincex albicantes...................... 42

Linc, brown ........................... $4_{2}^{2}$

Ilio-pectincal................... I $_{3}$

Liquor ammi........................... 33

Iithopation.......................... 35

Lochia............................... 103

Lying-in period....................., 102

MAMMARY GLAND.............. 28

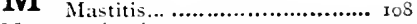

Meatus urinarius....................... 22

Meconium............................... 34

M Iechan ism of Iabor..................... $5^{8}$

Membranes, rupture of ................ 55

- premature do............... $7^{1,77}$

wwisting of .................... 52

Menopause............................. 27

Menstruation ........................... 25

- cessation in pregnancy ......... +3

Mill. vicarious ........................ 27

nterine...........................

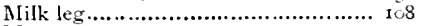

Miscarriage............................... 39

Mlole, fleshy ............................. $3_{3}^{8}$

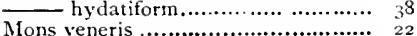

Monst rosities.............................. $\delta_{\mathbf{I}}$

Morning sickness ...................... 45

Motions of child.......................... 44

Multipara .............................. $5^{2}$

Myrtiform carumcles.................. 2I

NABOTHI OVULA................... I8

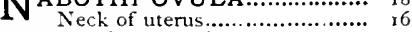

- emphysema of..................... $9^{2}$

Nerves of uterus.......................... 17

Neuralgias in pregnancy ............... 45

Nipple .................................. 28

Ny+men diseases of ......................... 109

Nymphæ...................................... 22, 27

\section{OBLiquity OF THE}

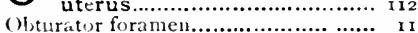

Occipito-anterior......................... 6r

Occipito-posterior .......................... $6_{1}$

Udontalgia ............................. ${ }_{4} 6$

CEdema of cervix..................... 73

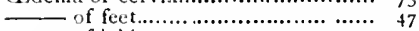

$\longrightarrow$ of litbia.......................... 75

Os innominatum ...................... 10

(j) internmm ............................ 16

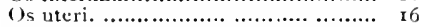

Ovaries ................................ 19

(j)iduct .................................... 19

Ovi $а$ ac...... ........................... 23

() vula Nathothi.......................... 18

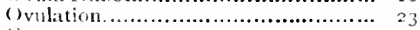

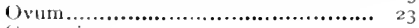

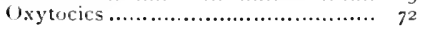

PAINS, LABOR................... 50

P.rovarium............................. is

Pectineal eminence.......................... 13

Pelvimetry............................. 76

Pelvis...................................... 9

- uses of ................................. 10

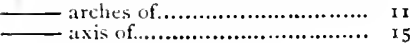

- deformities of......................... $7^{2}$

- diameters of ........................ I $_{4}$

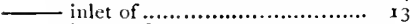

- joints of.......................... I 12

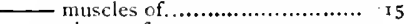

- planes of ........................... I 4

- outlet of ............................. I $_{3}$

Perforation................................... 99

Perineum. ................................ 23

- laceration of .......................... $9^{2}$

motive power of......................... $5^{8}$ rigidity of.......................... $7^{2}$

- support of........................... 55

Phlegmasia alba dolens.................... I 88

Pica......................................... $4_{4}^{6}$

Placenta ................................. $3^{1}$ battledore............................. 90 adherent............................... go

- delivery of............................. 51

- previa ............................. 82

retention of ...................... 40,90

ruccenturia......................... y y

Planes of pelvis ............................... if

- of fotal head ....................... 60

Podalic version............................... 97

Positions of fotus.......................... 6r

Porro's method................................ Ior

Post-partum hemorrhage................... 84

Pregnancy................................. 28

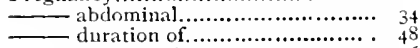

— extra-titerine......................... 36

bydatid.............................. 38

mole................................. $3^{8}$

- multiple.......................... $3+$

- signs of............................. it

- spurious............................. $3^{8}$

- ovarian ............................... $3^{36}$

- twin................................ 34

Premature Jabor............................ 39

- induction of....................... 102

Presentations................................ 59

Primipara................................... 52

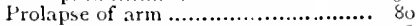

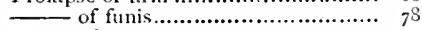

Proliger uterus........................... 47

Proligerous disk.......................... 24

promontory of sacrum................... I 3

Psoas iliacus muscle ...................... is

['seudocyesis............................. $3^{8}$

l'ubes...................................... 10

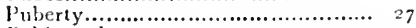

Pubie arch............................ 1

Pubis, symphysis.......................... I $_{3}$

J'uerperal state........................ 1

72 convulsions ..................... 8 7 
Pulie after lib PGE

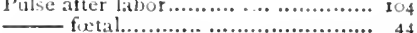

Iyriformis muscle ......................... If

$Q^{\text {UICKENING }}$

RESUSCITATION OF CHILD

Restutution

Retroversion................................. 47

Rigidity of cervix ....................... $7_{2}$

-

Rigor in l.ibor......................... 55

— ifter litbor........................... 57

kosenmüller, organ of.................... I9

kotation............................. 62, 63, I I 3

kupture of utcrus......................... 86

\section{SACRO-ILIAC BEAM}

Sacrum

Secondary hemorrba.......................... $7^{6}$

Segulentation of ovum.................. 29

Sencti......................................... 28

Septiciemia...................................... 105

Sigaultian ofyeration...................... 101

Signs of prégnancy........................ \&

Soufte, funic............................ 44

- utero+placental..................... \&4

Spondylolisthesis.......................... $7^{6}$

Sipontanexus evolution.................. by

- version............................... 699

Stages of lator.......................... 49

Strait, inferior............................ $1_{3}$

- superior ............................ 13

Subinvolution.............................. 103

Sub pubic arch............................ I I

Sipuerfetation ............................... 35

Situres.................................... 59

Symphysertomy........................ I

Symply sis pubis.......................... $1_{3}$

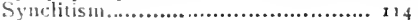

syucope.................................... 8

TAMPON............................ $40,8_{3}$ Temperatute, post-partum ........ 104

I'hrombosis, uterine ..................... 107

'l'hrombis of vilva ......................... 75

Iratction on forceps ........................ 95

l'ransserse presentation..............6 6r, $C_{9}$

Jrimbfusion.................................. 85

Jinbes, Fallopian............................ I9

Fumurs, obstructing labor................ 74

Prorning...................................... 97

I'win pregnancy........................ 34
PAGE

Twin labor .................................. 80

Iriplets ................................... 34

T MBILICUS......................... 34

Umbilical cord........................ 34

Un:tvoidable liemorrhage..................

Uramia..................................... 87

liethra .................................... 23

Uterus....................................... 16

- cavity of ................................. 16

—_ changes in pregnancy............ 3 .

- contractions of.................4 43, 50

- displacements of................... 47

- - dimensions of .................... \& 6

- double................................. 19

inertia of............................ $7^{\circ}$

- inversion of ......................... g $^{\mathrm{I}}$

_ involution of ........................... 102

- liwaments of ............................ 18

- nirves of........................... I7

- obliquity of ...................... I I I

- rupture of ........................... 86

- supports of ......................... is

Uterine inertia................................ 70

- milk............................... 32

- thrombosis......................... 107

Utero-placcntal sonfite................... 43

- vacuum ..........

VACUUM, UTERO-PLACEN-

tal.................................. 89

Vagina... ................................... 20

bulb of.................................

- change in pregnancy.............. 42

rectis....................................... 97

Velanentous insertion of cord.......... 91

Venesection ............................... So

Vernix caseosa............................ 33

Version.................................... 97

Vertex presentation................ 59, 61,63

Fesicle, umbitical......................... 3i

Vertibule................................. 22

Viable..................................... 39

Vicarious menstruation..................... 27

Vitclline membrane........................ 24

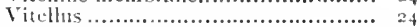

Vomiting in labor........................ 55

-iil preguancy....................... 45

Vulva................................... 21

Vulvo-vaginal gland ...................... 21

VJHARTON'S GELATINE... 32 Weid................................ 104

Womb (vicle uterus).................... 16 


\title{
THE ?QUIZ-COMPENDS?
}

A NEW SERIES OF COMPENDS FOR STUDENTS.

\author{
For Use in the Quiz Class and when \\ Preparing for Examinations.
}

Price of Each, Bound in Cloth, \$1.00 Interleaved, \$1.25.

Based on the most popular text-books, and on the lectures of prominent professors, they form a most complete set of manuals, containing information nowhere else collected in such a condensed, practical shape. The authors have had large experience as quiz-masters and attachés of colleges, with exceptional opportunties for noting the most recent advances and methods. The arrangement of the subjects, illustrations, types, etc., are all of the most improved form, and the size of the books is such that they may be easily carried in the pocket.

\section{No. 1. ANATOMY. (nlustrated.) THIRD REVISED EDITION.}

A Compend of Human Anatomy. By Samuel O. L. PO'TTER, M.A., M.D., U. S. Army. With 63 Illustrations.

"The work is reliable and complete, and just what the student needs in reviewing the subject for his examinations." - The Physician and Surgeon's Investigator, Buffalo, N. Y.

"To those desiring to post themselves hurriedly for examination, this little book will be useful in refreshing the memory." -New Orleans Medical and Surgical fournal.

"The arrangement is well calculated to facilitate accurate memorizing, and the illustrations are clear and good."-North Carolina Medical Fournal.

\section{Nos. 2 and 3. PRACTICE.}

A Compend of the Practice of Medicine, especially adapted to the use of Students. By DAN'L E. Hucills, M.D., Demonstrator of Clinical Medicine in Jefferson Medical College, Philadelphia. In two parts.

PART I.-Continued, Eruptive, and Periodical Fevers, Diseases of the Stomach, Intestines, Peritoneum, Biliary Passages, Liver, Kidneys, etc., and General Diseases, etc.

PART II.-Diseases of the Respiratory System, Circulatory System, and Nervous System; Diseases of the Blood, etc.

* * These little books can be regarded as a full set of notes upon the Iractice of Medicine, containing the 
Synonyms, Definitions, Causes, Symptoms, Prognosis, I iagnosis, Treatment, etc., of each disease, and inclad. ing a number of new prescriptions. They have been compiled from the lectures of prominent Professors, and reference has been made to the latest writings of Professors Flint, Da Costa, Reynolds, Bartholow, RobekTs and others.

"It is brief and concise, and at the same time possesses an accuracy not generally found in compends." -Fas. W. French, 11.D., Ass't to the Prof. of Practice, Medical College of Ohio, Cincinnati.

"The book seems very concise, yet very comprehensive.

An unusually superior book."-Dr. E. T. Bruen, Demonstrator of Clinical Medicine, Unizersity of Pennsylvania.

"I have used it considerably in connection with my branches in the Quiz-class of the University of La." - F. H. Bemiss, Nezw Orleans.

"Dr. Hughes has prepared a very useful little book, and I shall take pleasure in advising my class to use it." $-D r$. George $W$. Hall, Professor of P'ractice, St. Louis College of Physicians and Surgeons.

\section{No. 4. PHYSIOLOGY.}

A Compend of Human Physiology, adapted to the use of Students. By AlperT P. Brubaker, M.D., Demonstrator of Physiology in Jefferson Medical College, Philadelphia.

"Dr. Brubaker deserves the hearty thanks of medical students for his Compend of Physiology. He has arranged the fundamental and practical principles of the science in a peculiarly inviting and accessible manner. I have already introdnced the work to my class." - Miawice N. Willer, M.D., Instructor in Practical Histology, formerly Demonstrator of Physiology, Lniversity City of Nez" lork.

"QQuiz-Compend' No. 4 is fully up to the high standard established by its predecessors of the same series."-Medical Bulletin, Philadelphia.

"I can recommend it as a valuable aid to the student." $-C$. $N$. Ellinaood, MI.D., P'rofessor of Physiology, Cooper Midical College, San Francisco.

"This is a well written little book."-London Lancet.

\section{No. 5. OBSTETRICS.}

A Compend of Obstetrics. For Physicians and Students. By HeNRY G. LANDIS, M.D., Professor of Obstetrics and I iseases of Women, in Starling Medical College, Columbus. Hllustrated.

"We have no doubt that many students will find in it a most valuable aid in preparing for examination." - The American Fournal of Obstetrics.

"It is complete, accurate and scientific. The very best hook of its kind I have seen," $-\mathcal{Y}$. S. Knox, M.D., Lecturer on Obstetrits, Kush Midical College, Chicago.

Price of each Book, Cloth, \$1.00. Interleaved for Notes, \$t.25. 
"I have been teaching in this department for many years, and am free to say that this will be the best assistant I ever had. It is accurate and comprehensive, but brief and pointed."-Prof. P. D. Yost, St. Louis.

No. 6. MATERIA MEDICA. Revised Ed. $A$ Compend on Materia Medica and Therapeutics, with especial reference to the Physiological Actions of Drugs. For the use of Medical, Dental, and Pharmaceutical Students and Practitioners. Based on the New Revision (Sixth) of the U.S. Pharmacopreia, and including many unofficinal remedies. By SAMUEL $O$. L. Potter, M.A., M.D., U. S. Army.

"I have examined the little volume carefully, and find it just such a book as I require in my private Quiz, and shall certainly' recommend it to my classes. Your Compends are all popular here in Washington."-Fohn E. Brackett, .I.D., Professor of Materia Medica and Therapeutics, Howard Medical College, Hashingtin.

"Part of a series of small but valuable text-books. . . While the work is, owing to its therapentic contents, more useful to the medical student, the pharmaceutical student may derive much useful information from it." $-N$. Y. Pharmaceutical Record.

\section{No. 7. CHEMISTRY. Revised Ed.}

A Compend of Chemistry. By G. MAsun WARD, M.D., Demonstrator of Chemistry in Jefferson Medical Col. lege, Philadelphia. Including Table of Elements and various Analytical Tables.

"Brief, but excellent. . . It will doubtless prove an admirable aid to the student, by fixing these facts in his memory. It is worthy the study of both medical and pharmaceutical students in this branch." - Pharmaceutical Record, New Iork.

\section{No. 8. VISCERAL ANATOMY.}

A Compend of Visceral Anatomy. By Samuel O. L. POTTER, M.A., M.D., U.S. Army. With 40 Hllustrations.

*** This is the only Compend that contains full descriptions of the viscera, and will, together with No. I of this series, form the only complete Compend of Anatomy published.

No. 9. SURGERY. Illustrated.

A Compend of Surgery; including Fractures, Wounds, Dislocations, Sprains, Amputations and other operations, Inflammation, Suppuration, Ulcers, Syphilis, Tumors, Shock, etc. Diseases of the Spine, Ear, Eye, Bladder, Testicles, Anus, and other Surgical Diseases. By Orvilde IORwitz, A.M., M.D., with 43 Hllustrations.

Price of Each, Cloth, \$1.00. Interleaved for Notes, \$1.25. 


\title{
No. 10. ORGANIC CHEMISTRY.
} JUST PUBLISHED.

A Compend of Organic Chemistry, including Medical Chemistry, Urine Analysis, and the Analysis of Water and Food, etc. By HeNRy LefFmann, M.D., Professor of Clinical Chemistry and Hygiene in the Philadelphia Polyclinic; Professor of Chemistry, Pennsylvania College of Dental Surgery; Member of the N. I. Medico-Legal Society.

Cloth. \$1.00. Interleaved, for the addition of Notes, \$1.25.

Nature of Organic Bodies. Transformations under various conditions. Organic Synthesis. Homologous and Isomeric Bodies. Empirical and Rational formula. Classification of Organic Bodies. Hydrocarbon. Derivatives of Hydrocarbons, Alcolols and Fthers. Benzenes and Turpenes. Fat Acids, Oils and Fats, Sugars, Glucosirles. Cyanogen Compounds. Amines and Amides. Alkaloids. Ptomaines. Animal Chemistry. Nutrition and Assimilation. Food, Water and Air. Urinary Analysis. Index.

\section{The Essentials of Pathology.}

\author{
BY D. TOD GILLIAM, M.D.,
}

Professor of Physiology in Starling .Medical College, Columbus, $O$.

With 47 Illustrations. $12 \mathrm{mo}$. Cloth. Price \$2.00.

** The olject of this book is to unfold to the beginner the fundamentals of pathology in a plain, practical way, and by bringing them within easy comprehension to increase his interest in the study of the subject. Though it will not altogether supplane larger works, it will be found to impart clear-cut conceptions of the generally accepted doctrines of the day, and to prevent confusion in the mind of the student.

A POCKET-BOOK OF

\section{PHYSICAL DIAGNOSIS \\ Diseases of the Heart and Lungs.}

A MANUAL FOR SIUUDENT AND PHYSICIANS.

BY DR. EDWARD T. BRUEN,

Demonstrator of Clinicul Medicine in the Lnicersity of P'ennsylzania, Assistant Ihysician to the Lnizersity Hospital, etc.

Second Edition, Revised. With new Illustrations. 12 mo. \$1.50.

***The subject is treated in a plain, practical manner, avoiding quections of historical or theoretical interest, and without laying special clain to originality of matter, the author has made a bool: that presents the sonsewhat difficult points of Physical Diagnosis clearly and distinctly. 


\section{ROBERTS' PRACTICE.}

Fifrh EnITION.

Recommended as a Text-book at linizersity of Rennsyliania, Long Island College Hospital, Jiale and Harrard Cólleges, Bishop's College, Montreal, Uniz'ersity of Michigan, and ozer taenty other. Medical Schools.

A HANDBOOK OF THE THEORY AND PRACTICE OF MEDICINE. By Frenerick T. RoberTs, M.d., M.r.c.P., Professor of Clinical Medicine and Therapeutics in University' College Hospital, London. Fifth Edition. Octavo.

\section{CLOTH, \$5.00; LEATHER, \$6.00.}

*** This new edition has been subjected to a careful revision. Many chapters have been rewritten lmportant additions have been made throughout, and new illustrations introduced.

"A clear, yet concise, scientific and practical work. It is a capital compendium of the classified knowledge of the subject." -Prof. F. Adams Allen, Rush Medical College, Chicago.

"I have become thoroughly convinced of its great value, and have cordially recommended it to my class in Hale College." Prof. David P. Smith.

"I have examined it with some care, and think it a good book, and shall take pleasure in mentioning it among the works which may properly be put in the hands of students." - $A$. B. Yalmer, Prof. of the Practice of Meaticine, Lniversity of Michigan.

"It is unsurpassed by any work that has fallen into our hands, as a compendium for students preparing for examination. It is thoroughly practical, and fully up to the times."-The Clinic.

BY SAME AUTHOR.

\section{ROBERTS' NOTES ON MATERIA MEDICA} AND PHARMACY.

Just Ready. I2mo. Cloth

A A new Compend for Students.

Price \$2.00.

\footnotetext{
BIDDLE'S MATERIA MIEDICA.

Ninth Revised EDition.

Recommended as a Text-book at Fale College, Uniziersity of Michigan, College of Physicians and Surgeons, Baltimore, Baltimore Medical College, Louisville Iledical College, and a number of other Colleges throughout the $U . S$.

BIDDLE'S MATERIA MEDICA. For the Use of Students and Physicians. By the late Prof. John B. Brodle, M.D., Professor of Materia Medica in Jefferson Medical College, Philadelphia. The Ninth Edition, thoroughly revised, and in many parts rewritten, by his son, Clemenr Biddle, M.D., Past Assistant Surgeon, U. S. Navy, assisted by HeNry Morris, M.D. CIOTE, $\$ 4.00$; LEATHER, $\$ 4.75$.

- I shall unhesitatingly recommend it (the gth Edition) to my students at the IBelinver Hospital Mínical College.-Prof. A. A. Smith, New York, Yune, 1883 .

"The larger works usually recommended as text-books in our medical schools are too voluminous for convenient use. This work will be found to contain in a condensed form all that is most valuable, and will supply students with a reliable guide."-Chicaso. Mid. $\mathscr{Y l}$.

***'Ihis Ninth Edition contains all the additions and changes in the U. S. Pharmacopoeia, Sixth Revision.
} 


\section{STANI)ARI) TEXT-BOOKS.}

BLOXAM'S CHEMISTRY. Inorganic and Organic, with Experiments. Fifth Edition. Revised and Illustrated.

8 vo, cloth, $\$ 3.75$; jeather, $\$ 4.75$

CARPENTER ON THE MICROSCOPE and ls Revelations. Sixth Edition, Enlarged. With 500 Illustrations and Colored Plates, handsonely printed. lemi 8vo, cloth, \$5.50

FLOWER, DIAGRAMS OF THE NERVES of the Human lody, Urigin, Divisions, Connections, etc. $4^{\text {to }}$, cloth, 3.50

GLISAN'S MODERN MIDWIFERY. A Text-book, 129 Illustrations. 8 vo, cloth, $\$ 4.00$; leather, $\$ 5.00$

HOLDEN'S OSTEOLOGY. A Description of the Bones, with Colored Delineations of the Attachments of the Muscles. Sixth Fdition. 6r Lithographic Plates and many Wood Engravings. Royal 8 vo, cloth, $\$ 6.00$

HEADLAND, THE ACTION OF MEDICINE in the System. Ninth American Edition. 8 vo, cloth, $\$ 3.00$

MANN'S PSYCHOLOGICAL MEDICINE and Allied Nervous Diseases; including the Medico-Jegal Aspects of Insanity. With Illustrations. $8 \mathrm{vo}$, cloth, $\$ 5.00$; leather, $\$ 6.00$.

MEIGS AND PEPPER ON CHILDREN, A Practical 'Ireatise on Diseases of Children. Seventh Edition, Revised.

8 vo, cloth, $\$ 6.00$; leather, $\$ 7.00$

PARKES' PRACTICAL HYGIENE. Sixth Revised and Enlarged Edition. Illustrated. 8 vo, cloth, $\$ 3.00$

RIGBY'S OBSTETRIC MEMORANDA. 32mo, cloth, .50

SANDERSON \& FOSTER'S PHYSIOLOGICAL LABORATORY. A Handbook for the Laboratory. Over 350 lllustrations. 8 vo, cloth, $\$ 5.00$; leather, $\$ 6.00$

WILSON'S HUMAN ANATOMY. General and Special. Tenth Edition. 26 Colored Plates.and 424 lllustrations. $\$ 6.00$

WYTHE'S MICROSCOPIST. A Manual of Microscopy and Compend of the Microscopic Sciences. Fourth Edition. 252 Illustrations. $8 v o$, cloth, $\$ 3.00$; leather, $\$ 4.00$

ACTON, ON THE REPRODUCTIVE ORGANS. Their Functions, Disorders and Treatment. 6th Edition. Cloth, 2.00

FOTHERGILL, ON THE HEART. Its Diseases and their Treatment Second Edition. $8 \mathrm{vo}$, cloth, $\$ 3.50$

HARLEY ON THE LIVER. Diagnosis and Treatment. Colored Plates and other Illustrations. 8vo, cloth, \$5.00; sheep, \$9.00

HOLDEN'S ANATOMY. Fifth Edition.

JUST PUBLISHED.

\section{A MANUAL OF THE DISSECTION OF THE HUMAN BODY.}

By Lutuer llomon, M.1., Late President of the Royal College of Surgeons of England, Consulting Surgeon to St. liartholomew's Hospizal. Fifth lidition; edited by JoHn LANGTON, M.D., F.R.C.S., Suryeon to, and Lecturce on Anatomy at, St. l'artholomew's 11 ospital; Member of the lboard of Examiners, Royal College of Surgeons of England; with 208 fine Wood Engravings. Octavo. About 880 pages. Cloth, \$4.50; Leather, \$5.50. 


\section{REESE'S \\ MEDICAL JURISPRUDENCE \\ AND TOXICOLOGY.}

A Text-book of Medical Jurisprudence and Toxicology. by JohN J. Reese, M. D., Professor of Medical Jurisprudence and Toxicology in the Medical and Law Departments of the University of Pennsylvania; Vice-President of the Medical Jurisprudence Society of Philadelphia; Physician to St. Joseph's Hospital : Corresponding Nlember of the New York Medico-legal Society. One Volume. Demi Octavo. 606 pages. Cloth, \$4.00; Leather, \$5.00.

"Professor ReEse is so well known as a skilled medical jurist that his authorship of any work virtually guarantees the thoroughness and practical character of the latter. And such is the cane in the book before us. * * * * We might call these the essentials for the study of medical jurisprudence. The subject is sheletonized, condensed, and made thoroughly up to the wants of the general medical practitioner, and the requirements of prosecuting and defending attorneys. If any section deserves more distinction than any other, as to intrinsic excellence, it is that on toxicology. This part of the book comprises the best outline of the subject in a given space that can be found anywhere. As a whole, the work is everything it promises and more, and considering its size, condensation, and practical character, it is by far the most useful one for ready reference that we have met with. It is well printed and neatly bound.-N. H. Nedical Record, Sept. 13th, I8S7.

\section{RICHTER'S CHEMISTRY,}

A TEXT-BOOK Of INORGANIC CHEMISTRY FO STUDENTS.

BY PROF. VICTOR von RICHTER,

University of Breslau,

Autmorized Translation from the Third German Edition,

By EDGAR F.SMITH, M.A., Ph.D.,

Professor of Chemistry in Wittenberg College, Spring field, Ohio; formerly in the Laboratories of the linizersity of Pennsylvania: Nember of the Chemical Society of Berlin.

12 mo. 89 Wood-cuts and Col. Lithographic Plate of Spectra. \$2.00

In the chemical text-books of the present day, one of the striking features and difficulties we have to contend with is the separate presentation of the theories and facts of the science. 'These are usually taught apart, as if entirely independent of each other, and those experienced in teaching the subject know only too well the trouble encountered in attempting to get the student properly interested in the science and in bringing him to a clear comprehension of the same. In this work of Pror. Von Richtir, which has been received abroad with such hearty welcome, two edation having been rapidly disposed of, theory and fact are hrought close wgether, and their intimate relation clearly shown. From careful observation of experiments and their results, the student is led to a correct understanding of the interesting principles of chemistry.

In preparation; "ORGANIC CHEMIST'RY," by the same author. 'Translated. 


\title{
YEO'S PHYSIOLOGY.
}

\author{
A MANUAL FOR STUDENTS. JUST READY. \\ 300 CAREFULLY PRINTED ILLUSTRATIONS. \\ FULL GLOSSARY AND INDEX.
}

By Gerald F. Yeo, M.D., F.R.C.s., Professor of Physiology in King's College, London. Small Octavo. $75^{\circ}$ pages. Over 300 carefully printed Illustrations.

\section{PRICE, CLOTH, \$4.00; LEATHER, $\$ 5.00$.}

\begin{abstract}
"By his excellent manual, Prof. Yeo has supplied a want which must have been felt by every teacher of physiology. $* * * *$ In conclusion, we heartily congratulate Prof. Yeo on his work, which we can recommend to all those who wish to find within a moderate compass a reliable and pleasantly written exposition of all the essential facts of physiology as the science now stands."The Dublin Fournal of Med. Science.

"The work will take a high rank among the smaller text-books of Physiology."-Prof. H. P. Bowditch, Harvard Med. School, Boston.

"The brief examination I have given it was so favorable that I placed it in the list of text-books recommended in the circular of the University Medical College."-Prof. Leatis A. Stimpson, MI. D., 37 East 33 d Street, New York.

" For students' use it is one of the very best text-books in Physiology." - Prof. L. B. How, Dartmouth Med. College, Hanozer, N. H.
\end{abstract}

\section{RINDFLEISCH. \\ THE ELEMENTS OF PATHOLOGY.}

TRANSLATED BY WM. H. MERCUR, M.D.

REVISED AND EDITED BY PROF. JAS. TYSON, Of the Unizersity of P'ennsyliania. ${ }_{26}$ PAGES. CLOTH. PRICE $\$ 2.00$.

* * It is the object of Prof. Rindfleisch to present in this volume of moderate size the fundamental principles of Pallology A large number of the general processes which underlie disease, a knowledge of which is essential to the practical physician, are plainly presented. They include, among others, inflammation, tumor formation, fever, derangements of nutrition, including atrophy, derangements of the movement of the lolood, of blood formation and blood purification, hyperiesthesia, anzsthesia, convulsions, paralysis, etc. The well-known reputation of the author, his thorough familiarity with and his method of treating the sul)ject, make this most recent work peculiarlyus as and the practicing fhysician who wist 


\section{VAN HARLINGEN}

A IIANDBOOK OF THE DISEASES OF TIIE SKIN, their Diagnosis and Treatment. Dy ARTHLR VAN IIARLINGEX, M.D., l'rofessor of lineases of the skin in the Philadelphia l'olyclinic, Consulting l'hysician to the biopensary for skin Diseases, ete. lllustrated by colored libugraphic plates.

12mo. 284 pages. Cloth. Price, $\$ 1.75$.

" It is a most useful compendium of the knowlectge to be had at the present time upon the injutant suljects $\mathbf{1} 0$ which it in cievoted: and is in all respect a credit to the well recus-

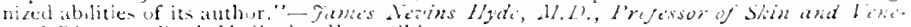

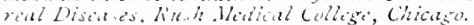

"Ihis new handbook is essentially a small encyclupedia of pathology and treament if Shin biseases, in which the smbjects atre arranged aphobetically. This arrangement was that tollowed by the late Jibury Fux, of London, in his handbook, which we believe was re-

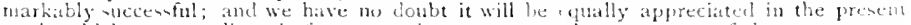
work, which compendious in firm contains at very complete summary of the present shate of dermatology. Lr. Van Harlingen's position in the profession, being at pesent sice. president of the American lermatelocical Asociation, which be nerved as secretary fir several years, and the ligh standard of his communications to his department, are vaficient

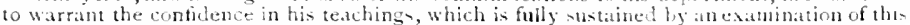
handbouk, which we heartily commend for its l,revity, cleamess an! evident careful prepa-

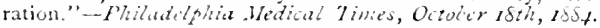

\section{RINDFLEISCH.}

THE ELENENTS OF PATIUIOGY. For students and Pliysicians. By ENWARI, RINIFLI.ISCH, M I., l'rufessor of Pahological Anatomy in the Lniversity of Wurhourg. Anthoried translation ly WiltidM II.

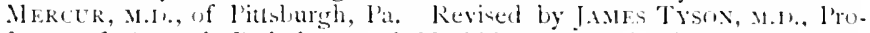
fessor of (ieneral lathology and Morbid Anatomy in the Lniversity of lennsylrania.

12mo. 263 pages. Cloth, \$2.00.

"The practical views rif one of the lest of the moden histolegiste in placed befire the profession in this alunirible work, in a mont careful and sy utenatic manner. 'The author, who is one of the leading pathologists, ete forth not only the gromal-woth in his department.

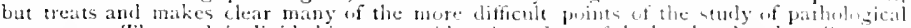

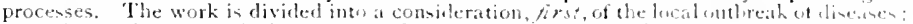

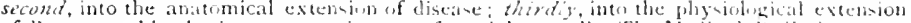

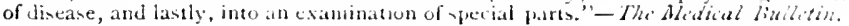




\section{BIDD LE'S}

Recommended as a Text-linol at Yale Collere, Unizersity of Michigan, College of Phrsicians and Surreons, Baltimore, Baltimore Medical College, Louisville Wedical Collese, and a number of other Colleges throushout the United States.

BIDDLE'S MATERIA MEDICA. For the Use of Students and Physicians. By the late Prof. John B. Biddle, M.D., Professor of Materia Medica in Jefferson Medical College, Philadelphia. The Ninth Edition, thoroughly revised, and in many parts rewritten, by his son, Clement BIDDle, M.D., Assistant Surgeon, U. S. Nary, assisted ly Henry Morris, M.D. Containing all the additions and changes made in the last revision of the United States Pharmacopaia. Octavo. Ready.

\section{Bound in Cloth. Price $\$ 4.00$; Leather, $\$ 4.75$.}

"It will be found a useful handbook by students, especially, who may be under the instruction of its able and accomplished author."-American Hedial Foumal.

"In short, it is just the work for a student, embracing as it does what will be discussed in a course of lectures on materia medica."-Cincinnati . Hedical lèri's.

"In truth, the work is well adlapted to the wants of students."-The Clinic.

"Nothing has escaped the writer's scan. All the new remedies against disease are duly and judiciously noted. Students will certainly appreciate its shapely form, grace of manner, and general multum in forro style."-American P'ructitioner.

" Jicklle's 'Materia Neelica' is well known to the profession, being a stand. ard text.hork in severill leading collegres." - New York Medical foumal.

"It contains, in a conlensed form, all that is valuable in materia medica, and furnishes the medical student with a complete manual on this subject."Canada Lancet.

"The necessity for a new elition of this work in so short a time is the best proof of the value in which it ts held by the profession." - Medical and Sursical Reporter.

"The standard 'Materia Medica' with a harge number of medical students is IBiklle"s."-Buffulo Midical and Surrical Fournal.

"The larger works usually recommended as text-books in our merlical schonls are too voluminous for convenient use. This work will be found to contain in a condensed form all that is most valuable, and will supply students with a reliable guide."-Chicas"o Midical Fon'nal.

$*_{*}^{*}$ "This Ninth Echition contains all the addlitions and changes in the U.S. Pharmacopuia, Sixth Revision. 


\section{PLEASE DO NOT REMOVE \\ CARDS OR SLIPS FROM THIS POCKET}

\section{UNIVERSITY OF TORONTO LIBRARY}

RG

531

L5

1885

BioMed.
Landis, Henry Gardner

A compend of obstetrics 
